\title{
Le Polmoniti: proposta di un percorso condiviso per la diagnosi microbiologica
}

\section{Claudio Farina}

UOC Microbiologia e Virologia, Azienda Ospedaliera "Ospedale San Carlo Borromeo", Milano

con la collaborazione di:

Stefano Andreoni ${ }^{4,18}$, Giancarlo Basaglia ${ }^{3,31}$, Maria Rosaria Capobianchi ${ }^{7,22}$, Edoardo Carretto ${ }^{10,16}$, Bruno del Prato $^{9,25}$, Maria Laura Garlaschi ${ }^{5,20}$, Giovanni Pietro Gesu' ${ }^{1,15}$, Massimo Giusti ${ }^{11,27}$, Martin Langer ${ }^{8,14,24}$, Francesco Nicola Lauria ${ }^{12,32}$, Esther Manso ${ }^{4,19}$, Piero Marone ${ }^{2,16}$, Pierluigi Nicoletti ${ }^{2,23}$, Paola Pauri, ${ }^{6,21}$, Alberto Podestà ${ }^{13,29}$, Gaetano Privitera $^{14,30}$, Vittorio Sambri ${ }^{10,26}$, Pierluigi Viale ${ }^{12,28}$, Egidio Franco Viganò ${ }^{3,17}$

I AMCLI, Comitato Studio Antimicrobici (CoSA)

2 AMCLI, Comitato Comitato Studio Batteriologia (CoSBat)

3 AMCLI, Comitato Studio Infezioni Ospedaliere (CoSIO)

4 AMCLI, Comitato Comitato Studio Micologia (CoSM)

5 AMCLI, Comitato Gruppo Lavoro Fibrosi Cistica (GLFiCi)

6 AMCLI, Comitato Gruppo Lavoro Medicina dell'Evidenza (GLMedEv)

7 AMCLI, Comitato GLNomenclatore

8 AAROI (Associazione Anestesisti Rianimatori Ospedalieri Italiani)

9 AIPO (Associazione Italiana Pneumologi Ospedalieri)

10 APSI (Associazione Prevenzione Studio Infezioni)

II FADOI (Federazione delle Associazioni dei Dirigenti Ospedalieri Internisti)

I2 SIMIT (Società Italiana Malattie Infettive Tropicali)

13 SIMEUP (Società Italiana Medicina Emergenza Urgenza Pediatrica)

14 SIMPIOS (Società Italiana Multidisciplinare Prevenzione Infezioni Organizzazioni Sanitarie)

15 Laboratorio di Microbiologia, A.O. "Ospedale Ca' Granda-Niguarda", Milano

I6 S.C.Virologia e Microbiologia, Fondazione IRCSS - Policlinico San Matteo, Pavia

17 Laboratorio di Microbiologia,A.O. "Ospedale San Gerardo”, Monza

18 Laboratorio di Microbiologia e Virologia, A.O. Universitaria "Ospedale Maggiore della Carità", Novara

19 Laboratorio Analisi Chimico-cliniche e Microbiologia, A.O. Universitaria “Ospedali Riuniti di Ancona”, Ancona
20 Laboratorio Analisi Chimico-cliniche e Microbiologia, Fondazione IRCCS OM Policlinico MaRE, Milano

2 I U.O. Patologia Clinica, ASUR Marche ZT5, Ospedale Civile, Jesi

22 Laboratorio di Virologia, Istituto Nazionale Malattie Infettive "Lazzaro Spallanzani" IRCCS, Roma

23 SOD Microbiologia e Virologia, A. O. Universitaria "Careggi”, Firenze

24 Anestesia e Rianimazione Università degli Studi e Fondazione IRCCS Istituto Nazionale dei Tumori, Milano

25 Dipartimento di Pneumologia, U.O.S.C. di Endoscopia Bronchiale ed Urgenze Broncopneumologiche, Azienda Ospedaliera di Rilievo Nazionale "Antonio Cardarelli", Napoli

26 Sezione di Microbiologia, DMCSS - A.O. Universitaria di Bologna Policlinico S. Orsola-Malpighi, Bologna;

27 SC Medicina Interna, "Ospedale San Giovanni Bosco”, Torino

28 Clinica di Malattie Infettive, A.O. Universitaria / Università di Udine, Udine;

29 UOC Pediatria,Azienda Ospedaliera “Ospedale San Carlo Borromeo”, Milano

30 UO di Igiene e Epidemiologia Universitaria, A.O. Universitaria Pisana, Pisa

3I SC Microbiologia, Immunologia e Virologia, Centro di Riferimento Oncologica, Aviano

32 Divisione di Malattie dell'Apparato Respiratorio, Istituto Nazionale Malattie Infettive 'Lazzaro Spallanzani' IRCCS, Roma

INDICE

A. Premessa e Obiettivi

B. Le polmoniti comunitarie

B1. L'epidemiologia microbica delle polmoniti comunitarie in età neonatale e pediatrica

B2. L'epidemiologia microbica delle polmoniti comunitarie in età adulta

B3. L'epidemiologia microbica delle polmoniti comunitarie in età geriatrica

B4. L'epidemiologia microbica delle polmoniti comunitarie del viaggiatore

B5. L'epidemiologia microbica delle polmoniti comunitarie nel soggetto esposto a contatti con animali

B6. L'epidemiologia microbica delle polmoniti comunitarie nel soggetto con pre-esistenti patologie respiratorie

B7. L'epidemiologia microbica delle polmoniti comunitarie nel soggetto variamente immunodepresso

C. Le polmoniti nosocomiali

C1. L'epidemiologia microbica delle polmoniti nosocomiali

D. La diagnosi microbiologica di infezione delle basse vie respiratorie

D1. Le modalità della diagnosi microbiologica

$$
\begin{aligned}
& \text { D1.1 La fase pre-analitica } \\
& \text { D1.2 La fase analitica }
\end{aligned}
$$

D1.2.1 L'esame microscopico diretto

D1.2.2 L'esame colturale
D1.3 L'interpretazione dei risultati

D1.4 I test di chemioantibioticosensibilità

D1.4.1 I test diretti

D1.4.2 L'antibiogramma, le MIC e le associazioni

D1.4.3 I test in vivo

D2. La diagnosi micologica di infezione delle basse vie respiratorie

D3. La diagnosi virologica di infezione delle basse vie respiratorie

D4. La ceppoteca/sieroteca

E. Conclusioni

F. Bibliografia essenziale

G. Allegati

G1. Modalità di prelievo

G2. Note per il paziente

G3. Procedure di tecnica microbiologica

G4. Flow chart operative:

G4.1 Algoritmo per la diagnosi eziologica delle polmoniti ospedalizzate (esami colturali)

G4.2 Tabella per la diagnosi eziologica a seguito di anamnesi epidemiologica

G4.3 Algoritmo per la diagnosi microbiologica

G4.4 Algoritmo per la gestione delle polmoniti

G5. Note di commento

\section{Corresponding author: Claudio Farina}

AO Ospedale San Carlo Borromeo, UOC Microbiologia e Virologia

Via Pio II, 3 - 20153 Milano - Tel.: 0240222456

E-mail: farina.claudio@sancarlo.mi.it 
Il presente documento, presentato in sessione plenaria nel corso della $13^{\wedge}$ sessione del XXXVII Congresso Nazionale dell'Associazione Microbiologi Clinici Italiani, a Stresa (5-8 ottobre 2008), è il risultato del confronto di numerose competenze: quelle dei microbiologi proposti dai vari Comitati di Studio dell'AMCLI, e quelli dei clinici operanti in discipline diverse ed indicati dalle rispettive Società Scientifiche. Vuole essere uno strumento utile per "fare il punto" della diagnostica microbiologica delle polmoniti, in risposta al quesito diagnostico che i clinici pongono al laboratorio. Bene sappiamo la complessità che caratterizza il tema delle infezioni delle basse vie respiratorie: evidentemente, il taglio del documento è, qui, prevalentemente "microbiologico-centrico". E, tuttavia, le argomentazioni riportate non esauriscono il tema, peraltro in rapidissima e costante evoluzione.

Le note che seguono vogliono rappresentare un'occasione, offerta ai colleghi microbiologi, per valutare l'operatività del proprio Centro, validandone sul campo le proposte, che rimangono - ad oggi - solo tentative, ed ai clinici per apprezzare il contributo che il laboratorio di Microbiologia può offrire alla gestione di casi spesso complicati.

$\mathrm{Ci}$ auguriamo certamente che questa prima stesura possa essere riformulata ed aggiornata sulla scorta delle osservazioni, delle critiche, delle proposte e dei suggerimenti che ci attendiamo numerosi.

\section{A. Premessa e Obiettivi}

Le infezioni delle basse vie respiratorie (Lower Respiratory Tract Infections, LTRI) includono tutti i processi infettivi a carico del parenchima polmonare (polmoniti) e dei bronchioli (bronchioliti), oltre all'ascesso polmonare (in cui la costituzione del parenchima è sovvertita per l'esistenza di cavità contenenti materiale purulento) ed all'empiema (in cui il pus occupa lo spazio pleurico).

Il presente documento, finalizzato alla precisazione della diagnosi eziologica, si riferisce esclusivamente al processo infettivo localizzato al parenchima polmonare: la polmonite. In particolare sono descritti gli aspetti relativi alle due forme nosologicamente più rilevanti di polmonite: la forma comunitaria che necessita di ricovero ospedaliero e quella nosocomiale.

Per quanto concerne le forme di Community-Acquired Pneumonia (CAP) che, per la gravità del quadro clinico di esordio, possono richiedere l'ospedalizzazione del paziente, si prendono in considerazioni gli aspetti relativi alla polmonite occorsa nelle diverse fasce di età (neonatale e pediatrica; giovane-adulta; geriatrica) e nelle diverse categorie a rischio (i viaggiatori; i soggetti a contatto con animali; i soggetti variamente immunodepressi; i soggetti con preesistenti patologie polmonari). Si segnala che il ricorso alle procedure di diagnosi eziologica sono raccomandate solo per le forme di CAP ospedalizzate, poiché per le altre, valutate dal medico di Medicina Generale o dal medico di Pronto Soccorso, l'approccio terapeutico consegue esclusivamente alla valutazione radiologica del torace e all'interpretazione dello Pneumonia Severità Index.

Per quanto concerne, invece, la forma nosocomiale, si definiscono: 1. Hospital-Acquired Pneumonia (HAP) le forme cliniche che si realizzano quando il paziente presenta polmonite dopo almeno 48 ore dal ricovero; 2. Healthcare-Associated Pneumonia (HCAP) le forme che si verificano in pazienti ospedalizzati per almeno due giorni nei tre mesi precedenti, oppure provenienti da strutture di lungodegenza o sottoposti a procedure mediche (emodialisi, trattamento di ferite, terapie e.v.), ed infine 3. Ventilator-Associated Pneumonia (VAP) le forme che si osservano dopo almeno 48 ore dall'intubazione endotracheale. Ai fini dell'elaborazione del presente documento le forme di HAP, HCAP e VAP sono considerate globalmente. Tema a sé stante infine, è la definizione differenziale su base eziologica tra infezione sensu stricto e colonizzazione.

Scopo di questo documento è la definizione delle nozioni di base in tema di polmoniti, domiciliari e ospedaliere, al fine di condividere tra microbiologi e clinici delle diverse discipline specialistiche chiamati a gestire infezioni polmonari i criteri di scelta dell'approccio di diagnosi eziologica, concordando le modalità preanalitiche relative al prelievo, alla conservazione ed all'inoltro dei campioni biologici, specificando le modalità analitiche delle indagini di laboratorio e definendo $i$ criteri di refertazione degli esami microbiologici, con la stesura di un protocollo diagnostico. I paragrafi relativi alla parte eziologica sono trattati secondo un approccio strettamente di microbiologia sistematica.
Non vengono, al contrario, affrontati gli aspetti diagnostici della tubercolosi e delle altre patologie da Mycobacterium spp., trattati in altra sede.

\section{B. Le polmoniti comunitarie}

(referenze essenziali: 12, 23, 27, 32-33, 37)

Le infezioni acute delle vie respiratorie rappresentano un problema sanitario di grande rilevanza in quanto costituiscono, ad oggi, una delle maggiori cause di morbosità, di mortalità $\mathrm{e}$ di ospedalizzazione in tutti $\mathrm{i}$ Paesi del mondo. Ubiquitarie, colpiscono soggetti di qualsiasi età, potendosi presentare più volte nell'arco della vita. Sebbene le infezioni del tratto respiratorio siano solitamente autolimitanti, secondo i dati dell'OMS, dopo i 55 anni di età, rappresentano mediamente il 13\% delle cause di morte. Inoltre, negli individui ad alto rischio (soggetti con patologie croniche) e nei bambini molto piccoli possono sovrapporsi gravi complicanze con aumento del numero e della durata delle degenze ospedaliere e dei casi di morte.

Da un punto di vista epidemiologico, Streptococcus pneumoniae è ancora il patogeno più rilevante, rappresentando negli USA circa il $6-10 \%$ di tutti i casi ed il $60 \%$ delle eziologie batteriche. Tale dato tuttavia risente in modo sostanziale della disomogeneità dei criteri e delle tecniche diagnostiche.

Una molteplicità di agenti infettivi, di natura virale e batterica, circola nella popolazione umana e provoca con particolare rilevanza epidemiologica manifestazioni di infezione respiratoria nel periodo compreso tra ottobre ed aprile, pur essendo rilevabili, in altri periodi stagionali, forme respiratorie per lo più causate dai cosiddetti patogeni respiratori atipici (come ad esempio Mycoplasma pneumoniae, Chlamydophila pneumoniae e Legionella spp.) che verosimilmente esercitano anche una funzione predisponente per una seconda infezione batterica, occupando in un'ipotetica top ten delle eziologie, le posizioni di immediato rincalzo.

Circa il 10\% delle CAP ospedalizzate richiedono un ricovero in reparti di terapia intensiva, per forme sostenute soprattutto da S. pneumoniae e da Legionella spp.

Il differente inquadramento eziologico delle polmoniti riscontrate tra pazienti curati al proprio domicilio e pazienti ospedalizzati è correlabile a molte variabili tra cui la severità della malattia all'atto della presentazione iniziale, la presenza di malattie concomitanti e la presenza di ben identificati fattori di rischio che aumentano il rischio di infezione.

Molti studi coordinati dalle maggiori società scientifiche nel corso degli ultimi dieci anni hanno definito i principali fattori di rischio responsabili di un decorso complicato delle CAP: British Thoracic Society (BTS, 1987-1993), American Thoracic Society (ATS, 1993 e 2001), Pneumonia Patient Outcomes Research Team (PORT, 1997), Infectious Diseases Society of America (IDSA, 1998), Canadian Infectious Diseases Society e Canadian Thoracic Society (CIDS/CTC, 2000). L'ATS ha così suddiviso i pazienti in quattro gruppi sulla base del luogo di cura, della coesistenza di malattie cardiopolmonari e dei fattori "modificanti", la cui valutazione, associata, su base epidemiologica, al profilo di antibioticosensibilità consente la correttezza dell'approccio terapeutico 
in merito alla scelta del luogo di cura (domicilio od ospedale) e dello schema terapeutico.

Tre sono gli SR maggiormente usati e proposti dalle società scientifiche internazionali:

- il PSI o "Pneumonia Severity Index" proposto da Fine nel 1997,

- il "The Modified American Thoracic Society Rule (m ATS)" basato sui criteri ATS di polmonite severa,

- il "CURB 65" di più recente introduzione, basato su alcuni segni e sintomi (stato mentale, frequenza respiratoria, pressione arteriosa sistolica e diastolica, ecc) indicative di severità di malattia.

In effetti gli score che "monitorizzano" la gravità della malattia come il CURB 65 o modelli prognostici come il PSI possono essere usati soprattutto per identificare pazienti con CAP candidati ad un trattamento domiciliare perché a basso rischio di morte, tenendo conto che, ad una valutazione "obiettiva" basata su criteri "ben codificati", occorre associare, da parte del curante, una valutazione che includa anche parametri soggettivi come la capacità e/o abilità ad assumere farmaci per via orale o la disponibilità di risorse economiche e sociali tali da permettere da parte del paziente, una corretta gestione domiciliare della malattia. Una gestione "domiciliare" della malattia in questi soggetti permette, inoltre, un più facile e rapido ritorno alla normale attività lavorativa senza tener conto che una ospedalizzazione, sicuramente non congrua, può portare ad un rischio aumentato di eventi tromboembolici e di superinfezione da germi ospedalieri resistenti. Più complessa è l'identificazione dei pazienti con CAP "severa" abbisognevoli di ricovero in Terapia Intensiva. Il "The Modified American Thoracic Society Rule (m ATS)", il CURB ed il PSI (classe V) non sono stati validati, singolarmente, come test decisionali per un ricovero in Terapia Intensiva dimostrandosi poco specifici. Recentemente, però, l'insieme dei criteri ATS e delle variabili del CURB sono stati indicati come criteri minori per una diagnosi di "polmonite severa" associati a due criteri maggiori cioè la presenza di uno shock settico richiedente l'uso di vasopressori e/o di una grave insufficienza respiratoria richiedente una intubazione e/o una ventilazione meccanica.

Generalmente le forme di CAP sono trattate con beta-lattamici (ad esempio: penicillina, amoxicillina o amoxicillina+clavulanato), fluorochinoloni, macrolidi o con terapie di combinazione con questi antibiotici.

\section{B1. L'epidemiologia microbica delle polmoniti comunitarie in età neonatale e pediatrica}

I virus sono di gran lunga i microrganismi più comunemente in causa: sono attualmente noti più di 200 sierotipi, antigenicamente differenti, correlati ad infezioni respiratorie. L'esistenza in natura di una vasta riserva di animali infetti, $i$ cui virus (quali quelli appartenenti alle Orthomyxoviridae e alle Coronaviridae) possono potenzialmente superare le barriere della specie ospite, determina il verificarsi di epidemie da ceppi emergenti.

I virus coinvolti nella eziologia delle polmoniti appartengono alle famiglie Orthomyxoviridae (generi: Influenzavirus A, B e C) e Paramyxoviridae (genere Respirovirus: Human parainfluenza virus di tipo 1 e 3; genere Rubulavirus: Human parainfluenza virus di tipo 2, 4 e $4 \mathrm{a}$; virus della parotite; genere Morbillivirus: virus del morbillo; genere Pneumovirus: Human Respiratory Syncytial Virus, hRSV; genere Metapneumovirus: Human Metapneumovirus (hMPV); genere Enterovirus: Human enterovirus A-D come Coxsackievirus A e B, Echovirus, Enterovirus 68-71; genere Parechovirus: Human parechovirus; genere Rhinovirus: Human Rhinovirus A e B), Adenoviridae (genere: Mastadenovirus), e Coronaviridae (Coronavirus: 229E e OC43). Anche virus di recente identificazione (Baculovirus) sembrano essere occasionalmente coinvolti in patologie respiratorie acute.

L'infezione da hRSV si presenta con andamento epidemico nel periodo invernale (acme in dicembre-febbraio) manifestandosi con quadri di bronchiolite acuta, con incubazione breve (2-4 giorni) nel bambino di età compresa tra 1 mese e 2 anni. Un terzo dei casi si osserva in bimbi prematuri (quelli nati dopo solo 33 settimane di gestazione presentano un rischio fino a cinque volte superiore rispetto a quelli nati a termine) o comunque immunocompromessi, in neonati con malformazioni congenite, con fibrosi cistica o con broncodisplasie. All'esordio di tipo rinitico che si estende ai seni ed all'orecchio medio fa seguito il coinvolgimento dell'albero respiratorio inferiore (trachea, bronchi e bronchioli). Tra $\mathrm{i}$ neonati infettati da hRSV il $40 \%$ presenta il coinvolgimento delle basse vie aeree mentre il $10-20 \%$ sviluppa una bronchiolite, con compromissione respiratoria ostruttiva, evidenziata dal segno clinico del cosiddetto tirage, sibili e rantoli subcrepitanti. Episodi di apnea sono osservati fino nel 20\% dei casi, con tassi di mortalità fino allo $0,2 \%$ (con picchi pari all'1-3\% per i casi ospedalizzati). Oltre alla bronchiolite, hRSV si rende responsabile del $5-40 \%$ dei casi di polmonite del lattante e del 10-30\% dei casi di bronchite del bambino. L'infezione da hMPV determina piccole epidemie invernali che spesso si sovrappongono a quelle da hRSV, sia dal punto di vista epidemiologico che dell'andamento clinico. Esse rappresentano il $5-10 \%$ delle forme respiratorie ad eziologia virale nel bimbo ospedalizzato di età inferiore a 2 anni.

Le infezioni da virus parainfluenzali si osservano in autunno, in piccole epidemie irregolari. Tutti i quadri clinici sono possibili, ma più frequentemente si osservano casi di bronchiolite febbrile da Human parainfluenza virus di tipo 3 (questo tipo rappresenta il $45 \%$ delle forme del bambino e la quasi totalità di quelle del neonato), e di laringotracheiti acute da Human parainfluenza virus di tipo 1 e 2.

Nell'ambito della possibile sepsi che segue talvolta alla colonizzazione, in età neonatale si descrive la polmonite da Streptococcus agalactiae. Fatta eccezione per Bordetella pertussis, i batteri sono più raramente descritti quali causa di broncopneumopatia in età pediatrica: Staphylococcus aureus deve essere tuttavia considerato per le forme del bimbo di età inferiore a 2 anni che presenti immagini bollose all'esame radiologico ed a seguito di episodi di infezione influenzale e S. pneumoniae riveste anche in età pediatrica un ruolo centrale; analogamente, Neisseria meningitidis (soprattutto di sierogruppo Y e W135) e Haemophilus influenzae rivestono, in meno del $2 \%$ dei casi anche a seguito dell'introduzione della vaccinazione, il ruolo di agenti sovrainfettanti post-influenzali. Le infezioni da Moraxella catarrhalis si manifestano, in età neonatale e pediatrica, con quadri di polmonite alveolare acuta.

Bordetella pertussis è responsabile della pertosse, la cui epidemiologia è stata decisamente modificata dall'introduzione di programmi vaccinali con elevata efficacia protettiva e scarsa incidenza di effetti collaterali avversi in età pediatrica. La sua evoluzione consente di distinguere tre periodi consecutivi, assolutamente ripetitivi e patognomonici: l'incubazione rigorosamente muta, la fase di invasione caratterizzata da tosse secca, notturna ma banale e la fase degli accessi di tosse spasmodica seguiti da apnea ed espettorazione. La diagnostica per immagini può evidenziare un addensamento juxtailare od un'opacità triangolare in sede paravertebrale.

\section{B2. L'epidemiologia microbica delle polmoniti comunitarie} in età adulta

Gli agenti infettivi responsabili di LTRI nei soggetti giovaniadulti appartengono a tutti i Regna microbici: in particolare, la parte maggiore dei casi è provocata da batteri e virus. Casistiche statunitensi rivelano che $S$. pneumoniae ricorre nel $10 \%$ dei casi, seguito da $H$. influenzae e da M. pneumoniae (quest'ultimo prevale nei soggetti età inferiore ai 50 anni). Frequenze minori si osservano per i casi di infezione da C. pneumoniae e da Legionella spp., che tuttavia si possono rendere responsabili di limitati episodi epidemici.

Le Enterobacteriaceae e Staphylococcus aureus sono di più 
raro riscontro. È utile ricordare che le polmoniti causate da $S$. pneumoniae e da Legionella spp. possono presentarsi con quadri di gravità tale da causare ipossia e/o shock settico condizionanti un ricovero in Terapia Intensiva

Un problema di crescente significato epidemiologico e clinico è rappresentato dalla polmonite da $S$. aureus, in particolare quella sostenuta da ceppi con peculiare fenotipo di resistenza alla meticillina (community acquired MRSA - CAMRSA): questi stipiti differiscono a livello genotipico dai ceppi di MRSA acquisiti in ospedale perché portatori della cassetta genetica SCCmec tipo IV e per la capacità di produrre una specifica tossina (Panton-Valentine leukocidin). In particolare, questa costituisce un potente fattore di virulenza in grado di determinare infezioni ad andamento necrotizzante. A differenza della classica polmonite di comunità da $S$. aureus, più frequente nelle età estreme della vita (neonati e grandi anziani) le forme sostenute da CA-MRSA privilegiano i soggetti di giovane età, dove determinano una polmonite multifocale con spiccato andamento necrotizzante e quindi con quadri radiologici caratterizzati da multiple aree di addensamento con tendenza all'escavazione.

Mycoplasma pneumoniae può causare fino al 15 - 60\% dei casi di polmonite comunitaria negli adolescenti e nei giovani adulti, anche se la frequenza delle forme clinicamente silenti e la benignità abituale della malattia non consente di valutarne appieno la prevalenza. Dopo un'incubazione di una-tre settimane, il quadro clinico si configura per la presenza di malessere, marcata astenia, febbre, brividi e cefalea, con tosse secca e talora dolori retrosternali. L'esame radiologico evidenzia, per lo più, opacità basali e ilifughe, spesso unilobari.

Chlamydophila pneumoniae può presentarsi sia in forma endemica che epidemica; più frequente nei bimbi in età scolare, colpisce comunque anche soggetti adulti. Studi sieroepidemiologici hanno documentato che negli Stati Uniti, cosi come in Italia, il 50\% dei soggetti di età superiore ai 45 anni presentano anticorpi specifici di tipo IgG. L'infezione acuta decorre frequentemente in modo asintomatico o paucisintomatico. Raramente può determinare quadri clinici di gravità variabile che inizialmente si presentano con sintomi da coinvolgimento delle vie aeree superiori (faringite, sinusite, bronchite). In una piccola percentuale di casi si osserva un quadro di polmonite con sintomi aspecifici e quadro radiografico caratterizzato da lesione singola, subsegmentale o, nelle forme più gravi, con estensione bilaterale con associato versamento pleurico.

Tra i virus, l'hRSV é causa, in alcune casistiche, fino al 12\% degli episodi di LTRI dell'adulto, manifestandosi con bronchite acuta ( $7 \%$ circa) e con polmonite ( $5 \%$ circa). La sintomatologia è composita, associandosi i segni ed i sintomi della sindrome pseudogrippale, con tosse, rinorrea, otalgie, sinusite a quelli tipici del coinvolgimento del parenchima polmonare (crepitii) e dei bronchioli (ronchi e sibili), ma senza leucocitosi. Tuttavia la comparsa di un quadro di distress respiratorio è raro. Le forme da Influenzavirus A, B e C ricorrono nel $5 \%$. Di riscontro più raro sono le forme sostenute da virus varicella-zoster, da virus di Epstein-Barr, da Coxsackievirus e da Hantavirus. Inoltre, le forme sostenute da Adenovirus sono di crescente interesse, considerato che recentemente sono state segnalate forme di particolare gravità sostenute dal sierotipo 14.

\section{B3. L'epidemiologia microbica delle polmoniti comunitarie in età geriatrica}

Tra i soggetti di età compresa tra i 60 ed i 90 anni le infezioni respiratorie sono frequenti. In particolare i pazienti affetti da broncopneumopatia cronica ostruttiva non raramente presentano episodi di sovrainfezione batterica acuta, sostenuta sia da cocchi Gram positivi, quali $S$. aureus e $S$. pneumoniae (33\%), sia, con maggiore rilevanza epidemiologica (67\%), da batteri Gram negativi come $H$. influenzae e $P$. aeruginosa, e gli enterobatteri. Le forme da $M$. catarrhalis conseguono ad un'affezione respiratoria predisponente e sul piano semeiolo- gico non si caratterizzano per aspetti patognomonici. Tuttavia, queste forme sono caratterizzate dalla frequente dissociazione tra l'impegno clinico e la risoluzione rapida delle alterazioni radiologiche.

Nell'anziano defedato, spesso sottoposto a trattamenti farmacologici complessi magari in terapia per patologie mentali senili con antidepressivi, ansiolitici e ipnoinducenti, frequenti sono le polmoniti aspirative favorite anche da disturbi della deglutizione e dalla cattiva igiene orale: le patologie croniche del cavo orale favoriscono la colonizzazione batterica con successivo passaggio di microrganismi nelle basse vie aeree per fenomeni microaspirativi.

Particolare significato di attualità riveste la Nursing Home Acquired Pneumonia (NHAP) che costituisce la seconda causa di infezione tra gli ospiti degli istituti di lungodegenza e la patologia più comune per cui viene richiesto il trasferimento in ospedale. Le particolari caratteristiche delle Nursing Home, esposte all'ambiente esterno comunitario ma nello stesso tempo simili all'ospedale per la tipologia dei soggetti residenti, condizionano alcune peculiarità nella distribuzione dei germi responsabili di polmonite e favoriscono la graduale comparsa di batteri multiresistenti, con un incremento significativo di MRSA, di S. pneumoniae penicillinoresistente, di enterobatteri ESBL-positivi, di P. aeruginosa e di Acinetobacter spp. Le caratteristiche del microrganismo responsabile, con la variante di fattori ambientali che possono essere diversi da istituto a istituto, e le condizioni cliniche di base del paziente rendono ragione di un tasso di mortalità media superiore al $30 \%$ caratterizzato da un incremento progressivo nel tempo essendo del $19 \%$ al $14^{\circ}$ giorno, del $59 \%$ a 12 mesi e del $75 \%$ a 2 anni. Questo dato è attribuito al peggioramento dell'autonomia e al progressivo e più rapido declino funzionale che segue l'episodio di polmonite.

Tornando al paziente anziano a domicilio le eziologie virali sono frequenti nei casi di rinite, faringolaringite, polmonite anche dispnoica (fino al $43 \%$ in talune casistiche). L'infezione da hRSV é frequentemente descritta, mentre agli Human Rhinovirus A e B è attribuito il $24 \%$ dei casi, ai Coronavirus: 229E e OC-43 il 12\% dei casi, agli Influenzavirus A, B e C ed ai virus parainfluenzali/adenovirus rispettivamente il 4 e 1'1\% dei casi. Nei soggetti istituzionalizzati è possibile osservare un'evoluzione di tipo epidemico. Fattori predisponesti sono concomitanti situazioni di insufficienza respiratoria cronica ostruttiva.

I segni clinici non sono specifici, pur osservandosi dispnea nel $65 \%$ e polmonite nell' $82 \%$ dei casi da hRSV. L'infezione esordisce con un quadro di rinite che evolve con la comparsa di tosse (90-97\% dei casi), di sibili e di febbre (50\% dei casi). Le forme da hRSV possono complicarsi con sovrainfezioni batteriche fino al 55\% degli episodi, determinando un tasso di mortalità elevato $(10 \%$ medio $)$. Analogamente a quanto riferito per hRSV, anche gli Human Rhinovirus A e B e gli Influenzavirus A, B e C sono descritti fino al 12\% dei casi di pneumopatie infettive che necessitano del ricovero in reparti di Terapia Intensiva. Il tasso di mortalità è del 3-5\% nei soggetti istituzionalizzati e del $10-20 \%$ in quelli ospedalizzati.

\section{B4. L'epidemiologia microbica delle polmoniti comunitarie del viaggiatore}

Il viaggiatore internazionale può infettarsi, nel corso del viaggio, con microrganismi endemici in aree geografiche diverse da quella italiana: tali patologie, del tutto inconsuete, devono essere sospettate qualora siano noti soggiorni in aree endemiche. Per le loro caratteristiche, si determinano quadri semeiologici assolutamente definiti. Gli agenti eziologici più probabili per il viaggiatore con sintomatologia respiratoria sono rappresentati, oltre che dai comuni patogeni, da quelli delle micosi endemiche, dalla tubercolosi e dalla febbre Q. In particolare, le patologie più probabili con un periodo di incubazione inferiore a 14 giorni sono costituite dalla legionellosi, dall'influenza e dalle micosi endemiche. Un paziente con sintomatologia febbrile e tosse insistente è più probabile che 
presenti una malaria, una febbre tifoide o la dengue, in accordo con il dato epidemiologico del Paese di provenienza e le modalità di contagio. In tal senso dovrebbe essere indirizzato l'iter diagnostico.

Si segnalano i casi definiti delle infezioni da batteri, miceti dimorfi, e da virus assenti nelle nostre Regioni.

Il carbonchio (infezione da Bacillus anthracis) polmonare primitivo deve essere sospettato nel caso della positività anamnestica per un soggiorno nelle regioni mediorientali dell'altopiano iraniano e delle catene caucasiche. Si manifesta con un quadro di broncoalveolite diffusa con compromissione pleurica ed espettorazione emorragica. Dopo un esordio assolutamente anonimo dal punto di vista clinico, la sintomatologia si aggrava per la comparsa di dispnea stridula e cianosi, e di immagini radiologiche di impegno mediastinico.

La peste polmonare (infezione da Yersinia pestis) è la forma più contagiosa e più grave di peste. Descritta in forme aneddotiche nell'altopiano iraniano, nell'India occidentale e nelle regioni desertiche degli Stati Uniti d'America (New Mexico), si caratterizza per un'incubazione breve (da poche ore ad un paio di giorni) seguita dalle fasi di invasione (febbre elevatissima, cefalea, brividi, nausea e vomito) e di stato (sensazione di oppressione toracica, tachipnea superficiale, cianosi e tosse; espettorato 'a sciroppo di fragola'; immagini radiologiche non raramente di cavitazione).

La melioidosi (infezione da Burkholderia pseudomallei) è endemica nell'Asia sudorientale, in Australia, nell'Africa centrale, occidentale e orientale, in India e in Cina. L'esordio della forma polmonare può essere improvviso o graduale, con cefalea, anoressia, dolore toracico o pleurico sordo e mialgia generalizzata. La febbre è di solito $>39^{\circ} \mathrm{C}$. Tosse, tachipnea e rantoli sono caratteristici; l'escreato può essere striato di sangue. Il radiogramma toracico evidenzia un consolidamento del lobo superiore, con cavitazioni frequenti o con lesioni nodulari e versamento pleurico.

Le forme batteriche sopraccitate devono essere prese in considerazione anche nell'ambito delle problematiche relative al bioterrorismo.

Per quanto attiene alle forme da miceti dimorfi, le infezioni da Histoplasma capsulatum devono essere sospettate in caso di soggiorno nelle zone endemiche degli Stati Uniti d'America (soprattutto la valle del Mississipi), dell'America caraibica e Centrale, e dell'Africa occidentale. Il quadro clinico si configura come una polmonite con infiltrati di tipo broncopneumonico a contorno irregolare e potenzialmente confluenti, bilaterali, multipli e diffusi, molto più raramente a lesioni uniche o paucifocali. Alternativamente, possono essere evidenziati infiltrati peribronchiali di provenienza ilare, od opacità rotondeggianti, isolate o raggruppate, miliariformi o nodulari, con interessamento dei linfonodi ilari. La sintomatologia consiste nella presenza di tosse, febbre modesta, astenia, anemia, calo ponderale, tachicardia sudorazioni profuse. Modesta è l'obiettività toracica a fronte dell'impegno evidenziato con la diagnostica per immagini e dalla significatività delle alterazioni degli indici infiammatori e della leucopenia.

Le infezioni da Coccidioides immitis devono essere sospettate in caso di soggiorno nelle zone semidesertiche al confine tra gli USA ed il Messico (dal Texas occidentale alla California), in America Centrale ed in quella Latina. Si tratta per lo più di zone altamente polverose. Il quadro evidenzia spesso un infiltrato pneumonico ilifugo dei lobi medio ed inferiore ovvero un nodulo solitario a margini netti che può evolvere con reazione fibrotica delimitante oppure cavitazione. Frequentemente concomitano manifestazioni cutanee. Significative sono le alterazioni degli indici infiammatori e la leucocitosi caratteristicamente eosinofila.

Le infezioni da Blastomyces dermatitidis devono essere sospettate in caso di soggiorno negli USA (lungo il corso dei fiumi Ohio, Missouri e Mississipi e nella zona dei Grandi Laghi) e nelle zone dell'Africa tropicale ed il Messico. Ai sintomi generali (febbre, brividi, sudorazioni notturne, calo ponderale ed astenia) si accompagnano tosse ed espettorazione mucopurulenta od emoftoica. La diagnostica per immagini mostra l'importante coinvolgimento dei linfonodi ilari e mediastinici. Significative sono le alterazioni degli indici infiammatori, la leucocitosi e l'anemia ipocromica.

Le infezioni da Paracoccidioides brasiliensis devono essere sospettate in caso di soggiorno nelle Americhe Centrale e Meridionale. Evidente è la dissociazione tra i sintomi generali, assai poveri, e la gravità delle lesioni radiologiche: infiltrati polmonari multipli, spesso paramediastinici ed ilifughi, con coinvolgimento dei linfonodi ilari, oppure micronoduli "a nido d'ape" scavati. Significative sono le alterazioni degli indici infiammatori, la leucocitosi (neutrofila, ma anche eosinofila e monocitica).

Tra le forme virali, la SARS (causata dal Severe Acute Respiratory Sindrome Coronovirus SARS-CoV) si è resa responsabile di un focolaio epidemico di più di 8000 casi (con 800 decessi) tra il 2002 ed il 2003 nei Paesi del Sud Est asiatico, in Nord America e, in forma assolutamente sporadica, in Europa. Causa di faringodinia, rinorrea, brividi, mialgie, cefalea, diarrea e sintomi respiratori, si associa spesso a linfopenia, rialzo delle transaminasi, della creatinfosfochinasi, della lattatodeidrogenasi e della Proteina C Reattiva (PCR) ed un allungamento del tempo di protrombina. La diagnosi di SARS deve essere sospettata ed ipotizzata solo in soggetti con polmonite radiologicamente documentata (infiltrati multipli) che riferiscano, nei dieci giorni precedenti l'insorgenza dei sintomi, un soggiorno in Cina, a Taiwan oppure ad Hong Kong oppure contatti con soggetti di ritorno da quei paesi. Assolutamente rilevante è il criterio diagnostico epidemiologico: in assenza di cluster d'infezione anche limitati numericamente, ma accertati dal punto di vista diagnostico, l'ipotesi di infezione da SARS-CoV deve essere posta in modo molto critico e prudenziale. Se oggi la SARS non rappresenta la prima ipotesi diagnostica, deve essere presa in considerazione per viaggiatori di provenienza dagli stessi territori l'influenza aviaria dovuta ad $\mathrm{H} 5 \mathrm{~N} 1$, sempre che riferisca in anamnesi una possibile esposizione al contagio. In ogni caso, il Ministero della Salute e l'OMS hanno emanato raccomandazioni per il viaggiatore proveniente da aree endemiche con indicazioni anche per l'iter diagnostico.

\section{B5. L'epidemiologia microbica delle polmoniti comunitarie nel soggetto esposto a contatti con animali}

Il riconoscimento di condizioni epidemiologiche particolari, quale l'esposizione ad animali o a prodotti di derivazione zootecnica, può essere d'ausilio nel riconoscimento eziologico di forme polmonari altrimenti di difficile inquadramento nosologico.

È il caso delle localizzazioni polmonari da Pasteurella multocida che sono riscontrate in soggetti genericamente immunodepressi (etilismo, tabagismo, bronchiectasie, neoplasie polmonari) i quali riferiscano contatti abituali con animali, in particolare suini. Queste forme non presentano quadri clinici patognomonici: oltre a localizzazioni delle vie aree superiori, sono descritte pleuriti e polmoniti.

Entità nosologica ben configurata è la psittacosi (infezione da Chlamydiophila psittaci), che si osserva in soggetti che, a contatto con volatili (pappagalli e parrocchetti, più raramente polli, piccioni, canarini e solo occasionalmente uccelli marini), inalano la polvere di penne o di guano. La psittacosi è una forma zoonotica che trova la sua origine anche in animali diversi dai volatili, come ovini, caprini e bovini: in questo caso si tratta con elevata frequenza di un'esposizione di tipo professionale. Dopo un'incubazione di 1-3 settimane, il quadro clinico si configura per la presenza di ipertermia, malessere e tosse secca o produttiva, con segni di addensamento polmonare ad andamento ilifugo. Il trattamento antibiotico (tetraciclina o doxicillina) deve essere continuato per almeno 14 giorni.

Tra i batteri responsabili di quadri polmonari in soggetti immunodepressi (in particolare se infettati da HIV) deve 
essere, infine, ricordato Rhodococcus equi, causa di quadri clinici eterogenei, dalle forme cavitarie a quelle lobari necrotizzanti: dato epidemiologico comune è il contatto con equini. Il trattamento antibiotico prevede l'utilizzo di glicopeptidi o di macrolidi.

L'infezione da Coxiella burnetii consegue a contatti con animali infetti (ovini e caprini in particolare, ma anche cani e gatti) o con loro derivati, ovvero con zecche (principalmente ixodidi o del genere Rhipicephalus). Descritta in tutto il mondo, la febbre Q è sottostimata a causa della sintomatologia aspecifica. Il periodo di incubazione è solitamente di 2-3 settimane. La diagnosi di laboratorio si basa sulla dimostrazione di anticorpi specifici nel siero del paziente nella fase di convalescenza. Se opportunamente trattata il tasso di mortalità inferiore è all' $1 \%$.

Assolutamente eccezionale è la localizzazione polmonare di Leptospira interrogans, responsabile delle forme influenzale e polmonare di leptospirosi. Essa deve essere sospettata in caso di negatività per altri patogeni in soggetti che, per motivi professionali o ricreazionali, vengano a contatto con deiezioni di piccoli roditori o di animali da reddito, allevati in modo intensivo (suini e bovini), disperse nel suolo o nelle acque stagnanti.

L'influenza aviaria è causata da un virus dell'influenza di tipo A (sierotipo H5N1) diffuso, a livello avicolo, in tutto il mondo e soprattutto nei Paesi del Sud-Est asiatico e nordafricani, dove la vendita di pollame vivo ai mercati costituisce la principale modalità di trasmissione. Il virus $\mathrm{H} 5 \mathrm{~N} 1$ (come altri sierotipi aviari) infetta svariati milioni di uccelli selvatici su scala mondiale, e si diffonde seguendo le principali rotte migratorie, senza per questo costituire un efficace patogeno umano: i casi di trasmissione umana sono quindi eventi assolutamente sporadici, che si generano in situazioni di stretto contatto ambientale fra uccelli ed esseri umani (allevamenti famigliari in zone a basso standard economico). Dopo un periodo di incubazione da due a sette giorni, la sintomatologia può variare da un quadro similinfluenzale a forme più gravi, caratterizzate da infezioni diffuse, quadri polmonari particolarmente gravi, spesso letali.

\section{B6. L'epidemiologia microbica delle polmoniti comunitarie} nel soggetto con "patologie strutturali del polmone"

Categoria a sé è quella dei soggetti con patologie strutturali del polmone tra le quali la forma più significativa è la fibrosi cistica. Anche i soggetti con bronchiectasie sono, tuttavia, assimilabili al paziente con fibrosi cistica in termini patogenetici, sebbene epidemiologicamente il rischio di infezioni sia minore. Tra questi devono essere inclusi i portatori di forme franche di immotilia cilia oppure quelli per i quali non è possibile evidenziare un nesso causale o patogenetico con patologie ciliari o altre patologie congenite. Alcuni di questi pazienti sono bambini con riscontro di polmoniti a lenta risoluzione o con storia di asma sin dalla prima infanzia, altri sono adulti spesso broncopatici cronici in trattamento cortisonico inalatorio.

A motivo di un difetto congenito del Cystic Fibrosis Transmembrane Conductance Regulator (CFTR), la fibrosi cistica si caratterizza per l'alterato trasporto di ioni, l'eccessiva produzione di muco, la comparsa di infiammazione e l'anomala adesività microbica: l'accresciuta produzione di muco, infatti, previene la clearance dei microrganismi che si moltiplicano all'interno delle vie aeree che, infette ed infiammate, cronicamente evolvono in una condizione di insufficienza respiratoria in cui la crescita batterica in forma di biofilm comporta l'impossibilità pratica dell'eradicazione microbica. La colonizzazione è spesso associata con un improvviso deterioramento generale, con sepsi e morte del paziente (20\% pazienti nell'arco di un anno). In particolare, $H$. influenzae e $S$. aureus sono i primi colonizzanti in età pediatrica (rispettivamente nel 15 e nel $48 \%$ dei casi), mentre $P$. aeruginosa segue nell'adolescenza convertendosi nelle forme "mucoide" e "nana" (dwarf) dopo circa due anni, per rappresentare poi fino al 59\% di tutti i microrganismi isolati.
Gli streptococchi viridanti commensali dell'orofaringe esercitano un effetto protettivo rispetto alla colonizzazione da Pseudomonas aeruginosa: poiché questi microrganismi risentono delle terapie antibiotiche prescritte per il trattamento di S. aureus, si sottolinea l'importanza della necessità di trattare le infezioni valutando con attenzione le colonizzazioni asintomatiche.

Il complesso Burkholderia cepacia è patogeno meno frequente $(3 \%$, soprattutto tra gli adolescenti ed i giovani adulti) ma assolutamente impegnativo dal punto di vista terapeutico e prognostico (è letale nel 20\%): B. multivorans e B. cenocepacia esercitano un ruolo patogeno certo, mentre è riconosciuto probabile quello di B. cepacia e possibile quello di B. stabilis, $B$. vietnamiensis, B. ambifaria, al pari di B. gladioli. Stenotrophomonas maltophilia ed Achromobacter xylosoxidans sono associati all'uso di antibiotici in adolescenti ed adulti (8\%). Altri batteri, quali Ralstonia pickettii, Alcaligenes spp. e Pandoraea spp. sono di isolamento occasionale e di significato incerto tra gli adolescenti e gli adulti, mentre significativi, sia dal punto di vista delle frequenza di riscontro (13\%) sia per il significato clinico, sono i micobatteri non tubercolari del $M$. avium complex ovvero quelli a rapida crescita come $M$. abscessus. Quest'ultimo, colonizzante potenziale per lunghi periodi unitamente ad altri microrganismi, può instaurare in modo improvviso una condizione, potenzialmente letale, di monocolonizzazione. I soggetti affetti da fibrosi cistica, infine, sono predisposti ad infezione da miceti filamentosi jalini (Aspergillus spp. si rileva nel $10 \%$ dei casi) e dematiacei (Scedosporium apiospermum) in tutte le classi di età, mentre certo è il ruolo patogeno di hRSV in età pediatrica e dei virus influenzali verosimilmente in tutte le classi d'età.

\section{B7. L'epidemiologia microbica delle polmoniti comunitarie} nel soggetto variamente immunodepresso

Si considerano condizioni diverse di immunodepressione, patologica (diabete mellito; immunodeficienze congenite od acquisite; malattie oncoematologiche maligne e trapianto di midollo osseo; trapianto d'organo solido) o iatrogena (terapie steroidee, con immunosoppressori, antiblastici o con antiTNF come Infliximab ed Etanercept).

Il paziente immunodepresso è fortemente soggetto a patologie da opportunismo microbico, sostenute da batteri, miceti, virus, in grado di determinare sia malattie con espressività clinica e di imaging ben definita sia quadri clinico-radiologici del tutto aspecifici.

Nocardia spp. (N. abscessus, N. cyriacygeorgica, N. farcinica, $N$. nova e $N$. otitidiscaviarum tra le altre), inalata con la polvere, è responsabile inizialmente di localizzazioni polmonari soprattutto in adulti di 60-80 anni (i maschi sono colpiti due volte più che le donne). Fattori predisponenti sono riconosciuti in circa $1{ }^{\prime} 80 \%$ dei casi: terapie steroidee $(35 \%$ circa dei casi), trapianti d'organo solido (12\%), malattie ematologiche maligne $(10 \%)$, patologie respiratorie come neoplasie, bronchiectasie, tubercolosi, silicosi, sarcoidosi, asma, BPCO (6\%), infezione da HIV (5\%). Altre condizioni di modesta immunodepressione sono le malattie del connettivo, il diabete, l'alcoolismo e la tossicomania. La nocardiosi polmonare assume le caratteristiche di pneumopatia cronica di diagnosi difficile in soggetti come i broncopatici cronici con malattia instabile e tendente a frequenti riacutizzazioni, pur potendo evolvere anche in modo rapido. La lesione polmonare, in un contesto di leucocitosi neutrofila e di anemia moderata, presenta aspetti assai polimorfi e poco specifici, fino all'ascesso con tendenza alla progressione.

Tra i miceti filamentosi, quelli che presentano particolare tropismo per l'apparato respiratorio sono quelli appartenenti al genere Aspergillus. Di più raro riscontro sono le localizzazioni polmonari da zigomiceti, da miceti dematicei e da Scedosporium spp.

Le aspergillosi (soprattutto da A. fumigatus e da A. terreus) si caratterizzano per tassi di prevalenza differenti nelle diverse categorie di soggetti a rischio, massimi per i soggetti HSCT 
e per quelli sottoposti a trapianto di polmone (fino al 25\%), oggi pressoché vicini a zero nei soggetti con infezione di HIV. Emergente, oggi, è l'incremento dell'aspergillosi anche nei soggetti affetti da BPCO in trattamento steroideo cronico.

L'importanza del ruolo sostenuto dal "terreno predisponente" è testimoniato dalla forma clinica nota con il nome di "aspergillosi semi-invasiva" che dal punto di vista epidemiologico si configura come malattia cronica di pazienti moderatamente immunodepressi (etilismo, diabete), affetti da preesistenti lesioni polmonari (collagenosi, sarcoidosi, broncopatia cronica ostruttiva). Clinicamente si apprezza un quadro di broncopolmonite febbrile eventualmente evolvente in infarto polmonare (dispnea, emottisi, pleurite) senza segni di ipossiemia. La diagnostica per immagini, su TAC del torace ad alta risoluzione $(\mathrm{HRCT})$, evidenzia quadri variabili: infiltrati o noduli più o meno disseminati con halo sign perifocale nei pazienti HSCT (80\% dei casi: soffusione emorragico-infartuale intorno alla zona centrale di necrosi coagulativa) o con l'air crescent sign. Differente è il meccanismo di insorgenza dell'aspergilloma, che, tipica patologia dell'adulto, necessita della preesistenza di una cavità polmonare in comunicazione con l'albero respiratorio (molte malattie possono produrre queste cavità come la tubercolosi, la sarcoidosi, le neoplasie, la fibrosi cistica, ecc). Da ultimo sono possibili manifestazioni allergiche come aspergillosi asmatica, alveolare infiltrativa, broncopolmonare allergica, alveolite allergica estrinseca.

Per quanto concerne la prognosi si segnala che: 1. l'evoluzione degli aspergillomi è imprevedibile, potendosi presentare con quadri asintomatici o con caratteristiche rapidamente e drammaticamente evolutive (emottisi massive in alcuni casi letali); 2. l'aspergillosi broncopolmonare allergica e l'alveolite allergica estrinseca da Aspergillus si caratterizzano per la lenta evoluzione alternando molteplici fasi di riacutizzazione e di remissione che comportano un danno polmonare esteso ed irreversibile; 3 . l'evoluzione dell'aspergillosi invasiva è gravata da prognosi spesso infausta, con tassi di mortalità complessiva superiori al 50\% nonostante la terapia con amfotericina B o con voriconazolo eventualmente associati a caspofungina.

Pneumocystis jirovecii è responsabile della pneumocistosi polmonare. Essa si osserva soprattutto nei pazienti immunodepressi, con grave deficit dei T-linfociti, classicamente quelli affetti da AIDS. Tra i pazienti non affetti da infezione da HIV la pneumocistosi si osserva in soggetti con deficit immunologici misti, malattie ematologiche maligne e trapiantati di midollo (58\%), malattie infiammatorie inclusa l'epatopatia alcolica eventualmente trattati con steroidi (26\%), tumori solidi $(17.5 \%)$ e trapianti d'organo solido ( $8 \%)$. L'insorgenza è acuta. Il quadro clinico è quello di una pneumopatia interstiziale acuta con variabile grading di ipossiemia.

Significato assolutamente controverso nella patogenesi di pneumopatie infettive è quello sostenuto dai lieviti: se è assolutamente dimostrato il tropismo respiratorio di Cryptococcus neoformans, il ruolo di Candida spp è in genere escluso. Il coinvolgimento polmonare di C. neoformans è per lo più asintomatico (anche se è possibile rilevare con la diagnostica per immagini quadri di criptococcoma solitario polmonare, di 2$10 \mathrm{~cm}$ di diametro, in sede sottopleurica), ma può anche accompagnarsi a coinvolgimento linfatico ilare e pleurico ovvero ad estesi infiltrati peribronchiali escavati. La criptococcosi si riscontra nell' $85 \%$ dei casi in soggetti affetti da AIDS (2-7 casi per 1000 infetti da HIV nelle casistiche preHAART), ovvero nei pazienti affetti da malattie oncoematologiche maligne, da sarcoidosi e da diabete mellito dove l'incidenza è però molto minore, intorno a 0.4-1.3 casi per 100000 . I soggetti che presentino deficit dell'immunità cellulo-mediata sviluppano con elevata frequenza infezione o malattia da Cytomegalovirus, con interessamento polmonare in una quota di tali pazienti. hCMV si localizza a livello dei macrofagi, delle cellule epiteliali alveolari, e delle cellule endoteliali, determinandone l'ingrandimento e la comparsa di inclusi citoplasmatici basofili e nucleari purpurei. Il danno comporta l'insorgenza di polmonite interstiziale con edema alveolare, essudato proteico e presenza di membrane ialine. Queste lesioni sono focali e non limitate ad un lobo.

Si segnala inoltre che anche hRSV riconosce nel soggetto sottoposto a trapianto di midollo osseo un fattore predisponente.

\section{Le polmoniti nosocomiali}

(referenze essenziali: 1, 3-5, 9, 11, 13, 16, 20, 22, 24, 31, $34,40-41)$

Le infezioni respiratorie nosocomiali costituiscono il $15 \%$ delle infezioni nosocomiali: 300000 sono i casi che annualmente si osservano negli Stati Uniti (5-10 casi ogni 1000 ricoveri), con un tasso di mortalità del 20-50\%. L'incidenza aumenta da 6 a 20 volte nei soggetti sottoposti a ventilazione meccanica, anche se è obiettivamente difficile stabilirne con precisione il tasso. Infatti, altre condizioni patologiche, quali le tracheobronchiti, possono simularne, almeno nel soggetto in ventilazione assistita, il quadro clinico, ed anche le diverse modalità di diagnosi microbiologica (colture qualitative invece che semiquantitative o quantitative) possono determinare il raddoppio delle diagnosi.

Molti studi effettuati dalle maggiori società scientifiche nel corso degli ultimi dieci anni hanno definito i principali fattori di rischio responsabili di HAP, proponendo l'adozione di punteggi. Tra questi, il Clinical Pulmonary Infection Score (CPIS), adottato congiuntamente da ATS e ISDA, considera uno score costruito su dati clinici, radiologici, fisiopatologici $\left(\mathrm{PaO}_{2} / \mathrm{FIO}_{2}\right)$ e microbiologici, assegnando un ruolo primario ai risultati dell'esame microscopico diretto (colorazione sec. Gram) e dell'esame colturale quantitativo del lavaggio broncoalveolare.

Recentemente alcuni autori hanno proposto il dosaggio nel siero della procalcitonina ( $\mathrm{pCT}$ ) come validissimo marker per la diagnosi ed il monitoraggio delle polmoniti nosocomiali (soprattutto VAP). Inoltre combinando questo marker con il CPIS score si è raggiunta una specificità del $100 \%$ permettendo un reale risparmio di antibiotici non necessari in quei casi etichettati in fase iniziale come falsi positivi.

\section{C1.L'epidemiologia microbica delle polmoniti nosocomiali} La ventilazione assistita costituisce il principale fattore predisponente: episodi di polmonite nosocomiale si osservano nel $9-27 \%$ dei pazienti intubati, con una frequenza quattro volte superiore rispetto a quella registrata in soggetti non intubati. Ciò è dovuto all'abolizione della barriera costituita dalla glottide, dalla più o meno grave compromissione del riflesso della tosse e della funzione mucociliare, al mancato filtro nasale e delle prime vie aeree, all'irritazione meccanica della mucosa, alla importante variazione dell'ecosistema microbico del tubo digerente.

Per quanto attiene alla definizione degli agenti eziologici delle polmoniti nosocomiali, è documentata una variabilità dei patogeni preponderanti in rapporto al timing di insorgen$\mathrm{za}$, in rapporto al momento del ricovero e, per le forme associate a ventilazione invasiva, al momento dell'intubazione.

Facendo riferimento al modello delle polmoniti associate a ventilazione invasiva (VAP), che rappresentano le forme più gravi di polmonite nosocomiale, si distinguono quindi dal punto di vista della diversa prevalenza di agenti eziologici, forme ad esordio molto precoce (very early-onset), precoce (early) e tardive, come indicato nella tabella di seguito riportata.

Le forme ad esordio precoce e molto precoce, la cui comparsa si osserva entro 2-4 giorni dall'intubazione, riconoscono come patogenesi prevalente un meccanismo di aspirazione e di trasposizione nel polmone profondo della flora microbica colonizzante ad opera del tubo da ventilazione. Pertanto gli agenti eziologici prevalenti sono per lo più microrganismi appartenenti alla flora endogena che hanno colonizzato le vie aeree superiori. Essi sono solitamente più sensibili ai chemioantibiotici, essendo normalmente poco esposti a pressione antibiotica.

Al contrario, le forme ad insorgenza tardiva sono sottese ancora ad un meccanismo prevalente di aspirazione ma di microrganismi colonizzanti sia l'ipofaringe, sia l'intestino 
Periods of risk for various microbial causes of VAP according to the duration of mechanical ventilation. Park DR Intensive Care, 2005

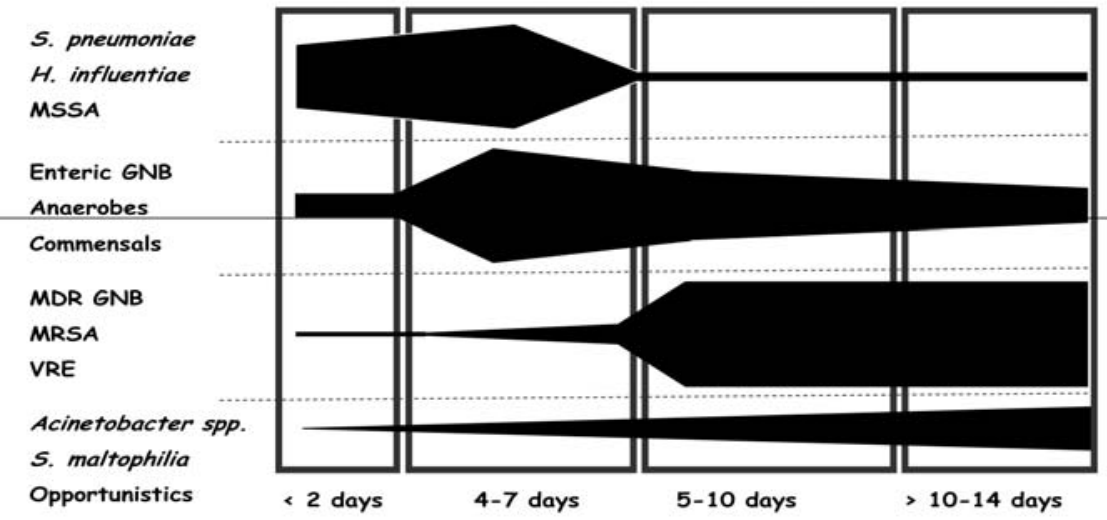

inconsueto meccanismo patogenetico.

Nel $55 \%$ dei casi sono in causa bacilli aerobi Gram negativi (Enterobacteriaceae, circa il 30\%; P. aeruginosa, circa il $17 \%$; H. influenzae, circa il 6\%) e $S$. aureus (circa il $15 \%)$. Inusuali sono le forme sostenute da batteri anaerobi del cavo orale (rinvenuti tuttavia con frequenza nelle polmoniti ad esordio precoce quali ad esempio le forme di Stroke Associated Pneumonia, SAP), da S. pneumoniae $(<3 \%)$ e da $M$. catarrhalis. A parte debbono essere considerate le legionellosi ospedaliere, al pari delle forme da Aspergillus spp. o da virus (influenzali o, soprattutto in età pediatrica, hRSV).

(gastro-pulmonary theory). Quest'ultima appare particolarmente rilevante nelle forme late, in quanto la condizione di persistente alcalizzazione del $\mathrm{pH}$ gastrico indotto dalla profilassi farmacologica dell'ulcera da stress, favorisce la risalita in faringe e da qui nell'albero respiratorio dei batteri colonizzanti il tratto GE. Alla luce di tale considerazione è evidente come il pattern di agenti eziologici sia estremamente più ampio ed in più sia rappresentato da specie residenti in ambito nosocomiale, quindi dotate di profili di resistenza complessi. Pseudomonas aeruginosa e S. aureus meticillina-resistente sono i microrganismi maggiormente rappresentati, seguiti da Enterobacteriaceae e da altri Gram negativi non fermentanti quali A. baumannii, B. cepacia e S. maltophilia. Assolutamente da non trascurare è altresì il rischio di polmonite nosocomiale correlata a colonizzazione esogena, ad opera di patogeni ambientali, prevalentemente contaminanti i sistemi idrici, che vengono inalati dopo aerosolizzazione delle acque. Legionella spp. rappresenta l'archetipo di tale categoria di patogeni, ma altri, quali P. aeruginosa, S. maltophilia, Aspergillus spp. e micobatteri a rapida crescita, hanno ruoli non secondari. La trasmissione in questi casi è legata a manovre di aspirazione, uso di broncoscopi contaminazione di nebulizzatori, umidificatori e circuiti di ventilazione.

La condizione di intubazione è fisiologicamente correlata ad un aumento del rischio di contaminazione microbica del device usato e delle vie aeree. Ciò comporta non poche difficoltà nell'interpretazione del dato microbiologico, ove non eseguito con le opportune metodiche, in quanto è spesso difficile discriminare tra microrganismo colonizzante ed agente causale di infezione. Alcuni autori, tuttavia, sostengono ancora l'utilità delle colture di sorveglianza (colture del comune aspirato tracheale eseguite quotidianamente) per l'accertamento della colonizzazione della trachea riscontrata prima dello sviluppo di una VAP nel 94\% dei casi. La colonizzazione del tubo endotracheale, con la creazione di un biofilm abitato da microrganismi, costituisce un rilevante fattore patogenetico, causa di successiva dispersione microbica nei distretti respiratori distali.

Anche in assenza di tubo endotracheale l'aspirazione delle secrezioni orali e faringee mantiene un ruolo rilevante nella patogenesi delle polmoniti nosocomiali. L'aspirazione è un fenomeno fisiologico ( $45 \%$ nel sonno), ed è particolarmente significativa nei soggetti in trattamento con beta-2-stimolanti, con sottostanti patologie neurologiche, a motivo delle disfunzioni della glottide, del permanere di secrezioni, e delle frequenti manovre di suzione effettuate con l'ausilio di dispositivi. Ciò comporta un importante ruolo dei batteri anaerobi residenti nel cavo orale: in questo caso gli episodi infettivi sono più frequenti nei primi cinque giorni di ricovero.

Al contrario, l'inalazione o la diretta inoculazione di microrganismi nelle vie respiratorie, al pari della metastatizzazione polmonare conseguente alla disseminazione ematogena in soggetti portatori di cateteri vascolari, costituiscono un
Nelle forme precoci di polmoniti nosocomiali, microrganismi tipicamente "domiciliari" quali $S$. aureus meticillino-sensibile, S. pneumoniae ed $H$. influenzae costituiscono circa il 55\% degli agenti eziologici. Al contrario, le forme ad esordio tardivo sono sostenute in più del $65 \%$ dei casi da microrganismi tipicamente nosocomiali, quali quelli multiresistenti (P. aeruginosa, Enterobacteriaceae produttrici di beta-lattamasi a spettro allargato, A. baumannii e $S$. aureus meticillino-resistente).

Il ruolo dell'eziologia si riflette anche sulla prognosi della polmonite acquisita in ambito nosocomiale: fattore prognostico sfavorevole é, infatti, oltre alla coesistenza di un quadro setticemico (presente in circa il 10\% dei casi, si associa ad una mortalità tre volte maggiore) il riscontro in coltura di bacilli Gram negativi (le polmoniti da $P$. aeruginosa sono gravate da mortalità pari al 70\%) o di microrganismi multiresistenti.

Per quanto attiene al ruolo rivestito dai lieviti, l'inquadramento nosografico della pneumopatia da Candida spp. rimanda a descrizioni assolutamente aneddotiche: i casi istologicamente documentati che sono stati osservati riguardano quasi esclusivamente localizzazioni polmonari nell'ambito di forme poliviscerali o disseminate. Diverso è il caso della mucosite tracheobronchiale da C. albicans. Significato pressoché nullo ha quindi il riscontro di Candida spp. nei campioni respiratori. Tuttavia si segnala che questo genere fungino è un marcatore indicativo del fatto che, rispetto al soggetto non colonizzato, il paziente ha una possibilità 1.58 volte superiore di sviluppare una VAP e di 2.22 volte superiore di avere un' eziologia sostenuta da $P$. aeruginosa.

\section{La diagnosi microbiologica di infezione delle basse vie} respiratorie

(referenze essenziali: 1, 6-8, 10, 14, 17-21, 24-25, 27, 29, 31, 33-34, 36-37)

La diagnosi di polmonite, soprattutto della forma nosocomiale, è procedura complessa, e può essere posta quando il paziente presenti un infiltrato polmonare di recente compartre criteri seguenti: 1 . comparsa di ipertermia, 2. presenza di secrezioni respiratorie purulente e 3 . leucocitosi neutrofila. Tale approccio diagnostico è sensibile ma poco specifico, tanto che solo nel $30 \%$ circa dei casi in cui, sulla base di questi criteri, è posta la diagnosi di polmonite è poi possibile pervenire ad una conferma di tipo eziologico ricorrendo ad un approccio colturale quantitativo. D'altra parte, si segnala come le tecniche diagnostiche stesse siano gravate da diversa sensibilità in ragione delle possibilità diagnostiche locali.

Perché effettuare una diagnosi eziologica?

Le finalità della diagnosi eziologica (in particolare per le forme nosocomiali) sono quelle di:

1. evitare di non trattare o di trattare in modo inadeguato $i$ casi di HAP, di VAP o di HCAP, perché questo costituisa o progressivamente evoluto in aggiunta ad almeno due dei 
sce un fattore rilevante associato ad un incremento della mortalità;

2. riconoscere la variabilità eziologica da un Centro all'altro, da un reparto all'altro, e in momenti diversi nello stesso Centro al fine di mettere in atto, su base epidemiologica, schemi di trattamento e di prevenzione ottimali;

3. trattare adeguatamente tutti i pazienti con HAP sostenute da germi multiresistenti quali $P$. aeruginosa, Acinetobacter spp., S. aureus meticillino-resistente o Enterococcus resistente ai glicopeptidi;

4. evitare il ricorso eccessivo agli antibiotici (per posologia e per durata) puntando su di una strategia terapeutica basata sui risultati degli esami colturali di materiali prelevati dalle basse vie aeree;

5. applicare idonee strategie di prevenzione.

Quali sono i punti critici della diagnosi eziologica?

Le criticità della diagnosi eziologica sono:

1. la disponibilità di un campione rappresentativo della sede anatomica di infezione e non contaminato, prelevato possibilmente in periodo precedente alla somministrazione di antibiotici;

2. il ricorso a strategie di laboratorio integrate, che considerino l'esame microscopico diretto e l'esame colturale semiquantitativo o meglio, quantitativo;

3. la disponibilità di test rapidi per la diagnosi di infezione batterica, fungina o virale.

\section{D1. Le modalità della diagnosi microbiologica}

Il ricorso ad un approccio di diagnosi eziologica, ricorrendo a colture quantitative, ha una documentata utilità soprattutto in quei pazienti per i quali il sospetto diagnostico su base clinica è modesto. Per questo è necessario evitare ogni ritardo nell'effettuazione dei prelievi, che devono essere effettuati, compatibilmente con la situazione clinica di ogni singolo paziente prima dell'inizio di una (nuova) terapia antibiotica. Al momento del riscontro di un quadro di polmonite, sia comunitaria che nosocomiale, è opportuno procedere all'esecuzione di emocolture ( 2 set almeno): esse risultano positive, rispettivamente in circa l'11 ed il $25 \%$ dei casi.

I materiali più significativi per l'analisi microbiologica si ottengono preferibilmente con prelievo "distale" (dai bronchi segmentari o sub-segmentari, dove la contaminazione da saliva è improbabile). Il prelievo può essere effettuato attraverso broncoscopio (guidato) o con appositi cateteri "alla cieca". Inoltre, il prelievo può essere effettuato con un catetere "protetto" (essendo dotato di una doppia camera, dopo l'introduzione si estrae il catetere interno, protetto e sterile) o con un catetere "non protetto". Nonostante le notevoli differenze non è stato possibile stabilire con certezza quale sia la tecnica di prelievo migliore, mentre ci sono pochi dubbi sul fatto che l'esame microbiologico debba essere eseguito con modalità quantitativa e che per ogni tipo di campionamento debba essere definita una soglia di significatività in termini di carica microbica identificata.

\section{D1.1 La fase pre-analitica}

È responsabilità del Laboratorio di Microbiologia dare indicazioni perché il metodo di prelievo sia accurato: solo un prelievo di buona qualità pone le premesse per un risultato di buona qualità in termini biologici e clinici.

Anche la proposta del materiale da prelevare e, successivamente, da processare dovrebbe essere concordata dal Clinico con il laboratorio di Microbiologia, alla luce della significatività prevista delle procedure analitiche. È fondamentale ricordare che il prelievo dei campioni deve essere effettuato a partire dalle basse vie respiratorie, possibilmente prima dell'inizio della terapia antibiotica, che deve poi essere immediatamente iniziata nei pazienti critici.

Per ottimizzare la raccolta del campione e l'esecuzione dell'esame colturale è indispensabile la stretta collaborazione e lo scambio di informazioni tra microbiologo e medico curante: il
Laboratorio di Microbiologia dovrebbe essere informato in anticipo, prima che il prelievo sia eseguito, dell'invio di materiali raccolti con metodiche invasive. Inoltre, l'affidabilità del risultato microbiologico è proporzionale anche all'esperienza dell'operatore-endoscopista che procede al prelievo.

La compilazione del modulo di richiesta rappresenta un momento fondamentale per l'inquadramento anamnestico del singolo caso, per l'impostazione del prosieguo tecnico dell'esame e per l'interpretazione dei risultati. Il modulo di richiesta, pertanto, deve essere strutturato in modo tale da rendere possibile, in modo proficuo e completo, lo scambio di informazioni tra il Medico curante ed il Microbiologo, che va spesso completato attraverso un contatto diretto, telefoni$\mathrm{co}$, fra le due figure professionali coinvolte nella procedura diagnostica.

La scelta del campione biologico deve essere effettuata sulla base delle caratteristiche cliniche del paziente e delle possibilità tecniche disponibili nella sede ospedaliera locale. L'allegato G1 riporta le modalità di prelievo.

È, tuttavia, necessario ricordare che, ove possibile, alla raccolta di campioni ad alto rischio di contaminazione salivare (espettorato; espettorato indotto; espettorato protetto; aspirato endotracheale; aspirato da tracheostomia; lavaggio bronchiale o broncoaspirato) deve essere preferita la scelta di prelevare campioni a basso rischio di contaminazione con saliva (aspirato transcricoideo; aspirato endotracheale/bronchiale; lavaggio broncoalveolare, BAL; spazzolatura endobronchiale protetta; BAL mirato con cateterino; plugged telescoping catheter, PTC).

L'allegato G1 riporta le modalità consigliate per eseguire correttamente i prelievi. Si segnala che, ove non sia possibile ricorrere a tecniche di prelievo protette, tra le metodiche non protette di prelievo deve essere preferita quella dell'espettorato indotto.

L'allegato G2 riporta un modello per l'esplicazione di note da consegnare al paziente per la raccolta dei campioni di espettorato.

Si segnala che, in caso di soggetti affetti da fibrosi cistica, non sempre è agevole effettuare prelievi con tecniche protette, praticate tuttavia nei Centri di Riferimento clinici. E quindi opportuno considerare materiali respiratori idonei per la processazione analitica anche l'espettorato nel paziente adulto e nel bambino grande, l'aspirato rino-faringeo profondo nel bambino piccolo che non espettora.

Molto si discute se la modalità di prelievo debba prevedere l'ausilio della visione diretta endoscopica o se possa essere "alla cieca": i dati più recenti della letteratura, pur raccomandando la prima modalità, non la considerano obbligatoria.

I campioni, tuttavia, devono essere finalizzati all'esecuzione di colture quantitative, assai più utili clinicamente di quelle semiquantitative.

Per tutti valga l'esempio dei campioni prelevati con modalità non protette: si noti come la coltura qualitativa dell'aspirato tracheale sia di scarsissimo ausilio, se non per il valore predittivo negativo (se effettuato in assenza di antibiotici): la sensibilità risulta $>75 \%$ ma la specificità è $<25 \%$, mentre la coltura quantitativa dello stesso materiale respiratorio è accettabile, con sensibilità del $70-80 \%$ e specificità pari al $70 \%$.

La diagnosi di polmonite (e di polmonite microbiologicamente documentata) si basa sui risultati quantitativi delle colture di materiali respiratori prelevati da sedi distali con/senza broncoscopio:

$$
\begin{aligned}
& \text { * aspirato endotracheale } \\
& \text { * lavaggio broncoalveolare } \\
& \text { * spazzolato bronchiale }
\end{aligned}
$$

associate alle emocolture ed alla coltura del liquido pleurico. In particolare, il ricorso alle colture quantitative del liquido di lavaggio broncoalveolare o dell'aspirato endotracheale paiono garantire risultati qualitativamente analoghi dal punto di vista interpretativo. È opportuno procedere al prelievo di materiali respiratori distali (con metodica invasiva) quando vi sia garanzia che i risultati siano disponibili in tempi seria- 
ti (microscopia: in giornata; coltura: 18 ore; antibiogramma: 48 ore) e quando vi sia la "fiducia" dei curanti nelle capacità del laboratorio. Nei pazienti intubati è opportuno preferire il prelievo distale protetto all'aspirato tracheale.

Il materiale biologico deve essere inviato al Laboratorio di Microbiologia possibilmente entro 15 minuti dalla raccolta, previa conservazione a temperatura ambiente: è necessario evitare di conservare $\mathrm{i}$ materiali in soluzione fisiologica (che può inibire i microrganismi cosiddetti fastidious). Si segnala che la lidocaina ed altri anestetici possiedono attività antibatterica, al pari della formalina. Campioni che pervengono al Laboratorio di Microbiologia dopo 2 ore non dovrebbero essere esaminati, per l'elevata possibilità di ottenere risultati "falsi negativi" o "falsi positivi" e quindi clinicamente non solo inutili ma potenzialmente fuorvianti la diagnosi e la conseguente terapia antibatterica.

Ove non si consideri la possibilità di ricerche mirate, il protocollo delle indagini colturali sarà finalizzato alla ricerca dei microrganismi non esigenti e di quelli microaerofili (protocollo "minimo"). Pare opportuno segnalare la opportunità di procedere alla ricerca dei patogeni di seguito indicati in tabella: dere alla semina di un'aliquota del campione di materiale respiratorio su terreni selettivi per Legionella spp.;

- anticorpi circolanti di L. pneumophila con tecnica EIA o IFA: il siero prelevato all'ingresso non deve essere processato, ma conservato in sieroteca per essere esaminato contestualmente a quello prelevato dopo 21 giorni per accertare un'eventuale legionellosi. Questo approccio diagnostico sierologico ha ovviamente solo valore come dato di natura epidemiologica.

\section{D1.2 La fase analitica}

All'arrivo presso il Laboratorio di Microbiologia Clinica è necessario procedere, per quanto possibile, alla verifica della correttezza con cui la fase pre-analitica (raccolta, conservazione ed invio del materiale) è stata effettuata.

L'allegato G3 riporta la descrizione delle procedure tecniche per la diagnosi eziologica.

Gli allegati G4 (1-4) riportano in flow charts le indicazioni alle specifiche ricerche microbiologiche.

\begin{tabular}{lll} 
QUADRO CLINICO & RICERCHE “MICROBIOLOGICHE” & TEST SIEROIMMUNOLOGICI \\
\hline Polmonite domiciliare: & protocollo minimo & C. trachomatis, M. pneumoniae, \\
- nel bambino & S. agalactiae (< 30 giorni), B. pertussis & C. pneumoniae, hRSV, Adenovirus \\
\hline - nell'adulto: & protocollo minimo & M. pneumoniae, C. pneumoniae \\
* in immunodepresso & Nocardia spp., P. jirovecii, miceti & L. pneumophila, CMV \\
(preferenza a: BAL) & filamentosi & H. capsulatum, C. immitis \\
\hline * in viaggiatore internazionale & protocollo minimo & Influenzavirus \\
& $\begin{array}{l}\text { batteri a seconda della epidemiologia locale } \\
\text { miceti dimorfi }\end{array}$ & SARS-CoV (se provenienza da zone con \\
& & documentata trasmissione locale sec. WHO) \\
\hline in fibrosi cistica & protocollo minimo, B. cepacia complex, miceti filamentosi & M. pneumoniae, C. pneumoniae, hRSV \\
\hline a contatto con animali: & protocollo minimo & C. psittaci, Leptospira spp., \\
& & C. burnetii, P. multocida, R. equi \\
\hline BPCO & protocollo minimo & M. pneumoniae, C. pneumoniae \\
\hline Polmonite nosocomiale: & & M. pneumoniae, C. pneumoniae, \\
$*$ in paziente ventilato & protocollo minimo & L. pneumophila, hRSV \\
\hline in paziente in Stroke Unit & protocollo minimo & \\
ed in caso di ab ingestis & anaerobi &
\end{tabular}

In particolare, al momento del riscontro di un quadro di polmonite comunitaria è opportuno procedere all'esecuzione di test specifici:

- antigene (da campione urinario) di Legionella pneumophila (obbligatoriamente di tipo 1, possibilmente anche di tipo 2-14) e di Streptococcus pneumoniae, con tecnica immunocromatografica o con tecnica EIA: in caso di positività per Legionella o per pneumococco è opportuno procedere alla semina di un'aliquota del campione di materiale respiratorio rispettivamente su Agar Sangue (incubato in microaerofilia) e su terreni selettivi per Legionella.

Si segnala tuttavia che in età pediatrica la ricerca dell'antigene urinario di pneumococco ha significato solo modesto. Si segnala inoltre che la ricerca dell'antigene di L. pneumophila deve essere riservata ai casi di CAP severa o enigmatica, in caso di fallimento di terapie con beta lattamici, in pazienti in ICU, per quelli che presentano specifici fattori di rischio e durante le epidemie.

Inoltre, nei pazienti con fibrosi cistica è opportuno prevedere, oltre che prelievi per la definizione eziologica delle riacutizzazioni, anche controlli su base trimestrale, finalizzati soprattutto alla ricerca di P. aeruginosa, di B. cepacia complex, di $S$. aureus e di miceti filamentosi.

Ancora, al momento del riscontro di un quadro di polmonite nosocomiale è opportuno procedere all'esecuzione di test per la definizione di:

- infezione da Legionella spp.;

- antigene (da campione urinario) di L. pneumophila con tecnica immunocromatografica o con tecnica EIA: in caso di positività per Legionella spp. è opportuno proce-

\section{D1.2.1 L'esame microscopico diretto}

L'osservazione microscopica diretta del materiale respiratorio riveste un duplice ruolo: 1 . verifica dell'idoneità del campione (se rappresentativo, cioè, delle basse vie respiratorie, senza contaminazione salivare. Nel caso dei materiali prelevati con tecniche non protette è imperativo effettuare la determinazione del Q score, e 2. dimostrazione dei morfotipi microbici presenti (indicativa, in via presuntiva, di una possibile eziologia).

L'osservazione microscopica diretta del materiale respiratorio è utile (previa citocentrifugazione) in ogni caso: un campione di lavaggio broncoalveolare che mostri la presenza $>1 \%$ di cellule squamose depone per un prelievo non correttamente eseguito e, in quanto potenzialmente contaminato con materiale orale, di significato microbiologico e clinico ambiguo. Al contrario, il riscontro di cellule cigliate è indicativo del fatto che il materiale proviene dalle basse vie respiratorie.

Inoltre, l'esame microscopico, effettuato sottoponendo il campione a colorazione di Gram (e, in casi mirati, anche di Kinyoun o Auramina-rodamina per micobatteri, di ZiehlNielsen o di Kinyoun modificati per Nocardia spp., di Gomori-Grocott, Calcofluor White o PAS per miceti, di fluorescenza diretta per Legionella spp., Cytomegalovirus, virus respiratori o Pneumocystis jirovecii) consente di evidenziare la presenza di morfotipi microbici predittivi del microrganismo eventualmente riscontrato in coltura: la lettura (eseguita a x100 e x1000) consente di rilevare la presenza di batteri extracellulari (definendone la carica semiquantitativa) ed intracellulari (registrando la percentuale di polimorfonucleati e macrofagi contenenti microrganismi intracellulari). 
La presenza di batteri intracellulari o adesi alle pareti delle cellule in percentuale $>2 \%$ è indicativa di polmonite sostenuta dal morfotipo microbico osservato, e l'attendibilità di tale riscontro equivale a quello di una coltura quantitativa. D'altra parte, la negatività dell'esame microscopico non esclude tout court la polmonite, per la scarsa sensibilità dell'esame microscopico dopo colorazione di Gram.

I risultati dell'esame microscopico devono essere riferiti tempestivamente, con una refertazione preliminare, telefonicamente o via fax, anche e soprattutto se il materiale non risulta idoneo all'indagine microbiologica.

\section{D1.2.2 L'esame colturale}

L'esame colturale dei materiali respiratori prelevati con metodiche protette costituisce il passaggio fondamentale per l'accertamento eziologico: è necessario che il Laboratorio metta in atto procedure tecniche atte a valutare quantitativamente i risultati analitici.

Il campione non necessita in modo imperativo del pretrattamento con la fluidificazione. In presenza di materiale emorragico può essere utile procedere alla lisi degli eritrociti (che pure diluisce il materiale patologico originario).

Anche in questo caso le indagini (per ricerca diretta di batteri e miceti) prevedono un protocollo minimo di ricerche colturali, associate però alla determinazione quantitativa della carica batterica. Il campione, sottoposto ad esame colturale, deve essere interpretato dopo 24 e 48 ore di incubazione.

Ove non sussistano, a seguito di condizioni epidemiologiche particolari, sospetti eziologici mirati, il Laboratorio di Microbiologia provvede a mettere in atto un protocollo di ricerca colturale standard, finalizzato sostanzialmente alla ricerca di microrganismi a rapida crescita (Enterobacteriaceae, bacilli Gram-negativi non fermentanti il glucosio, Moraxella catarrhalis, Staphylococcus aureus, Streptococcus pneumoniae e Streptococcus pyogenes) o esigenti (Haemophilus spp., Legionella spp.). La ricerca dei batteri anaerobi dovrebbe essere riservata ai casi di sospetta polmonite $a b$ ingestis. La scheda G3 riporta l'iter diagnostico di laboratorio.

Nel caso di sospetto clinico basato su dati clinico-epidemiologici particolari (viaggi internazionali, contatti con animali, soggetti con fibrosi cistica) è necessario predisporre ricerche mirate, ricorrendo a terreni selettivi e differenziali ed a modalità di incubazione protratte indispensabili per la evidenziazione di microrganismi particolarmente esigenti, quali ad esempio Nocardia spp., R. equi e B. cepacia o miceti filamentosi.

L'interpretazione del risultato tiene conto delle modalità operative adottate in base al materiale processato, ricordando che la quantificazione della carica microbica deve essere opportunamente valutata sulla base del fattore di diluizione utilizzato. Qualora si proceda alla coltura di materiali distali prelevati con procedure protette, poiché si tratta di materiali provenienti da distretti fisiologicamente sterili, è necessario procedere all'identificazione di tutti i microrganismi, dal momento che non è possibile escluderne in alcun caso, a priori, il ruolo patogeno.

La valutazione quantitativa è obbligatoria, e l'interpretazione dei risultati della coltura dei materiali raccolti con metodiche protette deve tenere conto che per la spazzola endobronchiale (PSB, Protected Specimen Brush) o per i prelievi effettuati con la metodica PTC, in assenza di terapia antibiotica o con terapia antibiotica invariata da $>3 \mathrm{gg}$, la carica critica è indicata in $>10^{3} \mathrm{CFU} / \mathrm{ml}$; per il lavaggio broncoalveolare la carica critica è indicata in $>10^{4} \mathrm{UFC} / \mathrm{ml}$ e per il lavaggio broncoalveolare mirato con cateterino essa è indicata in $>10^{3}$ $\mathrm{UFC} / \mathrm{ml}$ (tale valore è stato desunto dalla comparazione con la coltura di frustoli bioptici di tessuto polmonare di $1 \mathrm{~mm}^{3}$ ). Ciò si correla con i valori di sensibilità e di specificità di seguito indicati, e con una concordanza autoptica $>70 \%$ :

\begin{tabular}{lcc}
\hline PRELIEVI BRONCOSCOPICI & $\begin{array}{c}\text { SENSIBILITÀ } \\
(\%)\end{array}$ & $\begin{array}{c}\text { SPECIFICITÀ } \\
(\%)\end{array}$ \\
\hline Lavaggio bronco-alveolare & $73 \pm 18$ & $82 \pm 19$ \\
Spazzolato bronchiale & $66 \pm 19$ & $90 \pm 15$ \\
\hline
\end{tabular}

In caso di terapia chemioantibiotica, iniziata recentemente $(\leq 3 \mathrm{gg})$, anche cariche batteriche $\leq 10^{2} \mathrm{CFU} / \mathrm{ml}$ possono essere significative.

In caso di raccolta del materiale da lavaggio bronco-alveolare mirato con cateterino e palloncino (Pro-BAL) è necessario interpretare i risultati scalando di un logaritmo. La carica critica è indicata in $>10^{5} \mathrm{CFU} / \mathrm{ml}$.

Dati recenti della letteratura evidenziano tuttavia la validità del ricorso a strategie non invasive di prelievo, con il ricorso ad aspirati endotracheali. In questo caso tuttavia è imperativo effettuare colture quantitative, giacché la sola interpretazione qualitativa non consente di discriminare i microrganismi commensali, riducendo di molto il VPP della coltura.

Il dato anamnestico di una precedente terapia antibiotica comporta l'adozione di diversi criteri interpretativi della carica microbica.

\section{D1.3 L'interpretazione dei risultati}

Essendo spesso verificata la presenza di polimicrobismo nelle colture, solo la determinazione quantitativa della carica microbica costituisce il criterio interpretativo che consente di riconoscere il patogeno nel contesto di una popolazione mista.

Gli agenti eziologici di polmonite sono generalmente presenti in alte concentrazioni nelle secrezioni respiratorie $\left(\geq 10^{5}\right.$ $10^{6} \mathrm{UFC} / \mathrm{ml}$ ) e nei tessuti ( $\geq 10^{4} \mathrm{UFC} / \mathrm{g}$ di tessuto), mentre la popolazione microbica contaminante delle alte vie superiori è presente in concentrazioni più basse $\left(<10^{4} \mathrm{UFC} / \mathrm{ml}\right)$ quando il materiale è prelevato correttamente. La determinazione della carica batterica aiuta così a discriminare i microrganismi responsabili di infezione da quelli più probabilmente contaminanti.

Questi due criteri di analisi microbiologiche (esame microscopico diretto ed esame colturale) sono inclusi anche nei criteri di costruzione del Clinical Pulmonary Infection Score (CPIS), anche se, in realtà, diverso nel tempo è stato il loro utilizzo. Numerosi dati di letteratura sono disponibili in merito alla comparazione dell'accuratezza del CPIS con la diagnosi microbiologica: le conclusioni sono spesso discordanti, con ampio range di sensibilità e di specificità complessive. Tuttavia, l'esclusione del criterio microbiologico dalla costruzione del CPIS comporta valori di sensibilità diagnostica dell' $83 \%$ ma di specificità solo del $17 \%$.

La negatività della coltura di secrezioni respiratorie in assenza di un nuovo antibiotico inserito nello schema terapeutico nelle ultime 72 ore precedenti il prelievo di materiale patologico esclude virtualmente la presenza di una polmonite batterica (VPN: 94\%). Infezioni virali, da Legionella e da altri patogeni "atipici", compresi M. pneumoniae e C. pneumoniae, non possono, tuttavia, essere escluse.

La colonizzazione tracheale è comune nei soggetti intubati: in assenza di segni clinici essa non è segno di infezione e non è meritevole di considerazione. Infatti, il monitoraggio di routine dell'aspirato tracheale per anticipare l'eziologia di un possibile quadro di polmonite è spesso altamente confondente dal punto di vista della possibile evoluzione clinica del mero dato microbiologico.

In caso di soggetti affetti da fibrosi cistica il riscontro di $S$. aureus, $P$. aeruginosa e $B$. cepacia è clinicamente significativo qualunque sia la carica microbica.

L'allegato G5 riporta alcuni modelli di note codificate di commento al referto.

\section{D1.4 I test di chemioantibioticosensibilità}

\section{D1.4.1 I test diretti}

L'esecuzione di test per la valutazione della chemioantibioticosensibilità a partire direttamente dal campione biologico, utilizzata in due condizioni cliniche: la polmonite in soggetti affetti da fibrosi cistica ed in caso di polmonite nosocomiale, non è tuttavia standardizzata. In entrambi i casi, dati di letteratura suggeriscono il ricorso al test di determinazione della MIC con metodo di Agar diffusione (Epsilometer test). 
Sebbene sia necessaria una certa qual esperienza da parte dell'operatore, i risultati evidenziano un outcome più favorevole in termini di durata della febbre, durata della somministrazione di antibiotici e comparsa di diarrea da Clostridium difficile tra i soggetti per i quali fossero stati resi disponibili i dati preliminari del test di sensibilità.

\section{D1.4.2 I test in vitro}

I test di chemiosensibilità devono essere effettuati a partire da colonie isolate in accordo con l'interpretazione della coltura. Si segnala che i metodi automatizzati, al pari del tradizionale metodo di diffusione in Agar sec. Kirby e Bauer, possono determinare risultati errati per la lentezza di crescita del batterio. In caso di infezione polmonare documentata in soggetti affetti da fibrosi cistica si raccomanda l'esecuzione dei test di sensibilità con metodi manuali su tutti $\mathrm{i}$ morfotipi differenti (lucidi, rugosi, lisci, nani) cui corrispondono genotipi identici ma differenti antibioticosensibilità.

L'esecuzione dell'antibiogramma deve essere affiancata dallo studio per la rilevazione delle beta-lattamasi e delle MIC in due condizioni cliniche: la polmonite in soggetti affetti da fibrosi cistica ed in caso di polmonite nosocomiale. In entrambi i casi, il ricorso al test di determinazione della MIC con metodo di Agar diffusione (Epsilometer test) appare quello dotato di maggiore praticità.

In caso di polmonite nosocomiale può essere opportuno, in casi specifici, procedere allo studio delle associazioni chemioantibiotiche, con la determinazione del FIC index. Anche in questo caso tuttavia non esistono procedure standardizzate riconosciute da organismi internazionali.

\section{D1.4.3 I test in vivo}

La terapia delle polmoniti nosocomiali deve essere attentamente monitorata. A tal proposito si rende necessario valutare, oltre al dosaggio della concentrazione sierica delle singole molecole, possibile con metodi automatizzati per i glicopeptidi (vancomicina e teicoplanina) e gli aminoglucosidi (gentamicina ed amikacina), anche i parametri farmacocinetici/farmacodinamici necessari per l'eradicazione microbica. In particolare è necessario valutare: 1. il rapporto "picco"/MIC (per gli aminoglucosidi); 2. il tempo superiore alla MIC nel tempo di somministrazione (per le molecole betalattamiche, linezolid e clindamicina); 3. AUC (area sotto la curva) delle 24 ore/MIC (per macrolidi, chinoloni, glicopeptidi).

\section{D2. La diagnosi micologica di infezione delle basse vie respiratorie}

La diagnosi di laboratorio è basata sull'esame micologico diretto (colorazione con cotton blue - lattofenolo; in alternativa: colorazione sec. Gram oppure con Calcofluor White) e, successivamente, su quello colturale finalizzato alla ricerca di miceti filamentosi (preferibilmente con incubazione a $35^{\circ} \mathrm{C}$ per 2 giorni proseguita a $30^{\circ} \mathrm{C}$ per almeno altre 2 settimane). In caso di colture di materiale polmonare bioptico é possibile incrementare la significatività della coltura mimando in vitro le condizioni fisiologiche $\left(35^{\circ} \mathrm{C}, 6 \% \mathrm{O}_{2}-10 \%\right.$ $\mathrm{CO}_{2}$ ). La coltura di materiali contaminati con saliva (espettorato) è comunque di discutibile utilità: il VPP comporta la necessità di analizzare prelievi multipli e seriati e di utilizzare per l'interpretazione uno score clinico-epidemiologico. È fondamentale ricorrere, in caso di sospetto diagnostico fondato, routinariamente alla diagnostica istopatologica (colorazione di Gomori-Grocott; in alternativa: PAS). E imperativo effettuare la diagnosi di genere del micete isolato in coltura, procedendo successivamente alla diagnosi di specie anche avvalendosi della eventuale collaborazione di Centri di Referenza.

La diagnosi precoce di infezione da Aspergillus spp. prevede la ricerca dell'antigene galattomannano di Aspergillus spp. (il siero non deve essere processato come singolo campione, ma deve essere conservato in sieroteca per poi essere esaminato contestualmente a quello prelevato serialmente, in quanto è la variazione del contenuto sierico dell'antigene galattomannano che assume significato clinico in termini di diagnosi di infezione invasiva. Tuttavia, la sensibilità del metodo è variabile a seconda delle categorie di soggetti, fino a raggiungere il minimo valore nei soggetti sottoposti a trapianto d'organo solido: $22 \%$. In caso di positività, è sempre opportuno confermare il risultato di positività). La ricerca di anticorpi antiAspergillus fumigatus (tecnica di doppia diffusione in Agar) deve essere riservata ai casi di sospetto aspergilloma e di sospetta infezione nei soggetti sottoposti a trapianto d'organo solido. Parimenti, si può ricorrere al test per la rilevazione degli anticorpi anti-A. flavus, A. nidulans, A. terreus ed A. niger. È necessario però tener presente il limitato valore clinico di questi test, sia in termini di bassa specificità e sensibilità dei metodi, sia in ragione del fatto che la positività del test si sviluppa in fasi avanzate dell'infezione.

La coltura per lieviti trova giustificazione solo nell'ambito di programmi di valutazione della colonizzazione. A ciò fa eccezione il sospetto clinico di localizzazione respiratoria di C. neoformans: in tal caso è necessario procedere alla rilevazione dell'antigene criptococcico sierico (metodo di agglutinazione al latice), alle emocolture ed eventualmente all'esame istologico da biopsia polmonare.

La diagnosi di infezione da miceti dimorfi prevede l'esecuzione dell'esame micologico diretto e della coltura dei materiali respiratori effettuata procedendo ad incubazione prolungata (almeno 4 settimane) a temperatura ambiente ed a $35^{\circ} \mathrm{C}$. $\mathrm{E}$ fondamentale ricorrere, in caso di sospetto diagnostico fondato, routinariamente alla diagnostica istopatologica (colorazioni di Gomori-Grocott). È imperativo effettuare emocolture (incubazione per 4 settimane). È opportuno effettuare la ricerca di anticorpi circolanti anti-Histoplasma capsulatum ed anti-Coccidioides immitis (metodica di doppia diffusione in Agar).

La diagnosi di infezione da $P$. jirovecii prevede l'analisi delle secrezioni bronchiali (colorazione sec. Gomori Grocott, sec. Giemsa o - preferibilmente - con tecnica di immunofluorescenza). Studi recenti indicano la buona attendibilità dei test di PCR eseguiti su lavaggio broncoalveolare.

L'esecuzione di test di chemioantibioticosensibilità non trova ancora alcuna indicazione diagnostica stringente.

\section{D3. La diagnosi virologica di infezione delle basse vie respiratorie}

I materiali respiratori finalizzati all'accertamento virologico devono essere prelevati tramite tampone (preferibilmente floccato) nasale o faringeo entro 3 giorni dall'esordio sintomatologico e comunque non oltre la quinta giornata di malattia. Il prelievo con la modalità dell'aspirato rino-faringeo deve essere riservato ai casi di massima gravità. I campioni devono essere inoltrati al Laboratorio in terreno di trasporto e devono essere processati al massimo dopo 24 ore di conservazione a $4^{\circ} \mathrm{C}$.

È possibile procedere alla fase analitica anche dopo tempi più prolungati solo se il materiale è conservato a $-70^{\circ} \mathrm{C}$.

Sono disponibili in commercio kit per la rilevazione antigenica con tecniche di Immunofluorescenza Diretta o Immunocromatografica.

In particolare, è imperativo effettuare in caso di bronchiolite, sporadica od epidemica, comunitaria o nosocomiale, la ricerca dell'antigene di Human Respiratory Syncytial Virus e di Mastadenovirus.

La diagnosi di laboratorio basata sulla possibilità di evidenziare i componenti del genoma virale (PCR singole o multiplex) presenta notevoli potenzialità ai fini diagnostici: le tecniche di amplificazione genica si sono dimostrate in grado di complementare e, in molti casi, di sostituire l'approccio immunologico e colturale. Grazie a tali metodiche è stato inoltre possibile raggiungere livelli di sensibilità estremamente elevati e di identificare direttamente la presenza del 
genoma virale in campioni biologici in modo assolutamente specifico, discriminando anche differenze non riconoscibili con la rilevazione anticorpale.

In caso di negatività dei test sopra descritti, potrà essere indagata in laboratori di livello superiore la presenza antigenica di Influenzavirus A e B con tecnica di immunofluorescenza.

La stessa metodologia si applica alla diagnosi di infezione da Human Metapneumovirus (hMPV), di Human parainfluenza virus di tipo 2, 4 e $4^{\circ}$, di Coxsackievirus A e B, Echovirus, Enterovirus 68-71, di Human Parechovirus e di Human Rhinovirus A e B. Come alternative tecniche sono attualmente in valutazione alcune tecniche di biologia molecolare.

La diagnosi virologica considera la possibilità di fare ricorso anche a tecniche di Microscopia Elettronica e di conferma colturale, da riservare a Centri di Referenza.

Per quanto attiene agli accertamenti sierommunologici, l'indicazione è di procedere solo in caso di mancata risposta alla terapia e nelle forme gravi. In tutti i casi è auspicabile congelare il siero di fase acuta che deve essere testato con quello prelevato in fase convalescente. La diagnosi indiretta effettuata su siero con tecniche EIA o di Fissazione del Complemento non devono essere considerate ai fini dell'accertamento diagnostico in fase acuta in quanto gravate da scarsa sensibilità nel periodo iniziale della malattia.

\section{D4. La ceppoteca/sieroteca}

E opportuno provvedere alla costituzione, in sede locale, di una ceppoteca dedicata, ove conservare gli stipiti microbici (batteri e miceti) identificati quali responsabili di polmonite nosocomiale, per eventuali successivi approfondimenti epidemiologici.

È inoltre, opportuno che il Laboratorio di Microbiologia provveda anche alla costituzione di una sieroteca per i sieri (di fase acuta e convalescente) dei pazienti.

\section{E. Conclusioni}

(referenze essenziali: 29, 42)

In conclusione è possibile sintetizzare nei punti seguenti le caratteristiche fondamentali dell'approccio microbiologico alla diagnosi di polmonite:

1. in caso di CAP e di HAP non complicate la diagnosi di polmonite si basa sui dati clinici e radiologici con rischio relativamente contenuto di errore diagnostico;

2. nelle forme di CAP non vi è in genere indicazione a praticare indagini microbiologiche, fatta eccezione che per le emocolture (positive nel 10\% circa delle forme di CAP). Generalmente le colture di materiali respiratori e la colorazione di Gram possono essere utili quando il paziente richiede l'ospedalizzazione oppure nei casi in cui si sospetti un'infezione da microrganismi resistenti o da patogeni poco comuni (ad esempio, in caso di anamnesi positiva per soggiorni in aree endemiche per miceti dimorfi o in circostanze note di epidemia);

3. in caso di CAP caratterizzate da un insuccesso terapeutico, da malattia severa e da infiltrati polmonari ben localizzati, e se l'anamnesi individuale (malattie linfoproliferative o neoplastiche, terapie chemio- o radioterapiche, immunodepressione patologica o iatrogena,...) oppure $\mathrm{i}$ dati epidemiologici locali fanno sospettare la presenza di patogeni quali $P$. jirovecii o $S$. pneumoniae penicillinoresistente, è opportuno un attento studio topografico dell'imaging toracico con successivo prelievo di materiali respiratori distali raccolti con tecniche protette per gli opportuni accertamenti microbiologici;

4. nel paziente sottoposto a ventilazione meccanica con sospetto di VAP, poiché i segni clinici e radiologici spesso non sono altamente specifici per una infezione polmonare, si dovranno considerare i metodi invasivi in corso di broncoscopia ai fini di una sicura diagnosi differenziale (patologia non infettiva, infezione extrapolmonare, ecc);

5. nel paziente sottoposto a ventilazione meccanica e con
ARDS il BAL, rispetto al PSB, permette non solo di definire l'eziologia ma anche di valutare l'entità del danno alveolare diffuso;

6. quando possibile la diagnostica microbiologica dovrebbe precedere l'inizio della terapia antimicrobica. Questo non è sempre possibile per i campioni di secrezioni respiratorie ma verosimilmente lo è, nella maggior parte dei casi, per le emocolture;

7. le colture quantitative possono essere effettuate, con diversi gradi di sensibilità e specificità, su aspirato tracheale o su campioni "distali" ottenuti sotto guida broncoscopica o meno;

8. la scelta del metodo dipende dall'esperienza in sede locale, dalla disponibilità organizzativa e dai costi che ciascuna struttura può affrontare;

9. ogni materiale respiratorio si caratterizza per suoi valorisoglia (UFC/ml) e per intrinseci limiti metodologici;

10. le tecniche che identificano i patogeni su base qualitativa determinano un maggior numero di trattamenti (clinicamente inutili);

11. se per un prelievo di secrezioni distali non è possibile usare una tecnica broncoscopica, è possibile ricorrere ad una modalità di prelievo "blind", purché la tecnica microbiologica utilizzata sia quantitativa al fine di avere una corretta possibilità di impostazione terapeutica;

12. il ricorso a colture quantitative di materiali respiratori distali raccolti con metodi protetti consente di estrapolare, da eventuali popolazioni polimicrobiche, i microrganismi responsabili del quadro clinico. Tuttavia comporta tempi di risposta non immediati e, pertanto, implica la necessità di eseguire test ancillari (Giemsa, Gram) per la definizione della cellularità e dei morfotipi microbici e per la rilevazione di batteri intracellulari;

13. le tecniche che identificano i patogeni su base semiquantitativa sono meno affidabili nel definire la presenza di polmonite e la necessità di una terapia. Entrambi gli approcci, quindi, devono essere fortemente scoraggiati;

14. la coltura dei materiali respiratori distali prelevati con metodica invasiva comporta un'interpretazione "prudente" e cumulativa con le circostanze cliniche per valori quantitativi borderline $( \pm 1 \mathrm{Log}$ dal cut off);

15. la variabilità dei risultati quantitativi, per la distribuzione irregolare degli organismi nelle secrezioni e per la esiguità del volume campionato, deve sempre essere tenuta presente in sede di valutazione clinica del risultato microbiologico;

16. in caso di presenza di versamento pleurico, è opportuno eseguire anche una toracocentesi.

17. i referti devono essere commentati, ove possibile (allegato G5).

L'iter della diagnosi eziologica delle polmoniti tiene conto, quindi, dell'esecuzione sistematica di:

- emocolture (2 set almeno);

- antigene (da campione urinario) di Legionella pneumophila (obbligatoriamente di tipo 1, possibilmente anche di tipo 2-14) e di Streptococcus pneumoniae, con tecnica immunocromatografica o con tecnica EIA. Si segnala tuttavia che in età pediatrica che la ricerca dell'antigene urinario di pneumococco ha significato solo modesto. Si segnala inoltre che la ricerca dell'antigene di L. pneumoniae deve essere riservata ai casi di CAP severa o enigmatica, in caso di fallimento di terapie con beta-lattamici, in pazienti in ICU, per quelli che presentano specifici fattori di rischio e durante le epidemie;

- in caso di positività dell'Ag urinario per Legionella e/o pneumococco: semina di un'aliquota del campione di materiale respiratorio rispettivamente su Agar Sangue (incubato in microaerofilia) e su terreni selettivi per Legionella;

- in caso di richiesta di anticorpi circolanti di L. pneumophila con tecnica EIA o IFA: il siero prelevato all'ingresso 
non deve essere processato, ma conservato in sieroteca per essere esaminato contestualmente a quello prelevato dopo 21 giorni per accertare un'eventuale legionellosi.

\section{BIBLIOGRAFIA}

1. Adair CG, Gorman SP, Feron BM et al. Implications of endotracheal tube biofilm for ventilator-associated pneumonia. Intensive Care Med 1999; 25: 1072-6.

2. Azoulay E, Timsit JL, Tafflet M et al. Candida colonization of the respiratory tract and subsequent Pseudomonas ventilator-associated pneumonia. Chest 2006; 129: 110-7.

3. Beardsley JR, Williamson JC, Johnson JW et al. Using local microbiologic data to develop institution-specific guidelines of hospital-acquired pneumonia. Chest 2006; 130: 787-93.

4. Bonten MJ, Bergmans DC, Stobberingh EE et al. Implementation of bronchoscopic techniques in the diagnosis of ventilator-associated pneumonia to reduce antibiotic use. Am J Respir Crit Care Med 1997; 156: 1820-4.

5. Bouchillon SK, Johnson BM, Hoban DJ et al. Determining incidence of extended spectrum $\beta$-lactamase producing Enterobacteriaceae, vancomycin-resistant Enterococcus faecium and methicillin-resistant Staphylococcus aureus in 38 centres from 17 countries: the PEARLS Study 2001-2002. Int J Antimicrob Agents 2004; 24: 119-24.

6. Bouza E, Guinea J, Peláez T et al. Workload due to Aspergillus fumigatus and significance of the organism in the microbiology laboratory of a general hospital. J Clin Microbiol. 2005; 43: 2075-9.

7. Bouza E, Torres MV, Radice C et al. Direct E-test (AB Biodisk) of respiratory samples improves antimicrobial use in ventilator-associated pneumonia. Clin Infect Dis 2007; 44: 382-7.

8. Casetta A, Doyon F, Antoun S et al. Diagnosis of nosocomial pneumonia in cancer patients undergoing mechanical ventilation: a prospective comparison of the plugged telescoping catheter with the protected specimen brush. Chest 1999;115: 1641-5.

9. Chastre J, Fagon JY. Ventilator-associated pneumonia. Am J Respir Crit Care Med 2002; 65: 867-903

10. Chastre J, Luyt CE, Combes A et al. Use of quantitative cultures and reduced duration of antibiotic regimen for ventilator-associated pneumonia to decrease resistance in the intensive care unit. Clin Infect Dis 2006; 43 (S2) S75-S81.

11. Cook DJ, Walter SD, Cook RJ et al. Incidence of and risk factors for ventilator-associated pneumonia in critically ill patients. Ann Intern Med 1998; 129: 440.

12. Cottin V, Capron F, Grenier P et al. Pneumopathies interstitielles diffuses idiopathiques. Rev Mal Respir 2004; 21: 299-318.

13. El Solh AA, Akinnusi ME, Wiener-Kronish JP et al. Persistent Infection with Pseudomonas aeruginosa in Ventilator Associated Pneumonia. Am J Respir Crit Care Med. 2008 May 8.

14. Fagon JY, Chastre J, Wolff $M$ et al. Invasive and noninvasive strategies for management of suspected ventilator-associated pneumonia: a randomized trial. Ann Intern Med 2000; 132: 621-30.

15. File TM. Community-acquired pneumonia. Lancet 2003; 362: 1991-2001

16. Gales AC, Jones RN, Forward KR, Linares J, Sader HS, Verhoef J. Emerging importance of multidrug-resistant Acinetobacter species and Stenotrophomonas maltophilia as pathogens in seriously ill patients: geographic patterns, epidemiological features, and trends in the SENTRY Antimicrobial Surveillance Program (1997-1999). Clin Infect Dis 2001 32: S104-S113

17. Gibot S, Cravoisy A, Levy B, Bene MC, Faure G, Bollaert PE. Soluble triggering receptor expressed on myeloid cells and the diagnosis of pneumonia. N Engl J Med 2004; 350: 451-8.

18. Goglio A, Amer M, Callegaro A et al. Infezioni della basse vie respiratorie da batteri e miceti: consensus sull'iter diagnostico microbiologico. Giorn It Infez Osp 1998; 5: 91-109.

19. Hayon J, Figliolini C, Combes A, et al. Role of serial routine microbiologic culture results in the initial management of ventilator-associated pneumonia. Am J Respir Crit Care Med 2002;165: 41-6.

20. Heyland DK, Cook DJ, Dodek PM. Prevention of ventilator-associated pneumonia: current practice in Canadian intensive care units. J Crit Care 2002; 17: 161-7.

21. Heyland DK, Cook DJ, Marshall J et al. The clinical utility of invasive diagnostic techniques in the setting of ventilator-associated pneumonia. Chest 1999, 115: 1076-84

22. Hilker R, Poetter C, Findeisen N et al. Nosocomial pneumonia after acute stroke. Implication for neurological intensive care medecine. Stroke 2003; 34: $975-81$.

23. Huvent-Grelle D, Puisieux F, Tettart-Hevin K et al. Pneumopathies du sujet âgé. Presse Méd 2004; 33: 522-9.

24. Klompas M, Kleinman K, Platt R. Development of an Algorithm for Surveillance of Ventilator-Associated Pneumonia With Electronic Data and Comparison of Algorithm Results With Clinician Diagnoses. Infect Control Hosp Epidem 2008; 29

25. Koenig SM, Truwit JD. Ventilator-associated pneumonia: diagnosis, treatment, and prevention. Clin Microbiol Rev 2006: 19: 637-57.

26. Kollef MH. Diagnosis of ventilator-associated pneumonia. $N$ Engl J Med 2006; 355: 2691-3.

27. Janssens JP, Krause KH. Pneumonia in the very old. Lancet Infect Dis 2004; 4: 112-24

28. Isenberg H.D. Clinical Microbiology Procedures Handbook. American Society for Microbiology, Washington DC, 2004

29. Mehta RM, Niederman MS. Nosocomial pneumonia in the intensive care unit: controversies and dilemmas. J Intensive Care Med 2003; 18: 175-88.

30. Muller B, Harbarth S, Stolz D et al. Diagnostic and prognostic accuracy of clinical and laboratory parameters in community-acquired pneumonia. BMC Infectious Diseases 2007, 7: 10 doi:10.1186/1471-2334-7-10.

31. Navarro D, Garcia-Maset L, Gimeno C et al. Performance of the Binax NOW Streptococcus pneumoniae urinary antigen assay for diagnosis of pneumonia in children with underlying pulmonary diseases in the absence of acute pneumococcal infetion. J Clin Microbiol 2004; 42: 4853-5.

32. Reimer LG. Community-Acquired bacterial pneumonias. Sem Resp Infect 2000; 15: 95-100

33. Rello J, Esandi M-E, Diaz E et al. The role of Candida sp isolated from bronchoscopic samples in nonneutropenic patients. Chest 1998; 114: 146-69.

34. Rello J, Ollendorf DA, Oster G et al. Epidemiology and outcomes of ventilator-associated pneumonia in a large US database. Chest 2002; 122: 2121.

35. Schurink CA, Van Nieuwenhofen CA, Jacobs JA et al. Clinical pulmonary infection score for ventilator-associated pneumonia: accuracy and interobserver variability. Intens Care Med 2004; 30: 217-24.

36. Shah P, Giudice J, Griesback R Jr et al. The newer guidelines for the management of Community-Acquired Pneumonia. JAOA 2004; 104

37. Smith PR. What diagnostic tests are needed for community-acquired pneumonia? Med Clinics North Am 2001; 85: 1381-96.

38. Société de Réanimation de langue française. Actualités en Réanimation et Urgences. Arnette ed., 1995.

39. Soto GJ. Diagnostic strategies for nosocomial pneumonia. Curr Opin Pulm Med 2007; 13: 186-91.

40. Trouillet JL, Chastre J, Vaugnat A et al. Ventilator-associated pneumonia caused by potentially drug-resistant bacteria, Am J Respir Crit Care Med 1998; 157: 531-9.

41. Vincent JL. Ventilator-associated pneumonia. J Hosp Infect 2004; 57: 272-80.

42. Waterer GW, Wunderink RG Controversies in the diagnosis of ventilatoracquired pneumonia. Med Clin North Am 2001; 85: 1565-81.

\section{Linee guida}

a. Alberta CGP Working Group. Guideline for the diagnosis and management of Nursing Home Acquired Pneumonia (NHAP). www.topalbertadoctors.org

b. American Thoracic Society; Infectious Diseases Society of America Guidelines for the

c. Management of adults with hospital-acquired, ventilator-associated, and healthcare-associated pneumonia. Am J Respir Crit Care Med 2005; 171: 388-416.

d. British Thoracic Society Guidelines for the management of community acquired pneumonia in adults. Thorax 2001, 56 (Suppl IV): iv1-iv65.

e. Hedlund J, Strålin K, Örtqvist Å, Holmberg H, the Community-Acquired Pneumonia Working Group of the Swedish Society of Infectious Diseases. Swedish guidelines for the management of community-acquired pneumonia in immunocompetent adults. Scand J Infect Dis 2005; 37: 791-805.

f. Honkanen PO, Rautakorpi U-M, Huovinen P. et al. Diagnostic tools in respiratory tract infections: use and comparison with Finnish guidelines. Scand J Infect Dis 2002; 34: 827-830.

g. Mandell LA, Wunderink RG, Anzueto A et al. Infectious Disease Society of America / American Thoracic Society on the management of community-acquired pneumonia in adults. Clin Infect Dis 2007; 44 (S2): S27-S72.

h. Miyasita N, Natsushima T, Oka M et al. The JRS guidelines for the management of community-acquired pneumonia: update and new recommendations. Intern Med 2006: 45: 419-428.

i. Niederman MS. Guidelines for the management of community-acquired pneumonia. Med Clinics North Am 2001; 85: 1493-1509.

j. Sociedade Portuguesa de Pneumologia; Comissão de Infecciologia. Portuguese Respiratory Society guidelines for the management of community pneumonia in immunocompetent adults. Rev Port Pneumol 2003 : 9 4 435-461.

k. Woodhead M, Blasi F, Ewig S et al. Guidelines for the management of adult lower respiratory tract infections. Eur Respir J 2005; 26: 1138-1180.

1. Zar HJ, Jeena P, Argent A et al. Diagnosis and management of community-acquired pneumonia in children. African Thoracic Society Guidelines. S Afr Med J 2005; 95: 977.981, 984-990.

\section{G. Allegati}

1. Modalità di prelievo

2. Note per il paziente

3. Procedure di tecnica microbiologica

4. Flow chart operative

4.1 Algoritmo per la diagnosi eziologica delle polmoniti domiciliari (esami colturali)

4.2 Algoritmo per la diagnosi eziologica su base epidemiologica

4.3 Algoritmo per la diagnosi microbiologica

4.4 Algoritmo per la gestione delle polmoniti ospedalizzate su base microbiologica

5. Note di commento

\section{G1. MODALITÀ DI PRELIEVO}

\section{PRELIEVO ED INVIO DEI MATERIALI AL LABORATORIO DI MICROBIOLOGIA CLINICA}

\section{Norme generali}

istruire il paziente circa le modalità di prelievo, assicurandosi che le indicazioni fornite siano comprese. In caso di prelievo con modalità protetta provvedere anche alla 
raccolta dell'adesione formale del paziente (firma del modulo di consenso informato);

- raccogliere i campioni preferibilmente prima dell'inizio della terapia chemio-antibiotica; in ogni caso, segnalare al Laboratorio di Microbiologia l'eventuale terapia antibiotica in atto;

- non raccogliere in modo cumulativo i materiali respiratori per tutto il corso delle 24 ore;

- non raccogliere campioni ad intervalli di tempo inferiori a 48 ore;

- indossare guanti sterili su entrambe le mani;

- utilizzare, per la raccolta, una provetta o un contenitore a bocca larga e tappo a vite, sterili;

- contrassegnare i campioni riportando correttamente i dati identificativi del paziente e la data e l'ora di esecuzione del prelievo;

- compilare accuratamente il modulo di richiesta;

- inviare tempestivamente il materiale al Laboratorio di Microbiologia Clinica, possibilmente entro 15 minuti dalla raccolta, conservandolo a temperatura ambiente. I campioni che pervengono al Laboratorio di Microbiologia Clinica in un tempo prevedibilmente superiore devono essere conservati a $+4^{\circ} \mathrm{C}$ : in ogni caso i campioni che pervengono al laboratorio dopo più di 2 ore non dovrebbero essere esaminati per la possibilità di risultati "falsi negativi" (è il caso di S. pneumoniae particolarmente labile) o "falsi positivi" per sovracrescita della popolazione microbica residente.

\section{Modalità di prelievo}

\subsection{Espettorato}

possibilità diagnostiche:

- questo campione può essere ottenuto da pazienti che siano in grado di espettorare. La produzione di escreato dalle basse vie aeree non è caratteristica costante dei pazienti immunocompromessi, in particolare di quelli neutropenici;

- effettuare la raccolta sotto la supervisione di personale addestrato (infermiere o fisioterapista);

- invitare a non usare dentifricio ed a non fare gargarismi con acqua del lavandino;

- evitare l'introduzione di materiale salivare o di secrezioni nasali nel contenitore per la raccolta. In caso contrario, ripetere la procedura dall'inizio;

- é possibile effettuare la ricerca dei batteri, micobatteri e miceti filamentosi e dimorfi.

prelievo:

1. rimuovere eventuali protesi dentarie;

2. grattare gentilmente, con spazzolino da denti o con tampone umidi, la mucosa interna delle guance, le gengive e la lingua;

3. sciacquare il cavo orale con acqua (o con soluzione fisiologica) sterile;

4. espettorare (con un colpo di tosse) in un contenitore a bocca larga sterile e con tappo a vite.

\subsection{Espettorato indotto}

possibilità diagnostiche:

- l'induzione dell'espettorazione consente di raccogliere il materiale da pazienti con tosse non produttiva. Inizialmente proposta per lo studio del polmone profondo in pazienti con asma e BPCO in soggetti per i quali non era possibile ricorrere a tecniche di prelievo invasive, questa tecnica è stata poi indirizzata a soggetti non espettoranti con sospetto di tubercolosi polmonare o con opacità a lenta risoluzione e di difficile diagnosi differenziale. La sua esecuzione trova particolare indicazione nel caso di pazienti ipossici anche immunodepressi e con alta probabilità di polmonite per i quali è sconsigliata l'esecuzione di prelievi in fibrobroncoscopia;

- effettuare la raccolta sotto la supervisione di personale addestrato (infermiere o fisioterapista); evitare l'introduzione di materiale salivare o di secrezioni nasali nel contenitore per la raccolta. In caso contrario, ripetere la procedura dall'inizio;

- l'indaginosità operativa limita di molto l'utilizzo di questa modalità di raccolta nella routine clinica;

- é possibile effettuare la ricerca di micobatteri e di P. jirovecii. È possibile ricercare anche batteri, miceti filamentosi e dimorfi.

prelievo:

1. rimuovere eventuali protesi dentarie;

2. grattare gentilmente, con spazzolino da denti o con tampone umidi, la mucosa interna delle guance, le gengive e la lingua il più a lungo possibile (almeno 5 minuti);

3. sciacquare il cavo orale con acqua (o con soluzione fisiologica) sterile;

4. sottoporre il paziente a manovre di fisioterapia;

5. inalare, con l'ausilio di un nebulizzatore ultrasonico, da 20 a $30 \mathrm{ml}$ di soluzione al 5\% di $\mathrm{NaCl} 0.9 \%$;

6. espettorare (con un colpo di tosse) in un contenitore a bocca larga sterile e con tappo a vite.

\subsection{Espettorato indotto protetto}

\section{possibilità diagnostiche:}

- l'induzione dell'espettorazione consente di raccogliere il materiale da pazienti con tosse non produttiva. Al pari di quanto indicato per l'espettorato indotto, la sua esecuzione trova particolare indicazione nel caso di pazienti ipossici per i quali è sconsigliata l'esecuzione di prelievi in fibrobroncoscopia;

- effettuare la raccolta sotto la supervisione di personale addestrato (infermiere o fisioterapista);

- evitare l'introduzione di materiale salivare o di secrezioni nasali nel contenitore per la raccolta. In caso contrario, ripetere la procedura dall'inizio;

- l'indaginosità operativa limita di molto l'utilizzo di questa modalità di raccolta. Nella routine clinica é possibile effettuare la ricerca dei batteri, micobatteri e miceti filamentosi, dimorfi e di $P$. jirovecii.

prelievo:

1. rimuovere eventuali protesi dentarie;

2. grattare gentilmente, con spazzolino da denti o con tampone umidi, la mucosa interna delle guance, le gengive e la lingua;

3. sciacquare il cavo orale con acqua;

4. individuare sulla faccia interna delle guance $i$ fori del dotto di Stenone e bloccarli con cilindretti di cotone sterile;

5. sottoporre il paziente a manovre di fisioterapia;

6. inalare, con l'ausilio di un nebulizzatore ultrasonico, da 20 a $30 \mathrm{ml}$ di soluzione al $5 \%$ di $\mathrm{NaCl} 0.9 \%$;

7. espettorare (con un colpo di tosse) in un contenitore a bocca larga sterile e con tappo a vite.

\subsection{Aspirato endotracheale/bronchiale}

possibilità diagnostiche:

- questo materiale può essere raccolto in pazienti intubati oppure no, provvedendo all'aspirazione delle secrezioni che ristagnano in trachea: il suo prelievo deve essere limitato ai casi di presenza di segni clinici di polmonite (febbre ed infiltrati);

- $\quad$ il materiale è scarsamente idoneo per le ricerche microbiologiche, salvo che per quella di patogeni stretti come Mycobacterium spp. e Legionella spp. L'interpretazione dell'esame deve tenere conto del fatto che la trachea è colonizzata dopo 24 ore dal momento dell'inserzione del tubo e per molti giorni dopo che il tubo è stato tolto. prelievo:

1. sfilare il sondino dalla confezione e connetterlo al sistema di aspirazione;

2. disconnettere il paziente dal respiratore evitando che il raccordo terminale si contamini ed inserire il moni- 
tor per la rilevazione eventuale di bradicardia (si può evitare di disconnettere il paziente dal respiratore utilizzando un tubo a due vie);

3. inserire delicatamente il sondino nel tubo endotracheale per una lunghezza pari a quella del tubo;

4. aspirare ad intermittenza il campione, ruotando il sondino per non più di 10 secondi, nell'apposito contenitore sterile raccordato al tubo endotracheale;

5. riconnettere il paziente al ventilatore o ventilarlo manualmente.

\subsection{Aspirato da tracheostomia}

\section{possibilità diagnostiche:}

- la raccolta del materiale consegue all'esecuzione di una tracheostomia in condizioni di asepsi, in sala operatoria (salvo che condizioni di urgenza richiedano un intervento di emergenza oppure al letto del paziente). Fino a quando la ferita da tracheostomia non è completamente cicatrizzata, è necessario impiegare tecniche "no touch"; il materiale è scarsamente idoneo per le ricerche microbiologiche. L'interpretazione dell'esame deve tenere conto del fatto che la trachea è colonizzata dopo 24 ore dall'inserzione del tubo ed i risultati microbiologici possono non correlare con la diagnosi eziologica;

- nel caso di soggetti affetti da fibrosi cistica:

1. non processare più di un campione al mese in pazienti non trapiantati ambulatoriali;

2. non processare più di due campioni al mese per pazienti ricoverati non trapiantati;

3. non utilizzare i criteri di non conformità per l'espettorato o gli aspirati endotracheali basandosi sui criteri di qualità del Gram, che sono di poco valore nei pazienti con fibrosi cistica. prelievo:

1. aspirare il campione nell'apposito contenitore sterile raccordato al tubo endotracheale.

\subsection{Tampone rino-faringeo}

\section{possibilità diagnostiche:}

- il ricorso a questa modalità di prelievo è indicata solo per

la ricerca mirata di virus, Bordetella pertussis e di

Chlamydophila spp. È conveniente utilizzare un tampone

floccato flessibile con calcio alginato, meno inibente la vitalità di $B$. pertussis. prelievo:

1. accertarsi che il capo del paziente sia immobilizzato;

2. inserire gentilmente il tampone in una narice, fino a raggiungere il retrofaringe;

3. lasciare in situ per pochi secondi;

4. strofinare la punta del tampone sulla mucosa della porzione medio-inferiore del turbinato inferiore;

5. ruotare ripetutamente la punta del tampone sulla mucosa, raccogliendo materiale cellulare;

6. estrarre il tampone;

7. inserire il tampone nel terreno di trasporto;

8. tagliare il tampone con forbici;

9. trattare il tampone secondo le indicazioni del Laboratorio di Microbiologia Clinica;

10. le modalità di invio devono essere concordate con il laboratorio.

\subsection{Aspirato rino-faringeo}

\section{possibilità diagnostiche:}

- il ricorso a questa modalità di prelievo è indicata solo per la ricerca mirata di virus, Bordetella pertussis e di Chlamydophila spp. È modalità accettata, in età pediatri$\mathrm{ca}$, anche per la valutazione della popolazione microbica dei soggetti affetti da Fibrosi Cistica. prelievo:

1. accertarsi che il capo del paziente sia immobilizzato;

2. inserire gentilmente il sondino in una narice, fino a raggiungere il retrofaringe;
3. aspirare le secrezioni;

4. le modalità di raccolta (tipo di contenitore) ed invio devono essere concordate con il laboratorio.

\subsection{Lavaggio bronchiale}

possibilità diagnostiche:

- il lavaggio bronchiale eseguito con broncoscopio flessibile a fibre ottiche è tecnica relativamente innocua e può risultare utile solo quando non sia possibile la raccolta di materiali più significativi, soprattutto in soggetti immunocompromessi;

- l'anestesia per aerosol è metodica descritta "teoricamente" ma scarsamente praticata se non in corso di broncoscopia diagnostica. Nelle polmoniti in soggetti coscienti e collaboranti tale prelievo viene effettuato in corso di broncoscopia in anestesia locale solo quando non è possibile praticare il BAL o come metodica diagnostica di routine in corso di broncoscopia diagnostica;

- il materiale non è idoneo per indagini microbiologiche (fanno eccezione i patogeni stretti quali Mycobacterium spp., Legionella spp., P. jirovecii e miceti filamentosi). prelievo:

1. sottoporre il paziente ad anestesia superficiale per aerosol;

2. inserire il broncoscopio per via trans-nasale o per via trans-orale (pazienti non intubati) oppure attraverso il tubo endotracheale (pazienti intubati);

3. iniettare soluzione fisiologica (con $\mathrm{NaCl} 0.9 \%$ ) in aliquote di 5-20 ml, per un quantitativo totale massimo di circa $100 \mathrm{ml}$, utilizzando una siringa applicata esternamente al broncoscopio;

4. rinviare le operazioni di brushing o le biopsie a quando la raccolta del materiale di lavaggio bronchiale sarà stata ultimata: un eccessivo sanguinamento nel liquido di recupero potrebbe modificare il rapporto tra le componenti cellulari e quelle non cellulari;

5. aspirare delicatamente la soluzione fisiologica direttamente in un contenitore sterile (provetta o contenitore a bocca larga e tappo a vite) prima di iniettare al paziente l'aliquota successiva. Mediamente viene recuperato circa il $50-75 \%$ del liquido iniettato. Raccogliere ogni aliquota in un contenitore dedicato;

6. registrare la quantità di soluzione fisiologica iniettata;

7. addizionare in un unico contenitore solo il materiale prelevato dallo stesso sito anatomico.

\subsection{Lavaggio bronco-alveolare}

\section{possibilità diagnostiche:}

- il lavaggio broncoalveolare eseguito con broncoscopio flessibile a fibre ottiche è tecnica relativamente innocua. Effetti collaterali di scarsa entità possono essere: tosse durante il lavaggio, febbre e brividi alcune ore dopo la manovra e infiltrazione alveolare transitoria 24 ore dopo il prelievo, transitorio deterioramento dei parametri di funzionalità respiratoria. La maggior parte degli effetti collaterali sono correlabili alla manovra endoscopica, alla sede ed all'estensione dell'area polmonare sottoposta a lavaggio nonchè al volume ed alla temperatura del fluido instillato;

la raccolta del campione deve essere effettuata con particolari cautele nei pazienti con anamnesi di asma bronchiale ed in quelli ipossici $\left(\mathrm{PaO}_{2}<60 \mathrm{~mm} \mathrm{Hg}\right)$ : in questi soggetti la broncoscopia, se mandatoria, può essere praticata previa ventilazione in maschera e/o assistenza anestesiologica a seguito di un'attenta valutazione del rapporto rischio beneficio).

- Problemi tecnici possono essere osservati nei soggetti affetti da bronchite cronica ostruttiva. I pazienti con severe patologie di base od in condizioni critiche possono richiedere la somministrazione di ossigeno, premedicazioni con beta-agonisti in aerosol ed il monitoraggio dell'elettrocardiogramma. Consigliabili sono la disponibilità di un saturimetro e di un accesso venoso; 
- un campione di BAL non è microscopicamente differenziabile da un campione di lavaggio bronchiale: il primo però è materiale proveniente dai bronchioli distali e dagli alveoli, il secondo, analogamente a quanto si realizza con l'aspirato bronchiale, da vie aeree più craniali;

- oltre a consentire lo studio dei fenomeni infiammatori ed immunitari, è metodica indicata per le ricerche batteriologiche, fungine, parassitologiche e virologiche. Per l'esame microbiologico del materiale da lavaggio broncoalveolare sono necessari almeno $10 \mathrm{ml}$. prelievo:

1. porre il paziente in posizione supina;

2. sottoporre il paziente ad anestesia e sedazione leggera, possibilmente evitando l'impiego di xylocaina. È consigliabile somministrare l'anestetico per aerosol piuttosto che per iniezione, poiché l'iniezione è modalità non scevra da rischio di contaminazione. Tuttavia, nei pazienti intubati e con sospetta VAP: non usare anestetico);

3. inserire il broncoscopio per via trans-nasale o per via trans-orale nel caso di pazienti non intubati. Inserire il broncoscopio attraverso il tubo endotracheale nel caso di pazienti intubati;

4. incuneare la punta del broncoscopio in un ramo subsegmentale del lobo medio o della lingula oppure, in caso di opacità distrettuali di sospetta natura infettiva, di altre sedi, facendo avanzare il più possibile lo strumento durante un'inspirazione profonda;

5. iniettare soluzione salina sterile $(\mathrm{NaCl} 0.9 \%, \mathrm{pH} 7.0)$ isotermica $\left(35^{\circ} \mathrm{C}\right)$ per un quantitativo pari a circa $100-150 \mathrm{ml}$ (quantitativo totale massimo di $200 \mathrm{ml}$ ) con siringa applicata esternamente al broncoscopio. È opportuno somministrare in aliquote di $20 \mathrm{ml}$ (almeno cinque) o di $50 \mathrm{ml}$ (almeno tre);

6. rinviare le operazioni di brushing o le biopsie a quando la raccolta del materiale di lavaggio bronchiale sarà stata ultimata: un eccessivo sanguinamento nel liquido di recupero potrebbe modificare il rapporto tra le componenti cellulari e quelle non cellulari;

7. aspirare manualmente e delicatamente la soluzione fisiologica direttamente in un contenitore sterile prima di iniettare al paziente l'aliquota successiva. Mediamente viene recuperato circa il 50-75\% (40$60 \%$ nei grandi fumatori) del liquido iniettato. Raccogliere ogni aliquota in un contenitore sterile dedicato;

8. registrare la quantità di soluzione físiologica iniettata, l'eventuale presenza macroscopica di sangue, la sede del prelievo in relazione alla sede della lesione documentata radiologicamente;

9. non utilizzare per le indagini microbiologiche le prime aliquote ("frazione bronchiale") ma usare invece le aliquote successive ("frazione alveolare"). La frazione bronchiale può essere utilizzata per ricerche di patogeni obbligati: Legionella spp., Mycobacterium spp.,...).

\subsection{Lavaggio bronco-alveolare mirato con cateterino} possibilità diagnostiche:

vale quanto detto per il Lavaggio bronco-alveolare. Si tratta di metodica altamente sensibile, evitando la contaminazione del materiale con flora orofaringea e permettendo la coltura di microrganismi in carica assai ridotta. Può essere effettuata sia con l'ausilio del fibro-broncoscopio che permette la visualizzazione del catetere nell'area interessata oppure senza fibro-broncoscopio [in questo caso il catetere si dirigerà al lobo inferiore destro ( $87 \%$ circa dei casi), al lobo inferiore sinistro ( $11 \%$ circa) ovvero si arrotolerà su se stesso $(2 \%$ circa $)]$. Può essere effettuata anche con cateterino dotato di palloncino gonfiabile all'estremità (Pro-BAL): tale metodica, indicata soprattutto per la valutazione della condizione di coloniz- zazione, è solo accennata. Rispetto alla coltura del brushing bronchiale risulta metodica meno costosa. È consigliabile effettuare in un primo momento il prelievo, con cateterino, per gli esami colturali batteriologici e successivamente, a prelievo batteriologico ultimato, procedere all'anestesia del paziente ed all'esecuzione di prelievi per esami citologici;

- oltre a consentire lo studio dei fenomeni infiammatori ed immunitari, è metodica indicata per le ricerche batteriologiche, fungine, parassitologiche e virologiche. Per l'esame microbiologico del materiale da lavaggio broncoalveolare sono necessari almeno $10 \mathrm{ml}$. prelievo:

1. porre il paziente in posizione supina;

2. sottoporre il paziente ad anestesia e sedazione leggera (possibilmente evitare l'impiego di xylocaina). È consigliabile somministrare l'anestetico per aerosol piuttosto che per iniezione, poiché l'iniezione è modalità non scevra da rischio di contaminazione;

3. inserire il broncoscopio, dotato di catetere a doppio lume con cateterino interno, telescopico, tamponato con glicole polietilenico all'estremità distale allo scopo di prevenire eventuali contaminazioni del materiale di prelievo;

4. inserire la punta del broncoscopio in un bronco segmentale, evitando di aspirare prima della manovra successiva;

5. spingere la camicia esterna del catetere per circa $3 \mathrm{~cm}$ al di là della parte distale del broncoscopio. In alternativa: iniettare $5 \mathrm{cc}$ di aria prima di effettuare la manovra;

6. spingere il cateterino interno nella camicia interna del catetere;

7. raccordare una siringa all'estremità esterna del catetere;

8. iniettare soluzione salina sterile $(\mathrm{NaCl} 0.9 \%, \mathrm{pH} 7.0)$ isotermica $\left(35^{\circ} \mathrm{C}\right)$ per un quantitativo pari a circa $15-20 \mathrm{ml}$;

9. aspirare, dopo il lavaggio, la soluzione fisiologica $(1-3 \mathrm{ml})$ per le indagini microbiologiche;

10. estrarre il catetere.

\subsection{Plugged telescoping catheter (PTC)}

\section{possibilità diagnostiche:}

- metodica altamente sensibile, potendosi evitare la contaminazione del materiale con flora orofaringea e permettendo la coltura di microrganismi in carica assai ridotta. Può essere effettuata sia "alla cieca", senza fibro-broncoscopio, che con l'ausilio del fibro-broncoscopio che permette la visualizzazione dell'area interessata;

questa tecnica è indicato in tutti i pazienti con abbondanti secrezioni e in coloro per i quali il BAL non è indicato (pazienti gravemente ipossici), che possono avvalersi del PTC "alla cieca" con minima invasività. Non è procedura indicata per prelievi parassitologici o virologici e ha bassa sensibilità in soggetti già sottoposti a terapia antibiotica;

- l'esame microbiologico viene condotto sul materiale aspirato ripetutamente a livello dei bronchioli terminali ("alla cieca" o in sede mirata).

prelievo:

1. porre il paziente in posizione supina;

2. sottoporre il paziente ad anestesia e sedazione leggera (possibilmente evitare l'impiego di xylocaina); consigliabile somministrare l'anestetico per aerosol;

3. inserire il broncoscopio, dotato di catetere a doppio lume con cateterino interno, telescopico, tamponato con glicole polietilenico all'estremità distale allo scopo di prevenire eventuali contaminazioni del materiale di prelievo;

4. inserire la punta del broncoscopio in un bronco segmentale, evitando di aspirare prima della manovra 
successiva;

5. spingere la camicia esterna del catetere per circa $3 \mathrm{~cm}$ al di là della parte distale del broncoscopio;

6. spingere il cateterino interno nella camicia interna del catetere;

7. eseguire 3-4 aspirazioni del materiale presente tramite aspirazione con siringa da $10 \mathrm{ml}$ collegata al broncoscopio;

8. introiettare il cateterino ed estrarre il broncoscopio;

9. spingere il cateterino interno in una provetta sterile con tappo a vite (senza toccare le pareti della provetta con le pareti del broncoscopio);

10. raccordare una siringa all'estremità esterna del broncoscopio;

11. iniettare nel lume interno $1 \mathrm{cc}$ di soluzione salina sterile $(\mathrm{NaCl} 0,9 \%, \mathrm{pH} 7.0)$ isotermica $\left(35^{\circ} \mathrm{C}\right)$ : tale liquido si recupera nella provetta sterile in cui è stato spinto il cateterino;

12. tagliare i $3 \mathrm{~cm}$ terminali del cateterino all'interno della provetta sterile, che va quindi riavvitata e inviata al laboratorio.

\subsection{Spazzolatura endobronchiale protetta (Protected Specimen Brush, PSB)}

possibilità diagnostiche:

- la tecnica del PSB, sviluppata da Wimberley alla fine degli anni 70 del XX secolo, consente un accesso diretto alle vie aeree inferiori attraverso il fibrobroncoscopio ed il recupero di secrezioni respiratorie non contaminate. Il brushing è costituito da una spazzola protetta da un doppio catetere telescopico, provvista di un tappo di glicole polietilenico riassorbibile all'interno della punta della camicia più esterna. Viene inserito nel canale operativo del fibrobroncoscopio e può essere portato (preferibilmente sotto controllo radiologico) direttamente nella sede dell'infezione mantenendo la sterilità della spazzola e permettendo di recuperare secrezioni non contaminate dalla flora orofaringea;

- vale quanto detto per il Lavaggio bronco-alveolare. Si tratta di metodica altamente sensibile, evitando la contaminazione del materiale con flora orofaringea e permettendo la coltura di microrganismi anche se presenti in carica assai ridotta. È particolarmente indicato in caso di colture virali.

prelievo:

1. porre il paziente in posizione supina;

2. sottoporre il paziente ad anestesia e sedazione leggera, possibilmente evitando l'impiego di xylocaina. È consigliabile somministrare l'anestetico per aerosol piuttosto che per iniezione, poiché l'iniezione è modalità non scevra da rischio di contaminazione;

3. aspirare delicatamente con un sondino da aspirazione le secrezioni presenti in orofaringe o nel tubo di ventilazione (se il paziente è ventilato) per eliminare la maggior parte delle secrezioni che rischierebbero di contaminare il prelievo;

4. inserire il broncoscopio per via trans-nasale o per via trans-orale nel caso di pazienti non intubati. Inserire il broncoscopio attraverso il tubo endotracheale nel caso di pazienti intubati;

5. posizionare il broncoscopio fino ad incunearlo nel bronco sede del processo infiammatorio (sulla base dell'imaging toracico e/o sul riscontro visivo endoscopico);

6. prelevare lavaggi bronchiali prima di eseguire il prelievo dello spazzolato: ciò riduce il rischio di un eccesso di sangue nel liquido recuperato;

7. introdurre il PSB nel canale operativo del broncoscopio precedentemente posizionato spingendo la spazzolina protetta almeno $2 \mathrm{~cm}$ oltre la punta del broncoscopio;

8. espellere il tappo riassorbibile distale mediante protrusione della cannula interna;
9. far avanzare la spazzola, ormai libera, di $2-4 \mathrm{~cm}$ al di fuori della cannula interna, nel contesto dell'addensamento parenchimale, cercando di compiere dei movimenti di va-e-vieni per alcuni secondi;

10. ritirare la spazzolina di alcuni centimetri nella stessa cannula interna;

11. sfilare delicatamente il PSB dal canale operativo del broncoscopio;

12. disinfettare con alcool $70^{\circ}$ la superficie esterna della camicia esterna;

13. spingere la camicia interna all'interno di quella esterna;

14. spingere la spazzola all'interno della camicia interna;

15. tagliare la spazzola sterilmente, ponendola in una provetta sterile contenente $1 \mathrm{ml}$ di soluzione fisiologica sterile.

\subsection{Aspirato transcricotiroideo}

possibilità diagnostiche:

- la manovra di aspirazione transtracheale attraverso la membrana cricotiroidea evita la contaminazione orofaringea. I rischi di complicanze (emottisi) sono possibili. La sensibilità e la specificità della metodica sono elevatissime. La manovra richiede esperienza tecnica e deve essere riservata a casi clinici assolutamente selezionati;

- è metodica indicata per le ricerche batteriologiche, fungine, parassitologiche e virologiche.

prelievo:

1. iperestendere il capo del paziente e posizionare un cuscino sotto le spalle;

2. disinfettare l'area cricotiroidea con polivinilpirrolidone-iodio;

3. eseguire anestesia di superficie;

4. inserire un ago 14 gauge nella regione cricotiroidea (alternativamente: inserire un'agocannula, ritirando l'ago e lasciando in sede il catetere);

5. connettere una siringa da $30 \mathrm{ml}$ al catetere di polietilene;

6. iniettare 1-2 $\mathrm{ml}$ di soluzione fisiologica sterile $(\mathrm{NaCl}$ $0.9 \%, \mathrm{pH} 7.0$ );

7. estrarre rapidamente il pistone della siringa;

8. sfilare il catetere ed applicare una pressione sul sito di ingresso;

9. travasare il materiale aspirato in una provetta sterile.

\subsection{Biopsia transbronchiale}

possibilità diagnostiche:

- la biopsia con pinza a bordi taglienti, fenestrata, eseguita, o meno, sotto controllo radioscopico, dopo individuazione approssimativa, su base radiologica, dell'area da prelevare, permette il prelievo di materiale polmonare. La metodica è tecnicamente impegnativa per la necessità di utilizzare l'amplificatore di brillanza. Il prelievo trova le maggiori indicazioni per esami di tipo istologico più che microbiologico;

- il rischio di complicanze, in mani esperte, è modesto. Tuttavia non deve essere sottovalutata la possibilità di pneumotorace e sanguinamento. Dopo il prelievo bioptico, è consigliabile verificare che non sia in corso un'estesa emorragia prima di ritirare il tubo del broncoscopio;

- la diagnosi eziologica di polmonite è possibile nel 40-70\% dei casi. Le maggiori indicazioni si hanno per l'accertamento di infezioni da micobatteri, miceti e $P$. jirovecii;

- un radiogramma del torace è obbligatorio e deve essere praticato qualche ora dal termine della procedura. prelievo:

1. inserire il broncoscopio per via trans-nasale o per via trans-orale nel caso di pazienti non intubati. Inserire il broncoscopio attraverso il tubo endotracheale nel caso di pazienti intubati;

2. inserire la punta del broncoscopio in un bronco segmentale;

3. inserire nel canale deputato alla biopsia del broncosco- 
pio la pinza da biopsia, dirigendola nell'area interessata dal processo patologico sotto controllo scopico, preferibilmente con una valutazione multiplanare (TC);

4. prelevare il materiale bioptico con pinza attraverso il canale del broncoscopio deputato alla biopsia;

5. inserire il campione in provetta sterile con $1 \mathrm{ml} \mathrm{di}$ soluzione fisiologica $(\mathrm{NaCl} 0.9 \%)$.

\subsection{Agobiopsia polmonare transparietale}

\section{possibilità diagnostiche:}

- la puntura-biopsia transparietale deve essere riservata al caso di opacità sviluppatesi a contatto con la parete toracica (nel caso di fallimento degli altri metodi diagnostici) e di pneumopatie croniche diffuse e deve essere effettuata sotto scopia o guida tomografica. Il prelievo trova le maggiori indicazioni per esami di tipo istologico più che microbiologico;

- la metodica è gravata da rischi non trascurabili (in particolare: pneumotorace e sanguinamento). Deve essere evitata in modo assoluto in caso di: diatesi emorragica, ipertensione polmonare, pneumonectomia controlaterale e di anomalia vascolare e di cisti idatidea. Controindicazioni relative sono il riscontro di insufficienza cardiaca o respiratoria, di enfisema bolloso e di patologia cardiaca severa. Dopo l'esecuzione del prelievo alcuni Autori suggeriscono l'esecuzione di un radiogramma, per accertare un eventuale pneumotorace o emopneumotorace;

- il campione, suddiviso in due aliquote, andrà indirizzato al Laboratorio di Anatomia Patologica (fissato in formalina) ed a quello di Microbiologia Clinica (conservazione in una minima quantità di soluzione fisiologica) per le indagini microbiologiche.

prelievo:

1. effettuare anestesia locale con xylocaina $2 \%$;

2. utilizzare aghi di $12 / 10-15 / 10 \mathrm{~mm}$ di diametro montati su siringa (da $20 \mathrm{ml}$ ) sterile a perfetta tenuta, contenente una piccola quantità di soluzione fisiologica (alternativamente: usare un trequarti di Küss, estraendo il mandrino ad ago introdotto ed innestando una siringa a tenuta);

3. evidenziare sotto scopia l'area ove eseguire il prelievo (in caso di lesioni diffuse procedere alla puntura nel cavo ascellare a livello del $3^{\circ}$ spazio intercostale oppure sulla faccia posteriore del lobo inferiore destro);

4. prelevare frustoli di $1-3 \mathrm{~mm}^{3}$, se possibile;

5. trasferire i frustoli in contenitori sterili, addizionati di pochi millilitri di soluzione fisiologica (non usare formalina).

\subsection{Agoaspirato polmonare (biopsia polmonare con ago fine)}

possibilità diagnostiche:

- questa metodica trova la massima applicazione per la diagnostica citologica. Di minore rilevanza sono le indicazioni al prelievo per esami microbiologici. La metodica è meno traumatica per il paziente;

- la metodica presenta gli stessi rischi descritti per l'agobiopsia polmonare transparietale;

- il campione, suddiviso in due aliquote, andrà indirizzato al Laboratorio di Anatomia Patologica (fissato in formalina) ed a quello di Microbiologia Clinica (conservazione in una minima quantità di soluzione físiologica) per le prelievo: indagini microbiologiche.

1. evidenziare sotto scopia l'area ove eseguire il prelievo;

2. inserire un ago fine (20-22 gauge) attraverso la parete toracica nell'infiltrato polmonare;

3. aspirare con la siringa il materiale dalla lesione: se la lesione è diffusa o le aree infiltrate sono multiple, prelevare più campioni.

\subsection{Biopsia polmonare a cielo aperto}

possibilità diagnostiche:

- la biopsia polmonare a cielo aperto si impone qualora, in presenza di lesioni nodulari, altre tecniche diagnostiche non abbiano dato alcun esito diagnostico;

- la metodica presenta gli stessi rischi descritti per l'Agobiopsia polmonare transparietale;

- il campione, suddiviso in due aliquote, andrà indirizzato al Laboratorio di Anatomia Patologica (fissato in formalina) ed a quello di Microbiologia Clinica (conservazione in una minima quantità di soluzione físiologica) per le indagini microbiologiche.

prelievo:

1. eseguire le valutazioni preliminari previste per ogni intervento chirurgico (bilancio pre-operatorio; valutazione anestesiologica; anestesia in intubazione, ...);

2. praticare una toracotomia estesa per incisione del $4^{\circ}$ o del $5^{\circ}$ spazio intercostale;

3. prelevare frustoli di $1-3 \mathrm{~cm}^{3}$, se possibile;

4. trasferire i frustoli in contenitori sterili, addizionati di pochi millilitri di soluzione fisiologica (non usare formalina).

\subsection{Biopsia pleurica}

\section{possibilità diagnostiche:}

- $\quad$ si tratta di esame semplice, meglio se eseguito sotto guida pleuroscopica, in anestesia locale;

- $\quad$ il prelievo è controindicato nei pazienti affetti da diatesi emorragiche e da forme ad eziologia batterica;

- il ricorso a questa modalità di prelievo è indicata esclusivamente per la ricerca mirata di Mycobacterium tuberculosis e micobatteri atipici. prelievo:

1. effettuare anestesia locale con xylocaina $2 \%$;

2. utilizzare aghi di diametro diverso montati su siringa (da $20 \mathrm{ml}$ ) sterile a perfetta tenuta, contenente una piccola quantità di soluzione fisiologica;

3. evidenziare, eventualmente sotto scopia (o tomografia), l'area ove eseguire il prelievo;

4. prelevare frustoli di pleura parietale di $1-3 \mathrm{~mm}^{2}$, se possibile;

5. trasferire $\mathrm{i}$ frustoli in contenitori sterili, addizionati di pochi millilitri di soluzione fisiologica (non usare formalina) per le indagini microbiologiche.

\subsection{Liquido pleurico}

possibilità diagnostiche:

- la raccolta di liquido pleurico è indicata qualora siano presenti versamenti pleurici in corso di polmonite. Il campione è per definizione sterile: un risultato positivo può comportare indicazioni terapeutiche immediate. La toracentesi riveste anche caratteri di manovra evacuativa a fini terapeutici, in caso di esteso versamento;

- $\quad$ il prelievo deve essere eseguito con prudenza in caso di anomalie della coagulazione. Dopo l'esecuzione del prelievo alcuni Autori suggeriscono l'esecuzione di un radiogramma, per accertare un eventuale pneumotorace (5\% dei casi);

- è possibile effettuare la ricerca dei batteri (esame colturale "di routine"), di batteri anaerobi, di Legionella spp., di Mycobacterium spp., di Nocardia spp., di C. neoformans e di miceti dimorfi. Talora è possibile isolare microrganismi rappresentativi della flora cutanea ( $P$. acnes, stafilococchi coagulasi negativi) il cui ruolo deve essere criticamente valutato. prelievo:

1. disinfettare la cute nella sede di prelievo e procedere all'anestesia locale;

2. inserire una siringa sterile da $50 \mathrm{ml}$ con ago da $14-18$ gauge immediatamente sopra l'ultima costa dove è possibile reperire il versamento (lo spazio ascellare 
posteriore costituisce il repere verticale ottimale); in alternativa utilizzare rubinetto a tre vie;

3. prelevare (se possibile) $10-40 \mathrm{ml}$ di liquido;

4. trasferire il contenuto della siringa in un contenitore sterile (coltura per microrganismi a metabolismo aerobio) oppure in un contenitore idoneo alla conservazione del materiale finalizzato anche alla coltura di microrganismi anaerobi.

\section{G2. NOTE PER IL PAZIENTE}

\section{MODALITÀ DI PRELIEVO DELL'ESPETTORATO}

Egregio Signore/Gentile Signora: di seguito troverà riportate le indicazioni per la corretta raccolta dell'espettorato che il Suo Medico curante Le ha prescritto per l'effettuazione degli esami microbiologici.

Le ricordiamo che la raccolta del campione, sebbene banale, è un momento fondamentale per la attendibilità dell'esame: per questo ci permettiamo di raccomandarLe lo scrupoloso rispetto di quanto indicato:

1. procurarsi un contenitore sterile a bocca larga e chiusura a vite: può essere acquistato in farmacia. In seguito, il mattino in cui prevede di procedere alla raccolta del campione e alla sua consegna al Centro Prelievi del Suo ospedale, dovrà comportarsi come di seguito indicato, procedendo preferibilmente lontano dall'assunzione di cibo ed evitando di raccogliere in modo cumulativo $i$ campioni respiratori:

2. togliere eventuali protesi dentali mobili;

3. non utilizzare dentrificio;

4. grattare gentilmente, con spazzolino da denti o con tampone umidi, la mucosa interna delle guance, le gengive e la lingua;

5. sciacquare il cavo orale con acqua (possibilmente sterile) prima della raccolta del campione;

6. se l'espettorazione spontanea è scarsa, eseguire manovre di fisioterapia e/o dopo inalazione, con l'ausilio di un nebulizzatore ultrasonico, di 20-30 ml di soluzione fisiologica ( $5 \% \mathrm{NaCl} 0.9 \%$ : "espettorato indotto");

7. espettorare (con un colpo di tosse) in un contenitore a bocca larga sterile e con tappo a vite;

8. raccogliere almeno $1 \mathrm{ml}$ di materiale;

9. evitare l'introduzione di materiale salivare o di secrezioni nasali nel contenitore per la raccolta. In caso contrario, ripetere la procedura dall'inizio utilizzando un altro contenitore;

10. riavvitare con cura il coperchio del contenitore;

11. consegnare il campione al Centro Prelievi entro un'ora dalla raccolta, conservandolo nell'attesa, in frigorifero.

Nel caso fosse richiesta la raccolta di espettorato in più giorni successivi, ciascun campione deve essere consegnato lo stesso giorno della raccolta entro un'ora (non è possibile consegnarli insieme).

Il Centro Prelievi è aperto, per la consegna dei campioni nei seguenti orari:

da lunedì a venerdì dalle ore ..... alle ore ....

il sabato dalle ore ..... alle ore ..........

\section{G3. PROCEDURE DI TECNICA MICROBIOLOGICA}

\section{MATERIALI RESPIRATORI: LA FASE ANALITICA E LA REFERTAZIONE}

\section{Norme generali}

All'arrivo presso il Laboratorio di Microbiologia Clinica deve essere verificata la correttezza della fase pre-analitica (raccolta, conservazione ed invio del materiale).

In taluni casi potrà essere indicata, oltre alla colorazione di
Gram, anche l'esecuzione di un esame a fresco o dopo specifiche colorazioni sul materiale, per evidenziare particolari strutture cellulari o microbiche.

Le indagini (per ricerca diretta di ricerca batteri e miceti) prevedono un protocollo minimo di ricerche colturali, associate alla determinazione, quantitativa della carica batterica.

a. Carica batterica: gli agenti eziologici di polmonite sono generalmente presenti in alte concentrazioni nelle secrezioni respiratorie $\left(\geq 10^{5}-10^{6} \mathrm{UFC} / \mathrm{ml}\right)$ e nei tessuti $\left(\geq 10^{4}\right.$ $\mathrm{UFC} / \mathrm{g}$ di tessuto); la flora contaminante delle alte vie superiori è invece presente in concentrazioni più basse $\left(<10^{4} \mathrm{UFC} / \mathrm{ml}\right)$ quando il materiale è raccolto correttamente. La determinazione della carica batterica consente così di discriminare la popolazione microbica responsabile di infezione da quella verosimilmente contaminante.

b. Protocollo minimo: è indirizzato alla ricerca di: Enterobacteriaceae, Bacilli Gram-negativi non fermentanti il glucosio, Haemophilus spp., Moraxella catarrhalis, Staphylococcus aureus, Streptococcus pneumoniae e Streptococcus pyogenes. La ricerca di microorganismi anaerobi deve, invece, essere limitata solo ad alcuni materiali.

Le indicazioni sottoriportate fanno riferimento al protocollo minimo di ricerche batteriologice sopra riportato che deve sempre essere applicato.

Ulteriori ricerche, trattate nel paragrafo "Ricerche particolari", dovranno essere effettuate solo in casi selezionati.

Nel caso in cui il campione pervenga al laboratorio dopo più di 2 ore dal prelievo, commentare: "L'esame colturale è eseguito su un campione prelevato da più di 2 ore: i risultati microbiologici possono risultarne falsati e debbono essere interpretati alla luce del quadro clinico".

\section{Microrganismi correlati alle forme cliniche di polmonite}

Si riportano, in modo assolutamente sommario e non necessariamente esaustivo, i microrganismi descritti quali agenti eziologici di polmonite.

\subsection{Eziologia delle CAP}

Batteri: Actinomyces spp., anaerobi orali, Bacillus anthracis, Bordetella spp., Chlamydia trachomatis, Chlamydophila pneumoniae, Chlamydophila psittaci, Francisella turalensis, Haemophilus influenzae, Legionella pneumophila, Legionella spp., Leptospira interrogans, Moraxella catarrhalis, Mycoplasma pneumoniae, Neisseria meningitidis, Nocardia spp., Pseudomonas pseudomallei, Staphylococcus aureus, Streptococcus agalactiae, Streptococcus pneumoniae, Streptococcus pyogenes, Yersinia pestis;

Miceti: Blastomyces dermatitidis, Coccidioides immitis, Cryptococcus neoformans Histoplasma capsulatum;

Virus: Adenoviridae, Coxsackievirus A e B, Human parainfluenza virus di tipo 1 e 3; Human Respiratory Syncytial Virus, Human Metapneumovirus, Influenzavirus A, B e C.

\subsection{Eziologia delle CAP del soggetto immunocompromesso} Batteri: Enterobacteriaceae, Legionella spp., Mycobacterium spp., Nocardia spp., Pseudomonas spp. e bacilli Gram-negativi non fermentanti il glucosio, Rhodococcus equi, Staphylococcus aureus, Streptococcus pneumoniae;

Miceti: Aspergillus spp., Cryptococcus neoformans, Fusarium spp., miceti dematiacei, Pneumocystis jiroveci, zigomiceti;

Parassiti: Cryptosporidium parvum, Dirofilaria immitis, Microsporidium spp., Strongyloides stercoralis, Toxoplasma gondii;

Virus: Cytomegalovirus, Hantavirus.

\subsection{Eziologia delle CAP da aspirazione}

Batteri: Fusobacterium nucleatum, Enterobacteriaceae, Peptostreptococcus spp., Porphyromonas asaccharolytica, Prevotella melaninogenica, Pseudomonas spp. 
3. Materiali ad alto rischio di contaminazione con saliva (Espettorato; Espettorato indotto; Espettorato protetto; Aspirato endotracheale; Aspirato da tracheostomia; Lavaggio bronchiale)

\subsection{Premessa}

Sui materiali di provenienza dalle basse vie aeree che possono essere contaminati da saliva è imperativa la valutazione preliminare della qualità del campione, allo scopo di evitare l'esame di materiali poco rappresentativi della lesione e, conseguentemente, la refertazione ai Clinici di risultati potenzialmente inesatti e devianti. Fanno eccezione in casi di prelievo finalizzato alla coltura di Legionella spp. ed i campioni da pazienti con fibrosi cistica.

\subsection{Esame microscopico}

\section{A. Preparazione dello striscio}

- pre-riscaldare un vetrino portaoggetti (evita l'interferenza della fibrina);

- scegliere porzioni purulente del campione;

- stendere il materiale a velo sottile su vetrino, preferibilmente operando in cabina a flusso laminare;

- lasciare asciugare all'aria, preferibilmente operando in cabina a flusso laminare;

- fissare preferibilmente con metanolo per 2-3 minuti (in alternativa: fissare alla fiamma).

\section{B. Colorazione di Gram}

- secondo le metodiche in uso.

\section{Lettura del Gram}

- esaminare almeno 10 campi (x100), scegliendo quelli più significativamente ricchi di materiale;

- determinare il numero medio di ciascun tipo di globuli bianchi (GB) e cellule epiteliali squamose (CS);

- calcolare il punteggio "Q" (Q score) sulla base della tabella seguente:

Cellule epiteliali squamose (CS)

\begin{tabular}{|c|c|c|c|c|c|c|}
\hline \multirow{6}{*}{$\begin{array}{l}\text { Leucociti } \\
\text { (GB) }\end{array}$} & \multicolumn{2}{|c|}{ Lettura del Gram } & \multirow{2}{*}{\begin{tabular}{|l|} 
no \\
0
\end{tabular}} & \multirow{2}{*}{$\begin{array}{l}1-9 \\
+ \\
\end{array}$} & \multirow{2}{*}{$\begin{array}{l}10-24 \\
++\end{array}$} & \multirow{2}{*}{$\frac{>25}{+++}$} \\
\hline & & Referto & & & & \\
\hline & no & 0 & 0 & -1 & -2 & -3 \\
\hline & $1-9$ & + & +1 & 0 & .1 & .2 \\
\hline & $10-24$ & ++ & +2 & +1 & 0 & -1 \\
\hline & $>25$ & +++ & +3 & +2 & +1 & 0 \\
\hline
\end{tabular}

+++ , Cellule epiteliali squamose + );

- morfotipi microbici rilevati all'esame diretto sec. Gram: interpretare i risultati procedendo alla media di almeno 10 campi, come di seguito indicato

\begin{tabular}{lll}
\hline & Gram & Referto \\
\hline \multirow{3}{*}{ Microrganismi } & $<1$ & + \\
\cline { 2 - 3 } & $1-2$ & ++ \\
\cline { 2 - 3 } & $3-10$ & +++ \\
\cline { 2 - 3 } & $>10$ & ++++ \\
\hline
\end{tabular}

3. Esame colturale: da effettuare sempre come indicato ai paragrafi 3.3 e 3.4 .

4. Procedere alla refertazione preliminare:

- riportare i risultati dell'esame microscopico x1000 (determinazione semiquantitativa di leucociti e di cellule epiteliali di sfaldamento);

- segnalare la presenza di batteri o miceti, descrivendo i morfotipi presenti, e la carica. In particolare:

1. se si rileva la presenza di una popolazione microbica monomorfa:

- riferire il morfotipo: es. "Bacilli Gram negativi + (o ++, +++, ++++)";

2. se si rileva la presenza di una popolazione microbica predominante:

- riferire il morfotipo predominante: es. "Bacilli Gram negativi + $(\mathrm{o}++,+++,++++)$ ";

- nel caso siano presenti anche altri morfotipi, aggiungere la nota: "Presenza anche di flora batterica mista: + (o ++,,+++++++$)$ ";

3. Se non è apprezzabile un morfotipo predominante, riferire: "Presenza di popolazione microbica mista all'esame microscopico diretto: + (o,+++++ , $++++)$ ";

4. Se non si apprezza alcun morfotipo microbico, refertare "Morfotipi microbici non apprezzabili all'esame microscopico diretto".

- commentare: "La valutazione del Q score effettuata con l'esame microscopico diretto del campione rileva che il materiale inviato è rappresentativo delle basse vie aeree: i risultati dell'esame colturale devono essere interpretati alla luce del quadro clinico".
D. Decisioni sulla base del punteggio “ $Q$ ”

\section{a. Punteggio $Q \leq 0$}

In questo caso:

1. Esame microscopico a immersione (x1000): non eseguire.

2. Non procedere ad indagini colturali.

3. Procedere alla refertazione definitiva:

- riportare i risultati dell'esame microscopico (determinazione semiquantitativa di Globuli bianchi e cellule epiteliali di sfaldamento);

- commentare: "L'esame colturale non è eseguito: il campione non è rappresentativo di secrezioni delle basse vie aeree. Si consiglia di valutare l'opportunità di inviare nuovo campione";

- in caso di prelievi effettuati a soggetti con fibrosi cistica commentare: "Il campione inviato non è rappresentativo di secrezioni delle basse vie aeree. L'esame colturale è tuttavia eseguito per la valutazione selettiva della colonizzazione microbica".

\section{b. Punteggio $Q \geq 1$}

Procedere a:

1. Esame microscopico a immersione (x1000):

- descrizione qualitativa e semiquantitativa dei batteri, concentrandosi sulle aree dove sono più presenti i leucociti;

2. Lettura del Gram:

- tipo e quantità delle cellule (ad esempio: Leucociti
3.3 Pretrattamento del campione (fluidificazione)

- scegliere le parti più purulente del campione;

- trattare il materiale con omogeneizzatore oppure diluire $1: 1(\mathrm{v} / \mathrm{v})$ con ditiotreitolo, lasciando il campione per 60 minuti a temperatura ambiente o per 30 minuti in termostato a $35-37^{\circ} \mathrm{C}$.

\subsection{Esame colturale}

A. Terreni

1. Agar sangue (5\%, di cavallo o di montone):

2. Mc Conkey o altro terreno selettivo-differenziale per Enterobacteriaceae e Bacilli Gram Negativi non fermentanti il glucosio;

3. Agar sangue $(5 \%$, di montone) con colistina ed acido nalidixico (CNA) con optochina (dischetto);

4. Agar cioccolato con bacitracina (nel terreno o dischetto) o TSA+BVX;

5. Sabouraud Dextrose Agar con cloramfenicolo e/o gentamicina.

\section{B. Semina}

Seminare le piastre usando la tecnica delle "tre zone":

depositare, con pipetta o direttamente con ansa calibrata, $10 \mu \mathrm{l}$ strisciare (5 linee avanti e cinque indietro per ogni quadrante) come a fianco indicato:

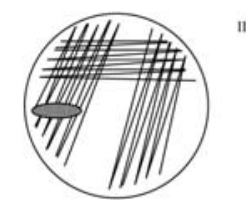

III 


\section{Incubazione}

1. incubare a $35-37^{\circ} \mathrm{C}$ in atmosfera aerobia per 24 ore: $M c$ Conkey Agar, Agar sangue e Agar CNA;

2. incubare a $35-37^{\circ} \mathrm{C}$ in atmosfera arricchita in $\mathrm{CO}_{2}(5-$ $10 \%)$ per 24 ore: Agar cioccolato;

3 . esaminare le piastre sopra menzionate dopo 24 ore e procedere ad identificazioni e/o isolamenti;

4. incubare a $35^{\circ} \mathrm{C}$ in atmosfera aerobia per 48 ore: Sabouraud Dextrose Agar con antibiotici;

5. re-incubare, in caso di negatività, le piastre di Mc Conkey Agar, Agar sangue, Agar CNA e di Agar cioccolato, e riesaminarle quotidianamente per altre 48 ore;

6. re-incubare le piastre di Agar Sabouraud Dextrose con antibiotici in atmosfera aerobia a $30^{\circ} \mathrm{C}$ per almeno altre 2 settimane, e riesaminarle a cadenza giornaliera.

D. Quantificazione della crescita:

\begin{tabular}{ccccc}
\hline $\begin{array}{c}\text { Carica } \\
\text { semiquantitativa }\end{array}$ & $\begin{array}{c}\text { I } \\
\text { quadrante }\end{array}$ & $\begin{array}{c}\text { II } \\
\text { quadrante }\end{array}$ & $\begin{array}{c}\text { III } \\
\text { quadrante }\end{array}$ & $\begin{array}{c}\text { Carica approssimativa } \\
\text { (CFU/mI) }\end{array}$ \\
\hline+ & $<10$ & & & $10^{3}$ \\
\hline++ & $>10$ & $<10$ & & $10^{4}$ \\
\hline+++ & $>10$ & $>10$ & $<10$ & $10^{5}$ \\
\hline++++ & $>10$ & $>10$ & $>10$ & $10^{6}$ \\
\hline
\end{tabular}

\subsection{Interpretazione dei risultati}

Procedere alle identificazioni microbiche se:

1. Streptococchi $\alpha$-emolitici $\rightarrow$ identificare S. pneumoniae;

2. Streptococchi $\beta$-emolitici $\rightarrow$ identificare S. pyogenes e, nel neonato, S. agalactiae;

3. Haemophilus spp. $\rightarrow$ identificare solo in caso di assente e scarsa flora salivare o se Haemophilus spp. predomina $(>2+)$ all'esame sec. Gram o nella piastra (ad esempio Haemophilus spp. +++, altra flora +; Haemophilus spp. ++++ , altra flora $++\mathrm{o}+$ );

4. Diplococchi Gram negativi $\rightarrow$ Acinetobacter spp., Neisseria spp. e Moraxella spp.: identificare solo se predomina (salto di due +) all'esame sec. Gram o se presenti all'interno dei neutrofili;

5. Enterobacteriaceae e BNF $\rightarrow$ identificare solo se sono presenti uno o due tipi di colonie. In caso di più di due tipi di colonie non si procede;

6. Bacilli Gram positivi $\rightarrow$ identificare se aspetto tipico delle colonie di Rhodococcus spp., Nocardia spp. Tra i coriniformi, identificare C. pseudodiphtericum e C. striatum;

7. Miceti filamentosi $\rightarrow$ identificare.

Nel caso di riscontro di morfotipi compatibili con cocchi Gram positivi e lieviti, procedere solo in accordo con lo schema di seguito indicato:

\begin{tabular}{ccc}
\hline $\mathbf{N}^{\circ}$ colonie & flora orofaringea (FO) & Azione \\
\hline+ & FO presente o assente & non procedere \\
\hline++ & $\begin{array}{c}\text { FO assente oppure patogeno } \\
\text { predominante al Gram }(>2+)\end{array}$ & identificare \\
\hline+++++++ & FO presente o assente & identificare \\
\hline
\end{tabular}

procedendo ad identificare:

8. Staphylococcus spp. $\rightarrow$ identificare solo S. aureus;

9. Enterococcus spp. $\rightarrow$ identificare;

10. lieviti $\rightarrow$ identificare.

\subsection{Refertazione dei risultati}

Nel referto definitivo devono essere riportati:

- i risultati dell'esame microscopico;

- $\quad$ il/i germe/i identificato;

- l'eventuale antibiogramma;

- eventuali commenti del microbiologo. Ad esempio:

1. in caso di positività per batteri $\rightarrow$ "Il riscontro in coltura dei microrganismi identificati non é di per sé rappresentativo dell'eziologia responsabile del quadro clinico. Si consiglia di confrontare tale dato con quello dell'esame microscopico diretto e di confer- mare il risultato inviando complessivamente tre campioni di materiale respiratorio in tre giorni diversi";

2 . in caso di positività per $S$. pneumoniae $\rightarrow$ "Il riscontro in coltura di $S$. pneumoniae non é di per sé indicativo di un quadro di polmonite pneumococcica. Si consiglia di inviare complessivamente: tre campioni respiratori, in giorni successivi, e tre set di emocolture per la conferma colturale, ed un campione di urine per la rilevazione dell'antigene pneumococcico";

3 . in caso di positività per Aspergillus spp. $\rightarrow$ "Il riscontro in coltura di Aspergillus spp. non é di per sé indicativa di un quadro di aspergillosi polmonare. Si consiglia di inviare almeno tre campioni respiratori, in giorni successivi, per la conferma colturale ed un campione di siero per la rilevazione dell'antigene galattomannano";

4. in caso di positività per Candida spp. $\rightarrow$ "Il riscontro in coltura pura di Candida spp. è rappresentativo di un quadro di colonizzazione o di infezione da lieviti del cavo orale. Si consiglia di valutare l'eventuale presenza di una mucosite orale";

5. in tutti i casi $\rightarrow$ "Si consiglia di valutare, in base agli eventuali riscontri dell'anamnesi epidemiologica (fattori predisponenti, contatti con animali, soggiorni in Paesi di endemia per microrganismi di importazione), l'opportunità di predisporre accertamenti colturali o sierologici per il riscontro di patogeni mirati".

4. Materiali a basso rischio di contaminazione con saliva (Lavaggio bronco-alveolare; Lavaggio bronco-alveolare mirato con cateterino; Spazzolatura endobronchiale protetta; Aspirato transcricotiroideo)

\subsection{Premessa}

Sui materiali di provenienza dalle basse vie aeree raccolti con tecniche protette di prelievo, a basso rischio di contaminazione salivare, la valutazione preliminare della qualità non modifica il successivo iter dell'esame: pare, però, utile effettuarla in ogni caso per permettere una più accurata interpretazione dei risultati.

\subsection{Esame microscopico}

\section{A. Preparazione dello striscio}

- procedere all'agitazione del campione, soprattutto nel caso di invio di spazzolino o catetere, con vortex per 30 60 secondi;

- preparare tre vetrini (o un solo vetrino, provvedendo però a conservare il materiale a $+4^{\circ} \mathrm{C}$ );

- se si dispone di citocentrifuga: allestire un vetrino del citocentrifugato $(100 \mu \mathrm{l}$ a $500 \mathrm{rpm}$ per 5 minuti; in mancanza di citocentrifuga utilizzare il sedimento ottenuto con centrifugazione, stendendo il materiale a velo sottile su vetrino (in presenza di fibrina si consiglia di utilizzare un vetrino pre-riscaldato), preferibilmente operando in cabina a flusso laminare;

- lasciare asciugare i vetrini all'aria (preferibilmente sotto cappa a flusso laminare);

- $\quad$ fissare con metanolo per 2-3 minuti.

\section{B. Colorazioni}

secondo le metodiche in uso.

eseguire sempre:

1. Gram, per valutare la popolazione microbica (la sensibilità del test è però bassa) e la cellularità (meglio valutabile con la colorazione di May-Grünwald Giemsa);

2. due strisci per eventuali ulteriori necessità (oppure conservare il materiale a $+4^{\circ} \mathrm{C}$ );

da valutare, in relazione al quadro clinico-epidemiologi- 
co e alle potenzialità diagnostiche, l'effettuazione di:

3. May-Grünwald Giemsa (per valutare la presenza e la conta differenziale delle cellule);

4. Colorazione per Bacilli acido-alcool resistenti (Kinyoun o Auramina-rodamina; Ziehl-Nielsen modificato per Nocardia spp.);

5. Colorazioni per miceti (Cotton Blue Lattofenolo, Calcofluor White, Gomori-Grocott o PAS);

6. Esame a fresco per ricerca di miceti e parassiti;

7. Fluorescenza diretta per Legionella spp., Cytomegalovirus, virus respiratori;

8. Colorazioni per Pneumocystis jirovecii;

9. ricerca di elastina ( $\mathrm{KOH}$ o citochimica); la presenza fa sospettare un'infezione da Gram negativi;

10. altre colorazioni per ricerche specifiche.

\section{Lettura del Gram}

Lettura (a x100 e x1000) e interpretazione

- determinare (obiettivo x10 e oculare x10) il numero di cellule e di batteri in 20-40 campi dello striscio, senza calcolare i campi senza cellule o batteri;

- procedere alla rilevazione dei batteri extracellulari (definendone la carica semiquantitativa) ed intracellulari (registrando la percentuale di polimorfonucleati e macrofagi contenenti microrganismi intracellulari). Infatti, la presenza dei batteri intracellulari in percentuale $>2 \%$ è indicativa di polmonite sostenuta da microrganismi corrispondenti ai morfotipi evidenziati all'esame diretto (la negatività non la esclude per la scarsa sensibilità del Gram);

- procedere - ove possibile sulla base delle colorazioni adottate - alla conta differenziale di macrofagi, neutrofili, eosinofili, linfociti, cellule epiteliali bronchiali (se presenti), cellule epiteliali squamose (se presenti). La conta si basa sull'osservazione di almeno 300 cellule, esclusi gli eritrociti (se la cellularità è scarsa, procedere alla conta su due vetrini):

determinare la presenza di cellule in \% :

- cellule cigliate in campioni di prelievi bronchiali o di cellule alveolari in campioni alveolari: il materiale proviene dalle basse vie respiratorie;

- cellule epiteliali squamose nel citocentrifugato $(>1 \%)$ : il materiale è stato verosimilmente contaminato con flora orofaringea;

- segnalare l'eventuale presenza di eritrociti.

D. Decisioni sulla base dell'esame microscopico diretto riferire tempestivamente (telefonicamente o via fax e con referto preliminare in giornata) i risultati dell'esame microscopico. Commentare i risultati come segue:

- a commento dell'esame microscopico, se segni di contaminazione con la mucosa del cavo orale (presenza di flora orofaringea e/o presenza di cellule epiteliali squamose, se $>1 \%$ ) $\rightarrow$ "La presenza di cellule epiteliali squamose del cavo orale e/o il riscontro in coltura di microrganismi rappresentativi della popolazione microbica del cavo orale depone per la possibile contaminazione durante la raccolta. Si consiglia di valutare i risultati alla luce dei dati clinici";

- a commento dell'esame microscopico, se cellularità rappresentativa delle basse vie aeree $\rightarrow$ "La presenza, all'esame microscopico diretto, di cellule cigliate conferma la qualità del materiale, di origine dalle basse vie respiratorie. Inoltre, l'eventuale presenza di batteri intracellulari in percentuale $>2 \%$ è indicativa di polmonite sostenuta da questi stessi microrganismi. Tuttavia, la negatività dell'esame microscopico non esclude l'eziologia microbica per la scarsa sensibilità del metodo (colorazione sec. Gram)";

\subsection{Pretrattamento del campione}

1. Non è richiesta la fluidificazione (nel caso venga effet- tuata, attenersi a quanto descritto precedentemente);

2 . in presenza di materiale emorragico può essere utile procedere alla lisi degli eritrociti, tenendo conto dell'eventuale diluizione al momento della semina.

\subsection{Esame colturale}

A. Terreni

1. Agar sangue ( $5 \%$, di cavallo o di montone);

2. Mc Conkey Agar o altro terreno selettivo-differenziale per Enterobacteriaceae e Bacilli Gram Negativi non fermentanti il glucosio;

3. Agar sangue (5\%, di montone) con colistina ed acido nalidixico (CNA) con optochina (dischetto);

4. Agar cioccolato con bacitracina (nel terreno o dischetto) o TSA+BVX;

5. Sabouraud Dextrose Agar con cloramfenicolo e/o gentamicina.

\section{B. Semina}

1. agitare il campione senza centrifugare (salvo che per colture mirate per Legionella spp. e miceti filamentosi e per l'allestimento di preparati per $P$. jirovecii) né citocentrifugare;

2. seminare sulle piastre in modo da rendere agevole la conta delle colonie:

a. per lavaggio bronco-alveolare, $(1 \mathrm{ml}$ di materiale in $10 \mathrm{ml}$ di soluzione di lavaggio $\rightarrow$ fattore di diluizione $1 / 10$ ) seminare $10 \mu \mathrm{l}$. Per ottenere colonie isolate può essere utile seminare su Agar sangue anche $1 \mu \mathrm{l}$; in tal caso la conta delle colonie sottoriportata dovrà essere moltiplicata $\times 10$;

b. per lavaggio bronco-alveolare mirato con cateterino, seminare $100 \mu \mathrm{l}$. Per ottenere colonie isolate può essere utile seminare su Agar sangue anche $10 \mu \mathrm{l}$; in tal caso la conta delle colonie soprariportata dovrà essere moltiplicata x 10 ;

c. per spazzola endobronchiale protetta, (raccoglie 0.01-0.001 $\mathrm{ml}$ di materiale, immerso in $1 \mathrm{ml} \rightarrow$ fattore di diluizione $1 / 100-1 / 1000$ ) seminare $100 \mu$ l. Per ottenere colonie isolate può essere utile seminare anche $10 \mu \mathrm{l}$ su Agar sangue: in tal caso la conta delle colonie soprariportata dovrà essere moltiplicata x 10 .

\section{Incubazione}

1. incubare a $35-37^{\circ} \mathrm{C}$ in atmosfera aerobia per 24 ore: $M c$ Conkey Agar, Agar sangue e Agar CNA;

2. incubare a $35-37^{\circ} \mathrm{C}$ in atmosfera arricchita in $\mathrm{CO}_{2}(5-$ $10 \%)$ per 24 ore: Agar cioccolato;

3 . esaminare le piastre sopra menzionate dopo 24 ore e procedere ad identificazioni e/o isolamenti;

4. incubare a $35^{\circ} \mathrm{C}$ in atmosfera aerobia per 48 ore: Sabouraud Dextrose Agar con antibiotici;

5. re-incubare, in caso di negatività, le piastre di Mc Conkey Agar, Agar sangue, Agar CNA e di Agar cioccolato, e riesaminarle quotidianamente per altre 48 ore;

6. re-incubare le piastre di Agar Sabouraud Dextrose con antibiotici in atmosfera aerobia a $30^{\circ} \mathrm{C}$ per almeno altre 2 settimane, e riesaminarle a cadenza giornaliera.

\section{Quantificazione della crescita}

1. per lavaggio bronco-alveolare: leggere la carica come segue:

\begin{tabular}{ccc}
$\mathbf{N}^{\circ}$ colonie per piastra & \multicolumn{2}{c}{ Conta totale } \\
\hline$<10$ & $<1 \times 10^{3}$ & $\mathrm{CFU} / \mathrm{ml}$ \\
\hline $10-100$ & $10^{3}-10^{4}$ & $\mathrm{CFU} / \mathrm{ml}$ \\
\hline $100-1.000$ & $10^{4}-10^{5}$ & $\mathrm{CFU} / \mathrm{ml}$ \\
\hline$>1.000$ & $>10^{5}$ & $\mathrm{CFU} / \mathrm{ml}$ \\
\hline
\end{tabular}

per lavaggio bronco-alveolare mirato con cateterino e per spazzola endobronchiale protetta: leggere la carica come segue: 
$\mathbf{N}^{\circ}$ colonie per piastra

\begin{tabular}{ccc}
\hline$<10$ & $<1 \times 10^{2}$ & $\mathrm{CFU} / \mathrm{ml}$ \\
\hline $10-100$ & $10^{2}-10^{3}$ & $\mathrm{CFU} / \mathrm{ml}$ \\
\hline $101-1.000$ & $10^{3}-10^{4}$ & $\mathrm{CFU} / \mathrm{ml}$ \\
\hline$>1.000$ & $>10^{4}$ & $\mathrm{CFU} / \mathrm{ml}$
\end{tabular}

\subsection{Interpretazione dei risultati}

1. identificare tutti i microorganismi;

2. se il prelievo è correttamente eseguito la carica microbica della popolazione residente nell'orofaringe è $<10^{4}$; la carica microbica dei patogeni è di solito $\geq 10^{6}$ (un cut off per la flora patogena di $10^{5}$ sembra più appropriato, così da includere anche le infezioni in trattamento antibiotico e $\mathrm{i}$ quadri clinici iniziali). Interpretare i risultati della coltura dei materiali raccolti con metodiche protette come segue:

a. per la spazzola endobronchiale la carica critica è indicata in $>10^{3} \mathrm{UFC} / \mathrm{ml}$

b. per il lavaggio broncoalveolare la carica critica è indicata in $>10^{4} \mathrm{UFC} / \mathrm{ml}$

c. per il lavaggio broncoalveolare mirato con cateterino la carica critica è indicata in $>10^{3} \mathrm{UFC} / \mathrm{ml}$ (tale valore è stato desunto dalla comparazione con la coltura di frustoli bioptici di tessuto polmonare di $1 \mathrm{~mm}^{3}$ ); in caso di terapia chemio-antibiotica, pregressa o in atto, anche cariche batteriche $\leq 10^{2}$ possono essere significative. Alcuni Centri effettuano la raccolta del materiale da lavaggio bronco-alveolare mirato con cateterino e palloncino (Pro-BAL): in tal caso è necessario interpretare i risultati scalando di un logaritmo.

\subsection{Refertazione dei risultati}

Nel referto definitivo devono essere riportati:

- i risultati dell'esame microscopico;

- $\quad$ il/i germe/i identificato;

- l'eventuale antibiogramma;

- eventuali commenti del microbiologo. Ad esempio:

1. in caso di positività per batteri $\rightarrow$ "Il riscontro in coltura dei microrganismi identificati é suggestivo dell'eziologia responsabile del quadro clinico. Si consiglia di confrontare tale dato con quello dell'esame microscopico diretto e di confermare il risultato inviando complessivamente tre set di emocolture per la conferma colturale";

2. in caso di positività per Aspergillus spp. $\rightarrow$ "Il riscontro in coltura di Aspergillus spp. non é di per sé indicativa di un quadro di aspergillosi polmonare. Si consiglia di inviare complessivamente tre campioni respiratori, in giorni successivi, per la conferma colturale ed un campione di siero per la rilevazione dell'antigene galattomannano";

3. in tutti i casi $\rightarrow$ "Si consiglia di valutare, in base agli eventuali riscontri dell'anamnesi epidemiologica, l'opportunità di predisporre accertamenti colturali o sierologici per il riscontro di patogeni mirati”.

\section{Materiali bioptici}

(Aspirato polmonare con ago fine; Biopsia transbronchiale; Agobiopsia polmonare; Biopsia polmonare a cielo aperto; Biopsia pleurica)

\subsection{Premessa}

Sui materiali di origine bioptica, la valutazione preliminare della qualità non è richiesta. In caso di colture di materiale polmonare bioptico é possibile incrementare la significatività della coltura mimando in vitro le condizioni fisiologiche $\left(35^{\circ} \mathrm{C}, 6 \% \mathrm{O}_{2}-10 \% \mathrm{CO}_{2}\right)$.

\subsection{Pretrattamento del campione}

Omogeneizzare il materiale in brodo triptosio in rapporto 1:10 (es. $0.5 \mathrm{~g}$ di tessuto in $5 \mathrm{ml}$ di brodo) con mortaio sterile oppure con omogeneizzatore di tessuti disposable o sterilizzabile.
5.3 Esame microscopico

1. deporre il materiale su vetrino:

- per apposizione su vetrini sterili, utilizzabile per pochi vetrini, oppure;

- striscio dall'omogeneizzato, utilizzabile per molte colorazioni;

2. procedere come indicato per i materiali a basso rischio di contaminazione con saliva.

\subsection{Esame colturale}

A. Terreni

1. Agar sangue (5\%, di cavallo o di montone);

2. Mc Conkey Agar o altro terreno selettivo-differenziale per Enterobacteriaceae e Bacilli Gram Negativi non fermentanti il glucosio;

3. Agar sangue (5\%, di montone) con colistina ed acido nalidixico (CNA) con optochina (dischetto);

4. Agar cioccolato con bacitracina (nel terreno o dischetto) o TSA+BVX;

5. Sabouraud Dextrose Agar con cloramfenicolo e/o Gentamicina;

6. brodo tioglicolato.

B. Semina

- agitare il campione (vortex 30-60 secondi);

- seminare secondo lo schema sottoriportato (si sconsiglia l'uso dell'ansa calibrata):

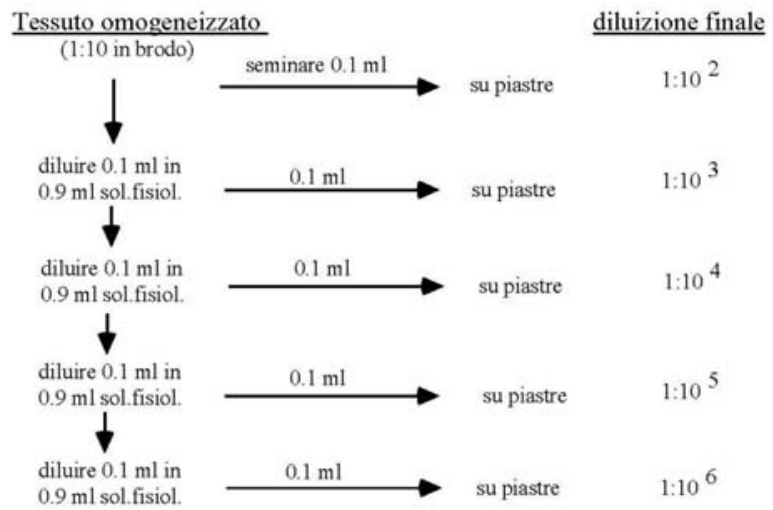

\section{Incubazione:}

1. incubare a $35-37^{\circ} \mathrm{C}$ in atmosfera aerobia per 24 ore: $M c$ Conkey Agar, Agar sangue, Agar CNA e Sabouraud Dextrose Agar con antibiotici;

2. incubare a $35-37^{\circ} \mathrm{C}$ in atmosfera arricchita in $\mathrm{CO}_{2}$ (5-10\%) per 24 ore: Agar cioccolato;

3 . esaminare le piastre sopra menzionate dopo 24 ore e procedere ad identificazioni e/o isolamenti;

4. re-incubare, in caso di negatività, le piastre di Mc Conkey Agar, Agar sangue, Agar CNA e di Agar cioccolato, e riesaminarle quotidianamente per altre 48 ore;

5. re-incubare le piastre di Agar Sabouraud Dextrose con antibiotici in atmosfera aerobia a $30^{\circ} \mathrm{C}$ per almeno altre 2 settimane, e riesaminarle a cadenza giornaliera.

\subsection{Interpretazione dei risultati}

1. identificare e refertare tutti i microrganismi;

2. interpretare l'arricchimento (brodo tioglicollato) come segue:

- se il brodo rimane limpido dopo 5 giorni di incubazione: scartare come negativo;

- $\quad$ se il brodo diventa torbido: effettuare colorazione di Gram.

Se il morfotipo apprezzato all'esame batterioscopico del brodo concorda con i risultati della crescita in piastra, non procedere a sottocolture. In caso di mancata concordanza, procedere a sottocolture utilizzando terreni idonei (anche per anaerobi) e poi identificare. 
3. commentare l'eventuale presenza di flora normale orofaringea con la nota: "Possibile contaminazione durante la raccolta. Si consiglia di valutare il risultato microbiologico alla luce dei dati clinici."

\section{Ricerche particolari}

Con l'esame colturale si effettuano sempre le ricerche "di routine" precedentemente segnalate.

Ricerche particolari che richiedono l'utilizzo di terreni supplementari e/o di tecniche particolari necessarie per l'evidenziazione (diretta o colturale) del microrganismo in questione sono eseguite solo nel caso di specifica indicazione. La decisione di allargare lo spettro delle ricerche è solo in parte responsabilità del microbiologo. I procedimenti sotto riportati si riferiscono a procedure minime di primo trattamento, comprensivo della semina e dell'incubazione. Laddove non fosse possibile l'effettuazione delle prove sottoindicate, é opportuno appoggiarsi ad altro Laboratorio. Per le procedure minime di identificazione si rimanda alle procedure operative standard.

Si riportano anche, in sintesi, le indagini effettuabili con tecniche sierologiche o di biologia molecolare.

\section{Anaerobi}

A. Indicazione

1. sospetta polmonite $a b$ ingestis (anamnesi positiva per contaminazione con materiale alimentare o proveniente dall'apparato digerente);

2. sospetta polmonite in soggetti di età geriatrica.

B. Terreni

1. Agar sangue (5\%, di cavallo o di montone) arricchito per anaerobi:

2. Agar sangue (5\%, di cavallo o di montone) selettivo, arricchito per anaerobi [PEA, feniletil alcool, o KV (kanamicina-vancomicina)].

C. Incubazione

Incubare a $35-37^{\circ} \mathrm{C}$ in atmosfera anerobia per 48 ore.

D. Criteri di base per l'identificazione

1. prova di aerotolleranza (semina su Agar sangue in anaerobiosi ed in $\mathrm{CO}_{2}$ );

2. identificazione con dischetti o kit commerciali (localmente o c/o Centri di riferimento);

3. in caso di positività, utilizzare la nota: "Il riscontro di batteri anaerobi deve essere valutato alla luce del quadro clinico e della possibilità di contaminazione con materiale di origine digestiva".

\section{Bacillus anthracis}

A. Indicazione

1. sospetto carbonchio (anamnesi positiva per viaggio in regione endemica o con epidemia nota;

2. sospetta azione di bioterrorismo.

B. Terreni

Agar sangue (5\%, di cavallo o di montone).

C. Incubazione

Incubare a $35-37^{\circ} \mathrm{C}$ in atmosfera aerobia per 48 ore.

D. Criteri di base per l'identificazione

1. colorazione di Gram o Blu di metilene;

2. test della mobilità;

3. test della produzione della capsula.

\section{Bordetella pertussis}

A. Indicazione

Sospetta pertosse.

B. Terreni

Agar Bordet Gengou.

\section{Incubazione}

Incubare a $35-37^{\circ} \mathrm{C}$ in atmosfera arricchita in $\mathrm{CO}_{2}(5-10 \%)$ per 7 giorni;

D. Criteri di base per l'identificazione

1. identificare per qualunque carica microbica;
2. catalasi;

3. ureasi.

\section{Burkholderia cepacia}

\section{A. Indicazione}

Sospetta infezione in soggetti con anamnesi positiva per fibrosi cistica.

B. Terreni

1. Agar sangue (5\%, di cavallo o di montone);

2. Agar selettivo per Burkholderia cepacia (quali: BCSA, OFPBL, PCA);

C. Incubazione

Incubare a $35-37^{\circ} \mathrm{C}$ in atmosfera aerobia per 5 giorni.

D. Criteri di base per l'identificazione

1. ossidasi;

2. kit commerciali per identificazione per l'identificazione di Burkholderia cepacia complex;

3. conferma da Centro di referenza per la definizione biomolecolare del genomovar;

4. antibiogramma.

\section{Burkholderia pseudomallei}

A. Indicazione

1. sospetto melioidosi (anamnesi positiva per viaggio in regione endemica o con epidemia nota;

2. sospetta azione di bioterrorismo.

B. Terreni

Agar sangue (5\%, di cavallo o di montone).

\section{Incubazione}

Incubare a $35-37^{\circ} \mathrm{C}$ in atmosfera aerobia per 48 ore.

D. Criteri di base per l’identificazione

1. identificare per qualunque carica microbica;

2. ossidasi;

3. kit commerciali per identificazione;

4. conferma da Centro di referenza per la diagnosi di specie;

5. antibiogramma.

\section{Legionella spp.}

A. Indicazione

Legionellosi accertata per la rilevazione dell'antigene urinario.

B. Terreni

Agar Buffered Charcoal Yeast Extract (BCYE); GVPC.

C. Incubazione

1. incubare a $35-37^{\circ} \mathrm{C}$ in atmosfera arricchita in $\mathrm{CO}_{2}(5-$ $10 \%$ ) per 48 ore;

2. re-incubare a $35-37^{\circ} \mathrm{C}$ in atmosfera arricchita in $\mathrm{CO}_{2}$ (5-10\%) fino a 14 giorni.

D. Criteri di base per l'identificazione

1. identificare per qualunque carica microbica;

2. crescita su BCYE;

3. agglutinazione su vetrino (localmente o c/o Centri di riferimento);

4. non si esegue antibiogramma.

E. Ricerca anticorpi

1. procedere alla conservazione del siero "di fase acuta";

2. segnalare al Curante che il siero "di fase acuta" sarà processato contestualmente al campione "di fase convalescente", utilizzando la nota: "Si comunica che la determinazione degli anticorpi anti-Legionella sul campione "in fase acuta" pervenuto in data odierna sarà effettuata contestualmente al secondo siero, che dovrà essere prelevato tra 3-5 settimane (in fase convalescente). Il siero è conservato nella sieroteca del laboratorio";

3. processare in un'unica seduta i sieri "di fase acuta" e "di fase convalescente"

7. Miceti filamentosi dimorfi (Blastomyces spp., Coccidoides spp., Histoplasma spp., Paracoccidioides spp.) A. Indicazione

Riservare ai casi di sospetto clinico o epidemiologico (soggiorno in area di endemia o epidemia nota). 
B. Terreni

Agar sangue (5\%, di cavallo o di montone) ed Agar Sabouraud.

\section{Incubazione}

Incubare a temperatura ambiente ed a $35-37^{\circ} \mathrm{C}$ in atmosfera aerobia per 30 giorni.

\section{Criteri di base per l'identificazione}

1. identificare per qualunque carica microbica;

2. esame macroscopico, previa inversione di fase;

3. esame microscopico, previa inversione di fase;

4. conferma da Centro di referenza per la diagnosi di specie.

\section{Nocardia spp.}

\section{A. Indicazione}

Riservare ai casi di sospetto clinico, radiologico o epidemiologico;

\section{B. Terreni}

Agar BCYE;

Agar sangue (5\%, di cavallo o di montone).

\section{Incubazione}

1. incubare a $35-37^{\circ} \mathrm{C}$ in atmosfera arricchita in $\mathrm{CO}_{2}$ (5-10\%) per 48 ore: BCYE;

2. re-incubare a $35-37^{\circ} \mathrm{C}$ in atmosfera arricchita in $\mathrm{CO}_{2}$ (5-10\%) fino a 14 giorni: BCYE;

3. incubare a $35-37^{\circ} \mathrm{C}$ in atmosfera aerobia: Agar sangue.

D. Criteri di base per l'identificazione

1. identificare per qualunque carica microbica;

2. crescita su terreni al sangue con colonie caratteristiche;

3. colorazione di Kinyoun modificata;

4. conferma da Centro di referenza per la diagnosi di specie;

5. antibiogramma (sec Kirby Bauer e MIC in Agar diffusione).

\section{Pasteurella multocida}

\section{A. Indicazione}

Riservare ai casi di sospetto clinico, radiologico o epidemiologico (etilismo, tabagismo, bronchiectasie, neoplasie polmonari e contatto con suini).

B. Terreni

Agar sangue (5\%, di cavallo o di montone).

\section{Incubazione}

Incubare a $35-37^{\circ} \mathrm{C}$ in atmosfera aerobia per 48 ore.

\section{Pneumocystis jirovecii}

\section{A. Indicazione}

Riservare ai casi di sospetto clinico, radiologico o epidemiologico (immunodepressione).

\section{B. Criteri diagnostici}

1. impregnazione argentica o immunofluorescenza;

2. se (1) positivo: confermare con altro metodo.

\section{Rhodococcus equi}

\section{A. Indicazione}

Riservare ai casi di sospetto clinico, radiologico o epidemiologico (immunodepressione; contatto con equini).

\section{B. Terreni}

Agar sangue (5\%, di cavallo o di montone).

\section{Incubazione}

Incubare a $35-37^{\circ} \mathrm{C}$ in atmosfera aerobia per 48 ore.

D. Criteri di base per l'identificazione

1. identificare per qualunque carica microbica;

2. crescita su terreni al sangue con colonie caratteristiche;

3. catalasi;

4. kit commerciali per identificazione;

5. conferma da altro Centro;

6. antibiogramma.

\section{Yersinia pestis}

A. Indicazione

Riservare ai casi di sospetto clinico o epidemiologico (soggiorno in area di endemia o epidemia nota).

\section{B. Terreni}

Agar sangue (5\%, di cavallo o di montone).

\section{Incubazione}

Incubare a $35-37^{\circ} \mathrm{C}$ in atmosfera aerobia per 48 ore (colonie puntiformi in Agar sangue dopo 24 ore).

D. Criteri di base per l'identificazione:

1. identificare per qualunque carica microbica;

2. ossidasi;

3. Kit commerciali per identificazione;

4. conferma da Centro di referenza per la diagnosi di specie;

5. antibiogramma.

\section{BIBLIOGRAFIA}

1. AAVV International Consensus Conference: Clinical Investigation of Ventilator-Associated Pneumonia, Chest 102 (S1): 551S-588S; 1992.

2. Bartlett JG, Breiman RF, Mandell LA, File TM, Community-Acquired Pneumonia in Adults: IDSA Guidelines for Management. Clin Infect Dis 1998: 26: 811-38.

3. Goglio A, Callegaro A, Farina C, Fortina G, Manso E, Piacentini I, Rescaldani R, Scagnelli M, GSDIR. L'esame colturale nella diagnostica microbiologica delle infezioni delle basse vie respiratorie. Microbiologia Medica, Boll 17, 5-10, 1996.

4. Isenberg HD. Clinical Microbiology Procedures Handbook. American Society for Microbiology, 1994.

5. Klech H, Pohl W. Technical recommendations and guidelines for bronchoalveolar lavage (BAL). Report of the European Society of Pneumology Task Group on BAL. Eur Respir J 1989; 2: 561-85.

6. Mandell LA, Marrie TJ, Grossman RF, Chow AW, Hyland RH. Canadian Guidelines for the Initial Management of CommunityAcquired Pneumonia: An Evidence - Based Update by the Canadian Infectious Diseases Society and the Canadian Thoracic Society Clinical Infectious Diseases 2002; 31: 383-421.

7. Murdoch DR, Laing RT, Mill GD, et al. Evaluation of a rapid immunochromatographic test for detection of Streptococcus pneumoniae antigen in urine samples from adults with community-acquired pneumonia. J Clin Microbiol 2001; 39: 3495-8.

8. Plouffe JF, File TM Jr, Breiman RF, et al. Reevaluation of the definition of Legionnaire's disease: use of the urinary antigen assay. Community Based Pneumonia Incidence Study Group. Clin Infect Dis 1995; 20: 1286-91.

9. Skerrett SJ. Diagnostic testing for community-acquired pneumonia. Clin Chest Med 1999; 20: 531-48.

10. Société de Réanimation de langue française. Actualités en Réanimation et Urgences. Arnette ed., 1995.

11. Van der Eerden MM, Vlaspolder F, de Graaff CS, et al. Value of intensive diagnostic microbiological investigation in low and high risk patients with community-acquired pneumonia. Eur J Clin Microbiol Infect Dis 2005; 24: 241-9.

\section{G4. FLOW CHART OPERATIVE}

G4.1 Algoritmo per la diagnosi eziologica delle polmoniti ospedalizzate (esami colturali)

\section{DIAGNOSI EZIOLOGICA DI POLMONITI (ESAMI COLTURALI)}

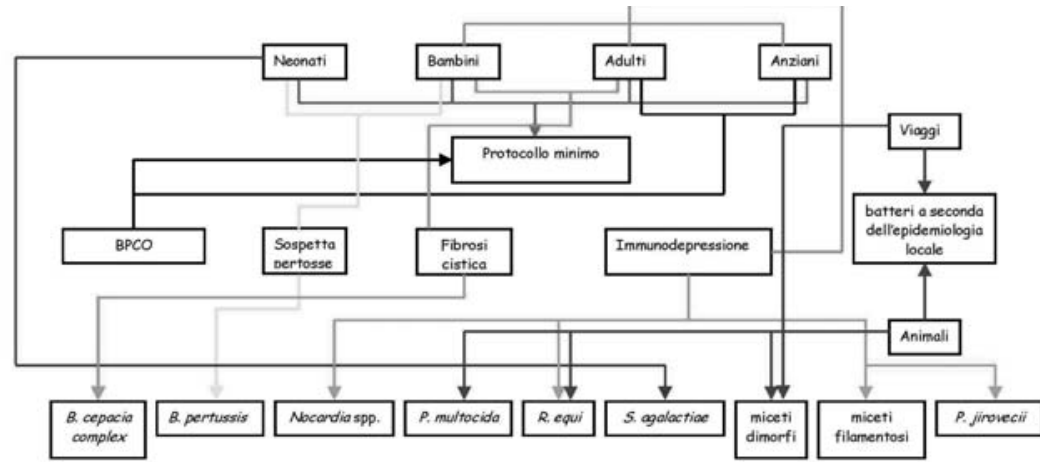


G4.2 Tabella per la diagnosi eziologica a seguito di anamnesi epidemiologica

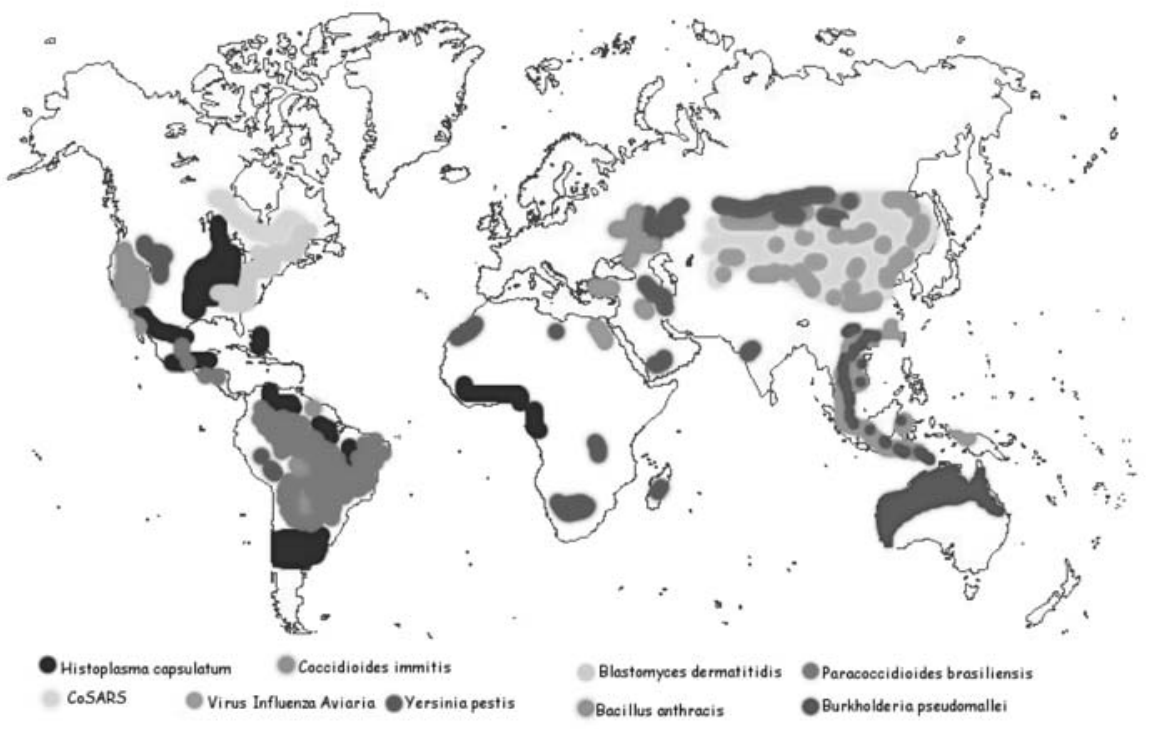

\begin{tabular}{|c|c|c|c|c|}
\hline Area endemica & Sospetto & $\begin{array}{c}\text { Quadro clinico- } \\
\text { radiologico }\end{array}$ & $\begin{array}{l}\text { Caratteristiche } \\
\text { ematochimiche }\end{array}$ & Test microbiologici \\
\hline $\begin{array}{l}\text { SudEst Asiatico } \\
\text { Australia }\end{array}$ & $\begin{array}{l}\text { Melioidosi } \\
\text { (Burkholderia } \\
\text { pseudomallei) }\end{array}$ & $\begin{array}{l}\text { - tachipnea } \\
\text { - espettorato } \\
\text { emorragico } \\
\text { - lesioni cavitarie o } \\
\text { nodulari } \\
\end{array}$ & $\begin{array}{l}\text { - leucocitosi } \\
\text { neutrofila }\end{array}$ & coltura materiali respiratori \\
\hline $\begin{array}{l}\text { Altopiano iraniano } \\
\text { Regioni caucasiche }\end{array}$ & $\begin{array}{l}\text { Carbonchio } \\
\text { (Bacillus anthracis) }\end{array}$ & $\begin{array}{l}\text { - broncoalveolite } \\
\text { diffusa } \\
\text { - espettorato } \\
\text { emorragico } \\
\end{array}$ & $\begin{array}{l}\text { - leucocitosi } \\
\text { neutrofila }\end{array}$ & coltura materiali respiratori \\
\hline $\begin{array}{l}\text { Altopiano iraniano } \\
\text { India Occidentale } \\
\text { USA (New Mexico) }\end{array}$ & $\begin{array}{l}\text { Peste } \\
\text { (Yersinia pestis) }\end{array}$ & $\begin{array}{l}\text { - tachipnea } \\
\text { - espettorato } \\
\text { emorragico } \\
\text { - lesioni cavitarie } \\
\end{array}$ & $\begin{array}{l}\text { - leucocitosi } \\
\text { neutrofila }\end{array}$ & coltura materiali respiratori \\
\hline $\begin{array}{l}\text { USA (valle del } \\
\text { Mississippi) } \\
\text { America Centrale e } \\
\text { Caraibica } \\
\text { Africa Occidentale }\end{array}$ & $\begin{array}{l}\text { Istoplasmosi } \\
\text { (Histoplasma } \\
\text { capsulatum) }\end{array}$ & $\begin{array}{l}\text { - lesioni cavitarie } \\
\text { infiltrati a contorno } \\
\text { irregolare, bilaterali e } \\
\text { multipli e diffusi }\end{array}$ & $\begin{array}{l}\text { - anemia } \\
\text { - leucopenia }\end{array}$ & $\begin{array}{l}\text { - esame micologico diretto } \\
\text { - coltura materiali respiratori } \\
\text { (incub: } 30 \mathrm{gg} \text { a } 25 \mathrm{e} 35^{\circ} \mathrm{C} \text { ) } \\
\text { - emocolture (incub: } 30 \mathrm{gg} \text { ) } \\
\text { - esame istopatologico (col. } \\
\text { Gomori-Grocott) } \\
\text { - ricerca di Ab anti- } \\
\text { H.capsulatum (met. doppia } \\
\text { diffusione in agar). }\end{array}$ \\
\hline $\begin{array}{l}\text { USA (Texas } \rightarrow \\
\text { California) } \\
\text { America Centrale e } \\
\text { Latina }\end{array}$ & $\begin{array}{l}\text { Coccidioidomicosi } \\
\text { (Coccidioides immitis) }\end{array}$ & $\begin{array}{l}\text { - infiltrati ilifughi o } \\
\text { cavitari }\end{array}$ & $\begin{array}{l}\text { - leucocitosi } \\
\text { eosinofila }\end{array}$ & $\begin{array}{l}\text { - esame micologico diretto } \\
\text { - coltura materiali respiratori } \\
\text { (incub: } 30 \text { gg a } 25 \text { e } 35^{\circ} \mathrm{C} \text { ) } \\
\text { - emocolture (incub: } 30 \mathrm{gg} \text { ) } \\
\text { - istopatologia (col. Gomori- } \\
\text { Grocott) } \\
\text { - ricerca di Ab anti-C. immitis } \\
\text { (met. doppia diffusione in } \\
\text { agar). }\end{array}$ \\
\hline $\begin{array}{l}\text { USA (Grandi Laghi } \\
\rightarrow \text { valle del } \\
\text { Mississippi) } \\
\text { Messico } \\
\text { Africa tropicale }\end{array}$ & $\begin{array}{l}\text { Blastomicosi } \\
\text { (Blastomyces } \\
\text { dermatitidis) }\end{array}$ & $\begin{array}{l}\text { - tachipnea } \\
\text { - espettorato } \\
\text { emorragico } \\
\text { - adenopatia ilare e } \\
\text { mediastinica }\end{array}$ & $\begin{array}{l}\text { - anemia } \\
\text { ipocromica } \\
\text { - leucocitosi }\end{array}$ & $\begin{array}{l}\text { - esame micologico diretto } \\
\text { - coltura materiali respiratori } \\
\text { (incub: } 30 \mathrm{gg} \text { a } 25 \text { e } 35^{\circ} \mathrm{C} \text { ) } \\
\text { - emocolture (incub: } 30 \mathrm{gg} \text { ) } \\
\text { - istopatologia (col. Gomori- } \\
\text { Grocott) }\end{array}$ \\
\hline $\begin{array}{l}\text { America Centrale e } \\
\text { Latina }\end{array}$ & $\begin{array}{l}\text { Paracoccidioidomicosi } \\
\text { (Paracoccidioides } \\
\text { brasiliensis) }\end{array}$ & $\begin{array}{l}\text { - paucisintomatologia } \\
\text { - espettorato } \\
\text { emorragico } \\
\text { - infiltrati multipli } \\
\text { paramediastinici o } \\
\text { micronodulari }\end{array}$ & $\begin{array}{l}\text { - leucocitosi } \\
\text { neutrofila o } \\
\text { eosinofila }\end{array}$ & $\begin{array}{l}\text { - esame micologico diretto } \\
\text { - coltura materiali respiratori } \\
\text { (incub: } 30 \mathrm{gg} \text { a } 25 \text { e } 35^{\circ} \mathrm{C} \text { ) } \\
\text { - emocolture (incub: } 30 \mathrm{gg} \text { ) } \\
\text { - istopatologia (col. Gomori- } \\
\text { Grocott) } \\
\text { - ricerca di Ab anti-P } \\
\text { brasiliensis (met. doppia } \\
\text { diffusione in agar). }\end{array}$ \\
\hline SudEst Asiatico & $\begin{array}{l}\text { SARS } \\
\text { (SARS CoV) }\end{array}$ & - infiltrati multipli & $\begin{array}{l}\text { - leucopenia } \\
\text { linfopenica } \\
\text { - >SGOT/SGPT, } \\
\text { LDH, CPK,PPT }\end{array}$ & - PCR \\
\hline
\end{tabular}




\begin{tabular}{|c|c|c|c|c|}
\hline Contatto con & Sospetto & Fattori di rischio & $\begin{array}{l}\text { Caratteristiche } \\
\text { cliniche }\end{array}$ & Test microbiologici \\
\hline & $\begin{array}{l}\text { Pastorellosi } \\
\text { (Pasteurella } \\
\text { multocida) }\end{array}$ & $\begin{array}{l}\text { - etilismo } \\
\text { - tabagismo } \\
\text { - bronchiectasie } \\
\text { - neoplasie polmonari }\end{array}$ & $\begin{array}{l}\text { - polmoniti } \\
\text { - pleurite }\end{array}$ & $\begin{array}{l}\text { coltura materiali } \\
\text { respiratori }\end{array}$ \\
\hline & $\begin{array}{l}\text { Psittacosi } \\
\text { (Chlamydophila } \\
\text { psittaci) }\end{array}$ & $\begin{array}{l}\text { - esposizione } \\
\text { professionale } \\
\text { - "pet disease" }\end{array}$ & - polmonite & $\begin{array}{l}\text { ricerca di } \mathrm{Ab} \text { anti-C. } \\
\text { psittaci }\end{array}$ \\
\hline & $\begin{array}{l}\text { Rodococcosi } \\
\text { (Rhodococcus equi) }\end{array}$ & - infezione da HIV & $\begin{array}{l}\text { - polmonite cavitaria } \\
\text { o lobare }\end{array}$ & $\begin{array}{l}\text { coltura materiali } \\
\text { respiratori }\end{array}$ \\
\hline & $\begin{array}{l}\text { Febbre Q } \\
\text { (Coxiella burnetii) }\end{array}$ & $\bullet$ & $\bullet$ & $\begin{array}{l}\text { - ricerca di Ab anti- } \\
\text { C. burnetii }\end{array}$ \\
\hline & $\begin{array}{l}\text { Leptospirosi } \\
\text { (Leptospira } \\
\text { interrogans) }\end{array}$ & $\begin{array}{l}\text { - esposizione } \\
\text { professionale } \\
\text { - malattia "del tempo } \\
\text { libero" }\end{array}$ & $\bullet$ & $\begin{array}{l}\text { - ricerca di Ab anti- } \\
\text { Leptospira. IgM } \\
\text { (met. blotting). }\end{array}$ \\
\hline & $\begin{array}{l}\text { Influenza Aviaria } \\
\text { (Virus Influenza A, } \\
\text { H5N1) }\end{array}$ & $\begin{array}{l}\text { - esposizione } \\
\text { professionale } \\
\text { - malattia "del tempo } \\
\text { libero" }\end{array}$ & $\bullet$ & $\begin{array}{l}\text { - ricerca Virus } \\
\text { Influenza A }\end{array}$ \\
\hline & $\begin{array}{l}\text { Istoplasmosi } \\
\text { (Histoplasma } \\
\text { capsulatum) }\end{array}$ & $\begin{array}{l}\text { - paucisintomatologia } \\
\text { - espettorato emorragico } \\
\text { - infiltrati multipli } \\
\text { paramediastinici o } \\
\text { micronodulari }\end{array}$ & - leucopenia & $\begin{array}{l}\text { - es. micologico } \\
\text { diretto } \\
\text { - coltura materiali } \\
\text { respiratori ( } 30 \mathrm{gg} \text {; } \\
\left.25-35^{\circ} \mathrm{C}\right) \\
\text { - emocolture ( } 30 \mathrm{gg}) \\
\text { - esame } \\
\text { istopatologico (col. } \\
\text { Gomori-Grocott) } \\
\text { - ricerca di Ab anti- } \\
\text { H.capsulatum } \\
\text { (met. doppia } \\
\text { diffusione in agar). }\end{array}$ \\
\hline
\end{tabular}


G4.3 Algoritmo per la diagnosi microbiologica

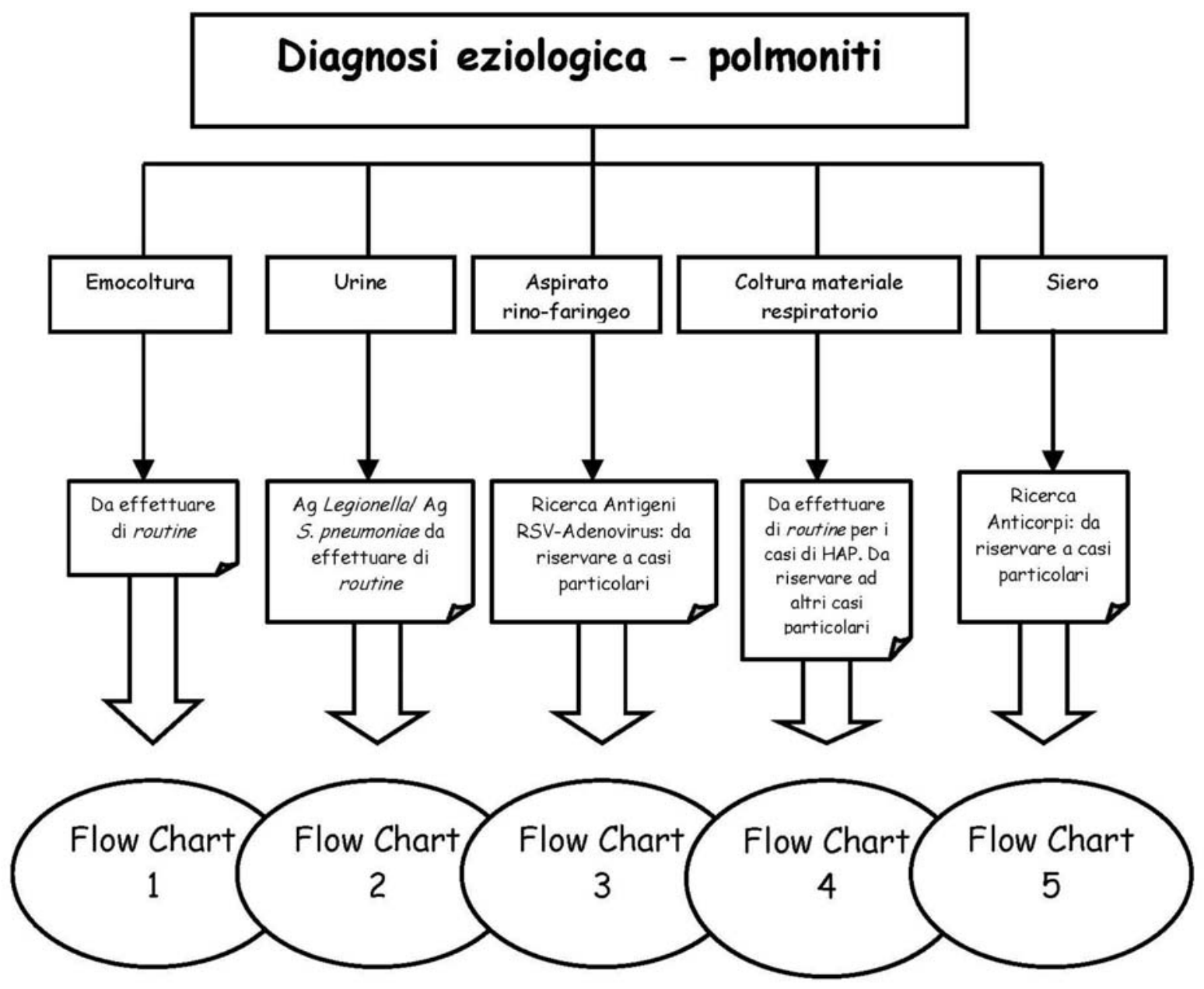




\section{Flow Chart 1: emocoltura}

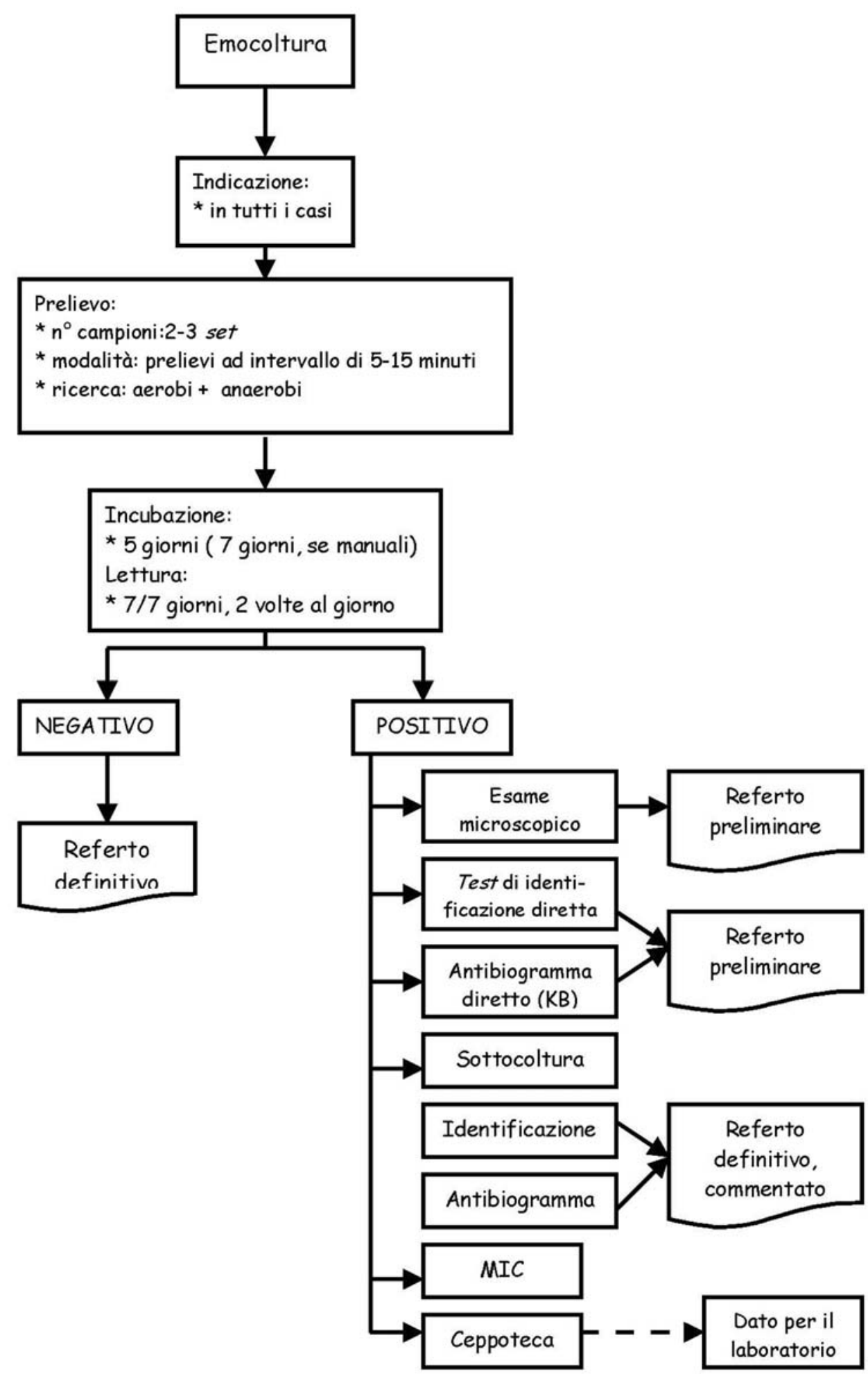




\section{Flow Chart 2: urina}

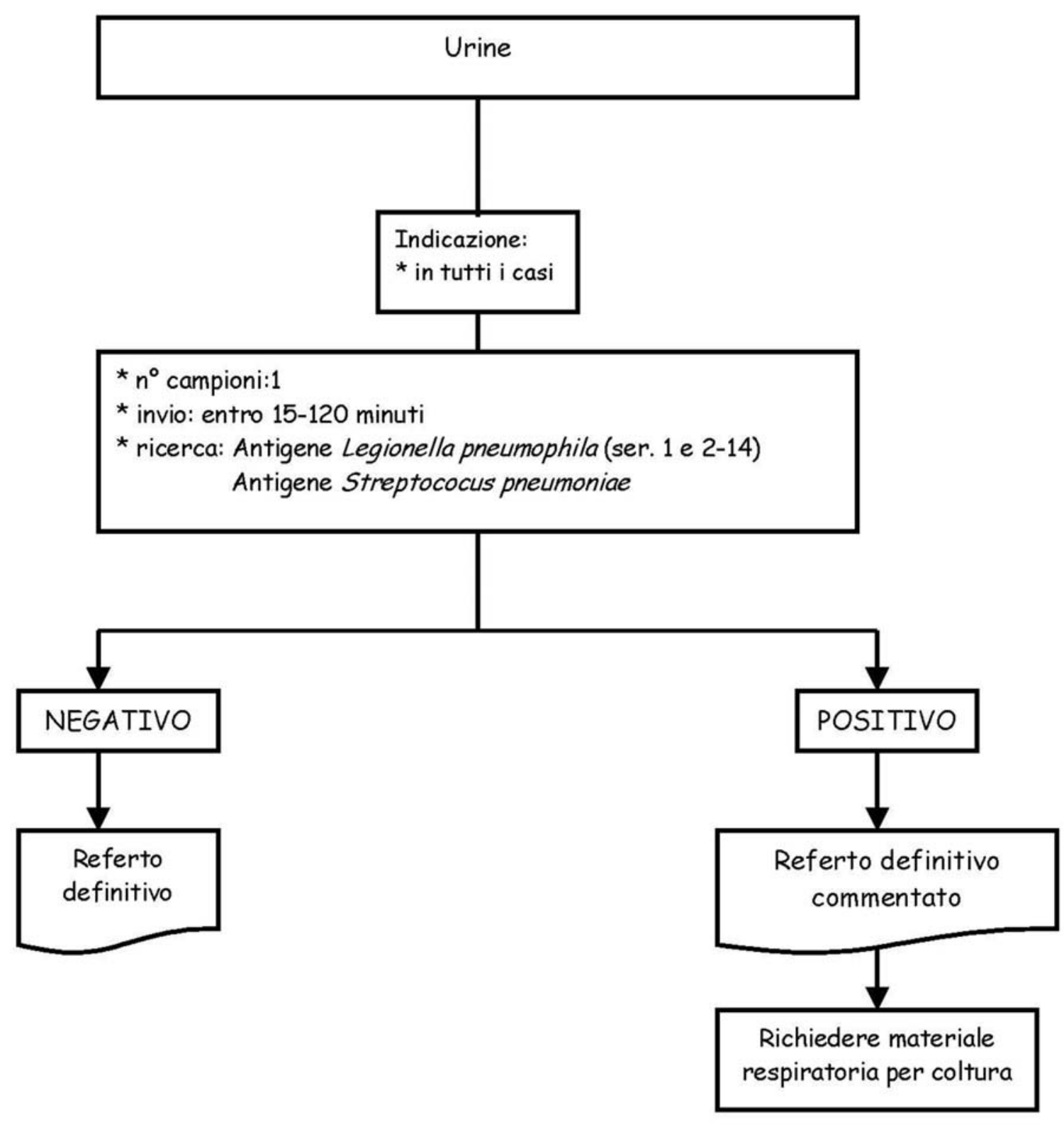




\section{Flow Chart 3: aspirato rino-faringeo}

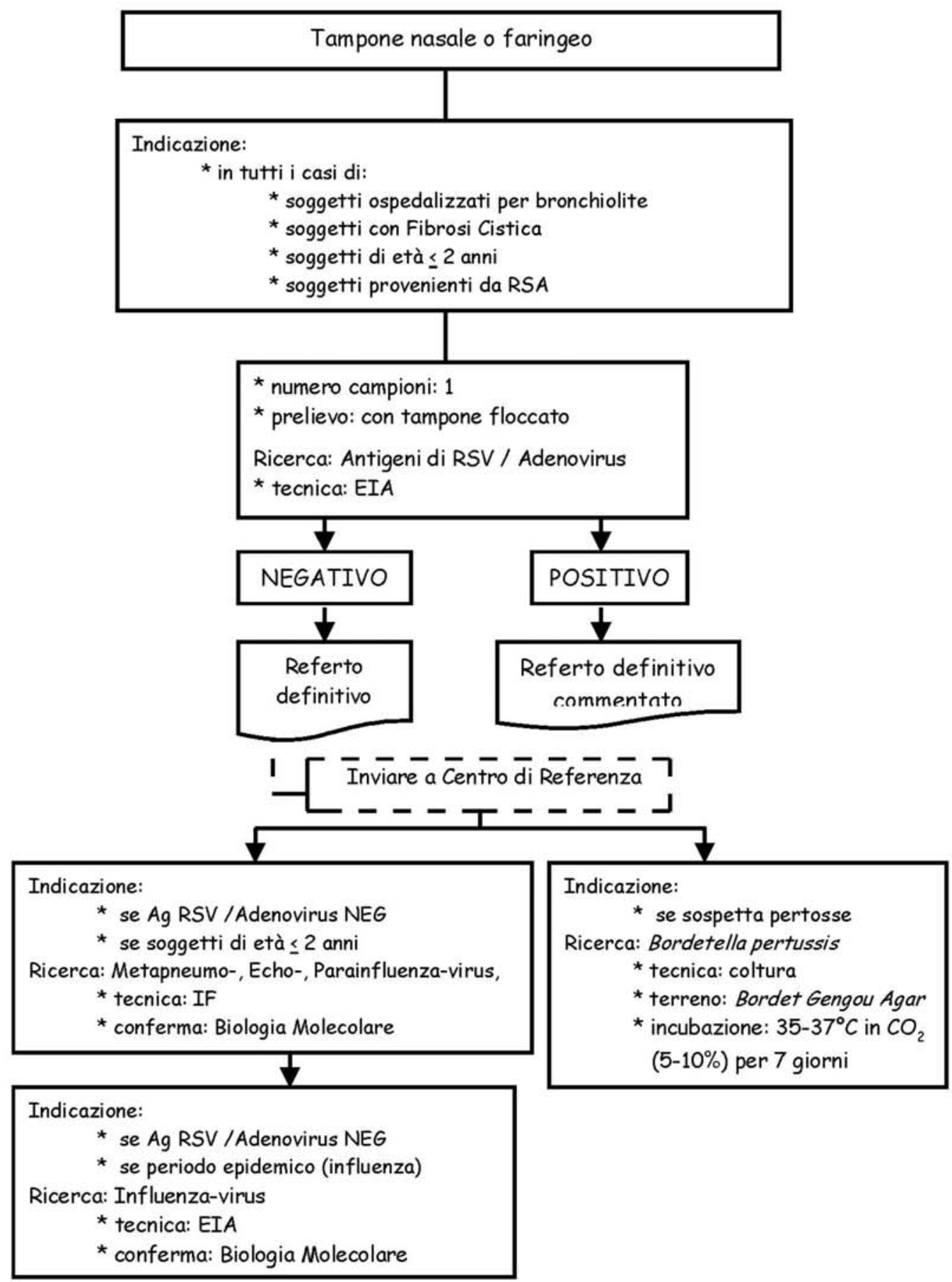




\section{Flow Chart 4: materiali respiratori "protetti"}

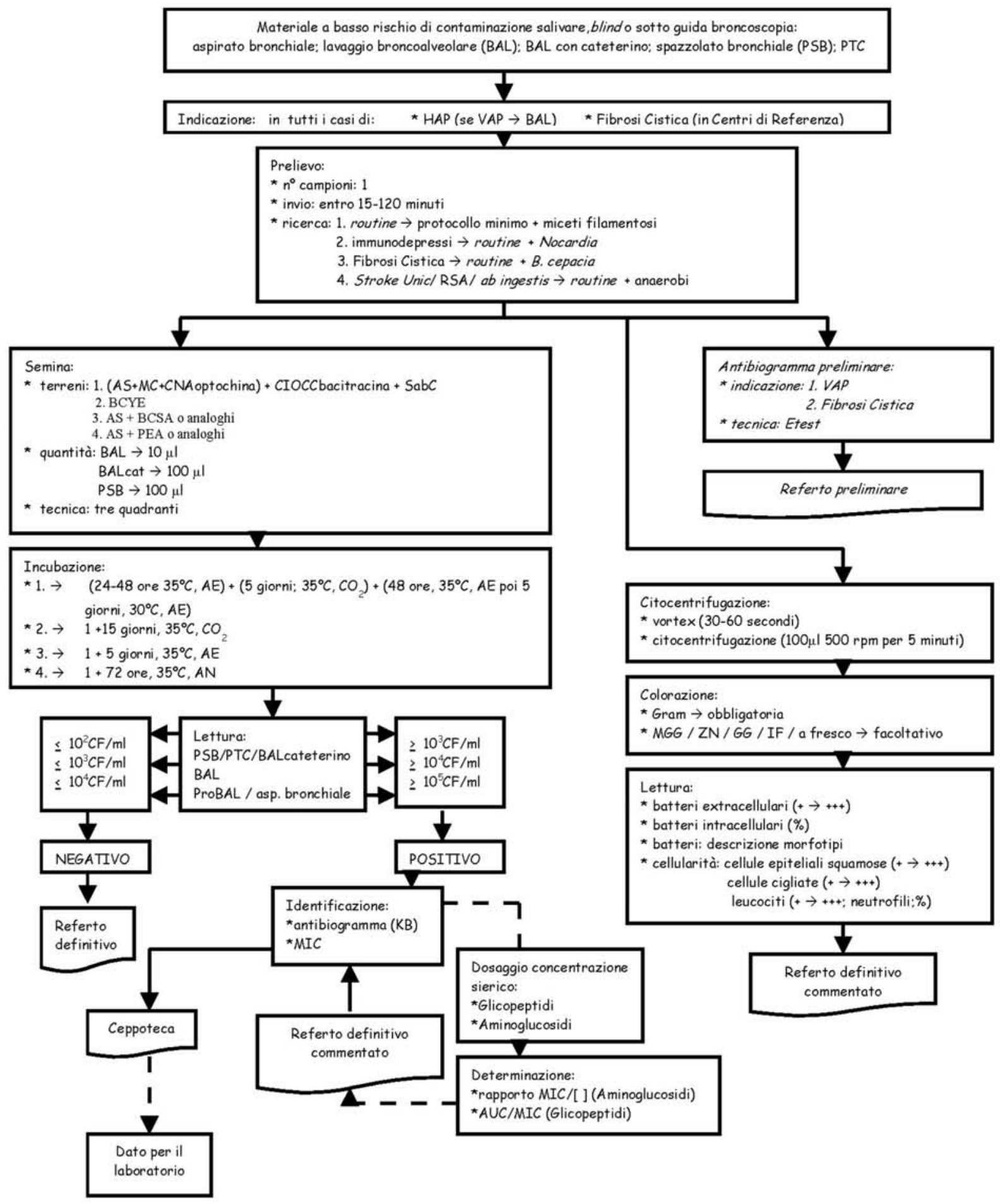


Flow Chart 5: siero

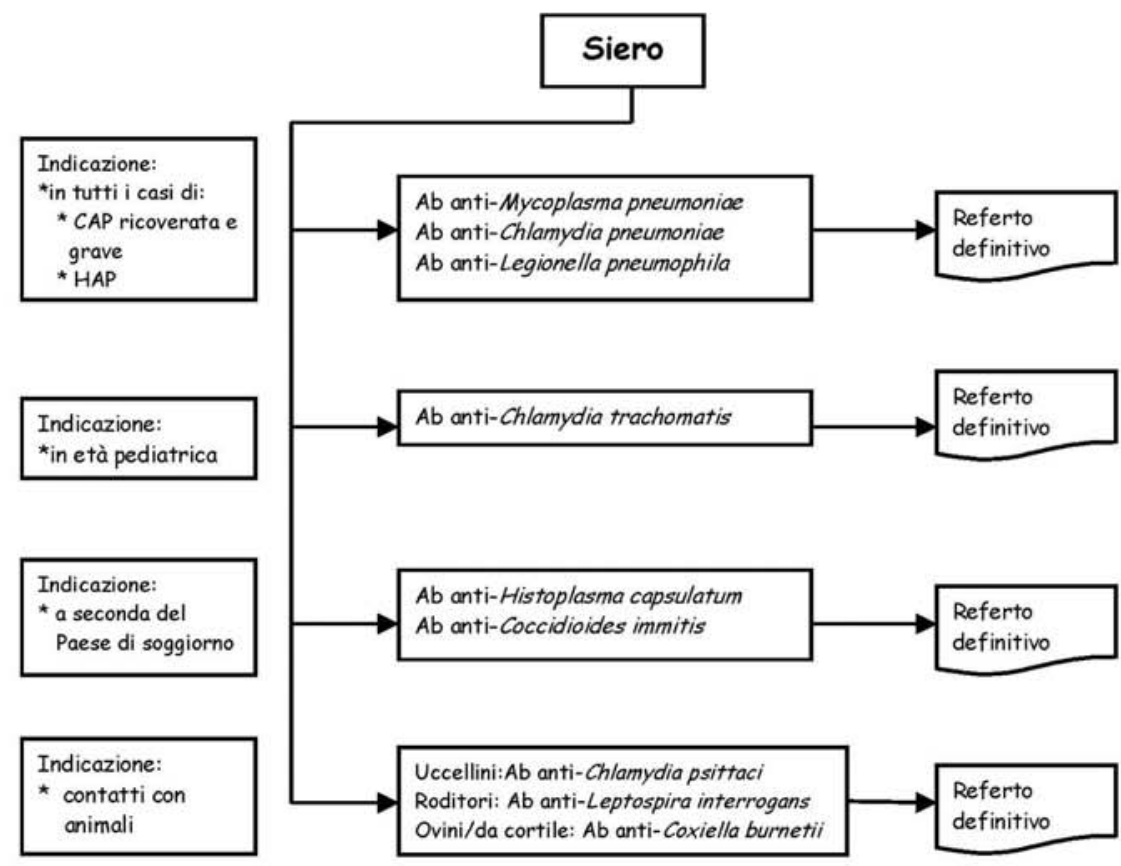

G4.4 Algoritmo per la gestione delle polmoniti ospedalizzate su base microbiologica

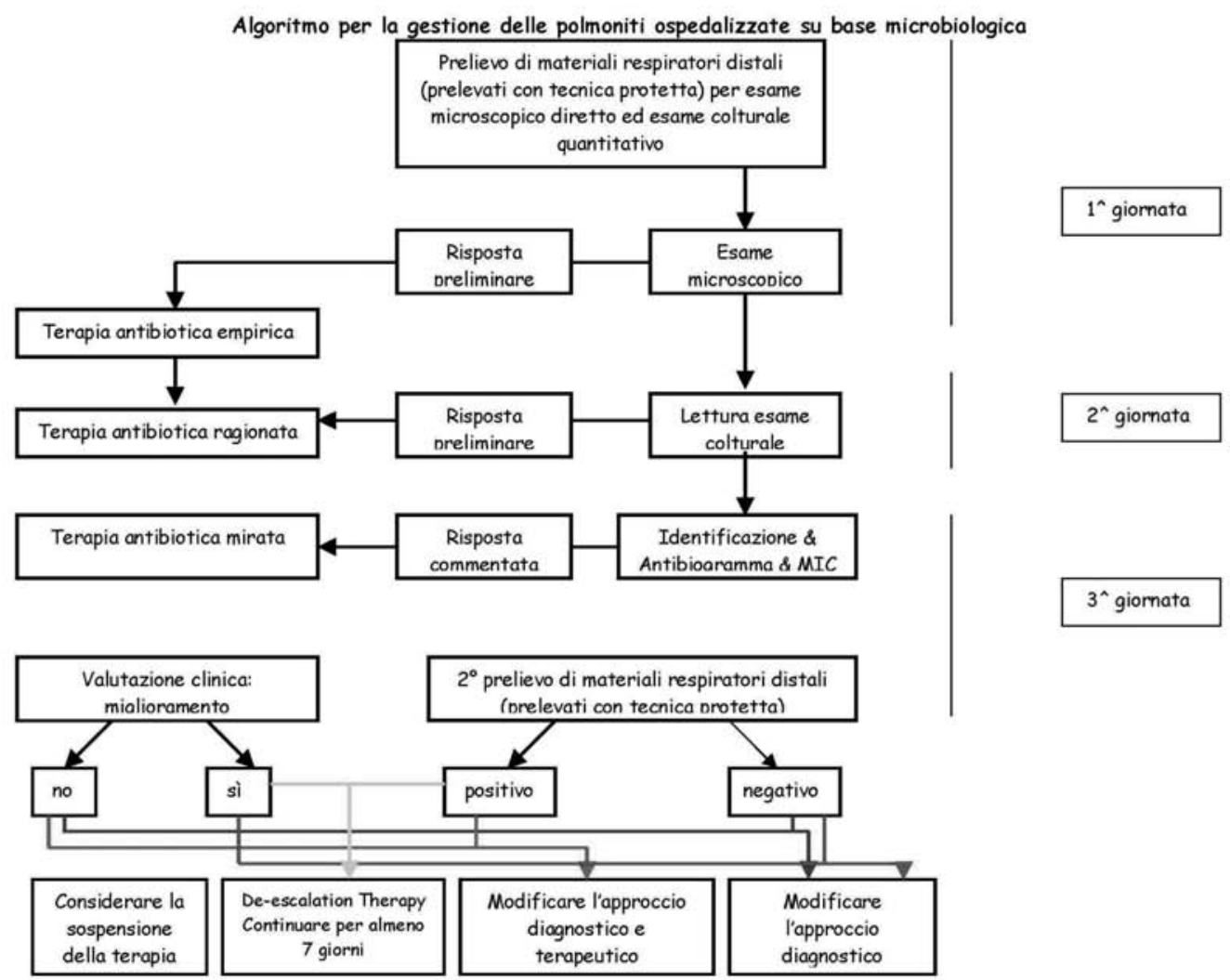




\section{G5. PROPOSTA DI NOTE DI COMMENTO}

\section{MATERIALI RESPIRATORI: LE NOTE DI COM}

\begin{tabular}{|l|l|}
\hline \multicolumn{1}{|c|}{ SITUAZIONE } \\
\hline $\begin{array}{l}\text { Nel caso in cui il campione pervenga al laboratorio } \\
\text { dopo più di } 2 \text { ore dal prelievo }\end{array}$ \\
\hline $\begin{array}{l}\text { Materiali ad alto rischio di contaminazione con } \\
\text { saliva: } Q \text { score } \leq 0\end{array}$ \\
\hline $\begin{array}{l}\text { Materiali ad alto rischio di contaminazione con } \\
\text { saliva: } Q \text { score } \leq 0 \text {, in soggetti con Fibrosi Cistica }\end{array}$ \\
\hline
\end{tabular}

\section{NOTA DI COMMENTO}

"L'esame colturale è eseguito su un campione prelevato da più di 2 ore: i risultati microbiologici possono risultarne falsati e debbono essere interpretati alla luce del quadro clinico".

"L'esame colturale non è eseguito: il campione non è rappresentativo di secrezioni delle basse vie aeree. Si consiglia di valutare l'opportunità di inviare nuovo campione".

"Il campione inviato non è rappresentativo di secrezioni delle basse vie aeree. L'esame colturale è tuttavia eseguito per la valutazione selettiva della colonizzazione microbica".

Materiali ad alto rischio di contaminazione con saliva: $Q$ score $\geq 1$

"La valutazione del Q score effettuata con l'esame microscopico diretto del campione rileva che il materiale inviato è rappresentativo delle basse vie aeree: i risultati dell'esame colturale devono essere interpretati alla luce del quadro clinico".

"Il riscontro in coltura dei microrganismi identificati non é di per sé rappresentativo dell'eziologia responsabile del quadro clinico. Si consiglia di confrontare tale dato con quello dell'esame

Materiali ad alto rischio di contaminazione con saliva: in caso di positività per batteri microscopico diretto e di confermare il risultato inviando complessivamente tre campioni di materiale respiratorio in tre giorni diversi".

Materiali ad alto rischio di contaminazione con saliva: in caso di positività per S. pneumoniae

"Il riscontro in coltura di S. pneumoniae non é di per sé indicativo di un quadro di polmonite pneumococcica. Si consiglia di inviare complessivamente: tre campioni respiratori, in giorni successivi, e tre set di emocolture per la conferma colturale, ed un campione di urine per la rilevazione dell'antigene pneumococcico".

"Il riscontro in coltura di Aspergillus spp non é di per sé indicativa di un quadro di aspergillosi polmonare. Si consiglia di inviare

Materiali ad alto rischio di contaminazione con almeno tre campioni respiratori, in giorni successivi, per la conferma colturale ed un campione di siero per la rilevazione dell'antigene galattomannano".

Materiali ad alto rischio di contaminazione con "Il riscontro in coltura di Candida spp è rappresentativo di un saliva: in caso di positività per Candida spp. quadro di colonizzazione o di infezione da lieviti del cavo orale. $\mathrm{Si}$ consiglia di valutare l'eventuale presenza di una mucosite orale".

"Si consiglia di valutare, in base agli eventuali riscontri dell'anamnesi epidemiologica (fattori predisponenti, contatti con animali, soggiorni in Paesi di endemia per microrganismi di importazione), l'opportunità di predisporre accertamenti colturali o sierologici per il riscontro di patogeni mirati".

Materiali ad alto rischio di contaminazione con saliva: in tutti i casi di positività

"La presenza di cellule epiteliali squamose del cavo orale e/o il

Materiali a basso rischio di contaminazione con saliva: se - all'esame microscopico diretto - segni di contaminazione con la mucosa del cavo orale (presenza di flora orofaringea e/o presenza di cellule epiteliali squamose, se $>1 \%$ ) riscontro in coltura di microrganismi rappresentativi della popolazione microbica del cavo orale depone per la possibile contaminazione durante la raccolta. Si consiglia di valutare i risultati alla luce dei dati clinici".

"La presenza, all'esame microscopico diretto, di cellule cigliate conferma la buona qualità del materiale, di origine dalle basse vie respiratorie. Inoltre, l'eventuale presenza di batteri intracellulari in

Materiali a basso rischio di contaminazione con saliva: se - all'esame microscopico diretto cellularità rappresentativa delle basse vie aeree percentuale $>2 \%$ è indicativa di polmonite sostenuta da questi stessi microrganismi. Tuttavia, la negatività dell'esame microscopico non esclude l'eziologia microbica per la scarsa sensibilità del metodo (colorazione sec. Gram)".

"Il riscontro in coltura dei microrganismi identificati é suggestivo dell'eziologia responsabile del quadro clinico. Si consiglia di confrontare tale dato con quello dell'esame microscopico diretto e di confermare il risultato inviando complessivamente tre set di emocolture per la conferma colturale".

Materiali a basso rischio di contaminazione con saliva: in caso di positività per batteri

"Il riscontro in coltura di Aspergillus spp non é di per sé indicativa di un quadro di aspergillosi polmonare. Si consiglia di inviare

Materiali a basso rischio di contaminazione con complessivamente tre campioni respiratori, in giorni successivi, per la conferma colturale ed un campione di siero per la rilevazione dell'antigene galattomannano".

saliva: in caso di positività per Aspergillus spp

"Si consiglia di valutare, in base agli eventuali riscontri

Materiali a basso rischio di contaminazione con dell'anamnesi epidemiologica, l'opportunità di predisporre accertamenti colturali o sierologici per il riscontro di patogeni mirati".

saliva: in tutti i casi di positività

"Possibile contaminazione durante la raccolta. Si consiglia di

Materiali bioptici: in caso di riscontro di flora normale valutare il risultato microbiologico alla luce dei dati clinici". 


\begin{tabular}{|c|c|}
\hline $\begin{array}{l}\text { In caso di refertazione del test per la rilevazione } \\
\text { dell'antigenuria di Streptococcus pneumoniae }\end{array}$ & $\begin{array}{l}\text { "Si segnala che la sensibilità del test utilizzato per la rilevazione } \\
\text { dell'antigenuria di S. pneumoniae è pari all' } 80 \% \text { in confronto con la } \\
\text { batteriemia da pneumococco, al } 52 \% \text { con la coltura } \\
\text { dell'espettorato e del } 55 \% \text { in uno studio pediatrico limitato". }\end{array}$ \\
\hline $\begin{array}{l}\text { In caso di positività del test per la rilevazione } \\
\text { dell'antigenuria di Strepococcus pneumoniae }\end{array}$ & $\begin{array}{l}\text { "La positività dell'antigene urinario di S. pneumoniae, in presenza } \\
\text { di un quadro clinico compatibile, è suggestiva di un'infezione } \\
\text { pneumococcica profonda. Si consiglia l'esecuzione di emocolture } \\
\text { e della coltura di secrezioni respiratorie". }\end{array}$ \\
\hline $\begin{array}{l}\text { In caso di positività del test per la rilevazione } \\
\text { dell'antigenuria di Legionella pneumophila }\end{array}$ & $\begin{array}{l}\text { "La positività dell'antigene urinario di L. pneumophila, in presenza } \\
\text { di un quadro clinico compatibile, è suggestiva di legionellosi. Si } \\
\text { consiglia l'esecuzione della coltura di secrezioni respiratorie e } \\
\text { l'invio di campioni di siero in fase acuta ed in fase convalescente, } \\
\text { dopo 3-4 settimane". }\end{array}$ \\
\hline $\begin{array}{l}\text { In caso di richiesta di ricerca di anticorpi di } \\
\text { Legionella pneumophila }\end{array}$ & $\begin{array}{l}\text { "Si comunica che la determinazione degli anticorpi anti-Legionella } \\
\text { sul campione 'in fase acuta' pervenuto in data odierna sarà } \\
\text { effettuata contestualmente al secondo siero, che dovrà essere } \\
\text { prelevato tra } 3-5 \text { settimane (in fase convalescente). II siero è } \\
\text { conservato nella sieroteca del laboratorio". }\end{array}$ \\
\hline In caso di richiesta di ricerca di anticorpi virali & $\begin{array}{l}\text { "Si comunica che la determinazione degli anticorpi anti- } \\
\text { Influenzavirus, anti-virusparainfluenzali, Coxsackievirus, Echovirus } \\
\text { ed Enterovirus sul campione 'in fase acuta' pervenuto in data } \\
\text { odierna sarà effettuata contestualmente al secondo siero, che } \\
\text { dovrà essere prelevato tra } 3-5 \text { settimane (in fase convalescente). II } \\
\text { siero è conservato nella sieroteca del laboratorio". }\end{array}$ \\
\hline $\begin{array}{l}\text { In caso di positività per anaerobi in sospetta } \\
\text { polmonite da aspirazione }\end{array}$ & $\begin{array}{l}\text { "Il riscontro di batteri anaerobi deve essere valutato alla luce del } \\
\text { quadro clinico e della possibilità di contaminazione con materiale } \\
\text { di origine digestiva". }\end{array}$ \\
\hline In caso di positività degli anticorpi anti-Leptospira & $\begin{array}{l}\text { "Il siero è stato inviato al Centro di Riferimento per le Leptospirosi } \\
\text { (come definito su base regionale: ad esempio, in Lombardia: } \\
\text { S.C. Virologia e Microbiologia, Fondazione IRCSS - Policlinico } \\
\text { San Matteo, Pavia per la titolazione e per la definizione del } \\
\text { serovar di Leptospira interrogans". }\end{array}$ \\
\hline In caso di diagnosi sieroimmunologica & $\begin{array}{l}\text { "Si segnala che la sensibilità e la specificità dei metodi utilizzati è } \\
\text { pari a ....\% ed a ....\%, rispettivamente". }\end{array}$ \\
\hline
\end{tabular}

